\title{
Significant Differences Between Solid State and Solution Photochemistry and Photophysics of Mesogenic Organometallic Gold Complexes
}

\author{
Kevin Tanner, Gabriel Marineau-Plante, Adrien Schlachter, Paul-Ludovic Karsenti, Armand \\ Soldera and Pierre D. Harvey. \\ Département de chimie, Université de Sherbrooke, Sherbrooke, QC, Canada, J1K 2R1.
}

Table of contents

1. Experimental Section........................................................................................ 7

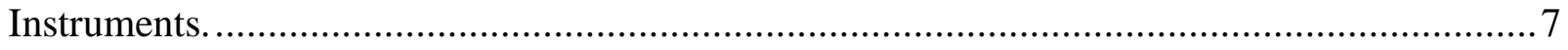

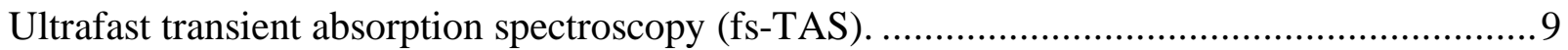

Density functional theory computations................................................................ 10

Structure resolution from powder X-ray diffraction patterns. ...................................... 10

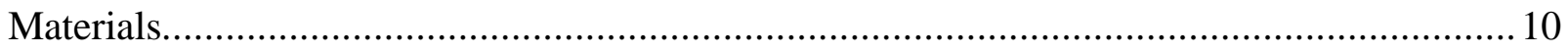

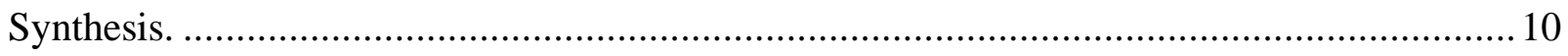

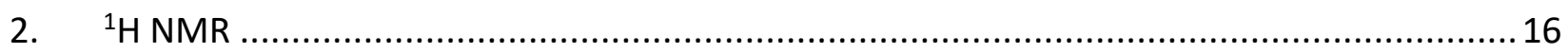

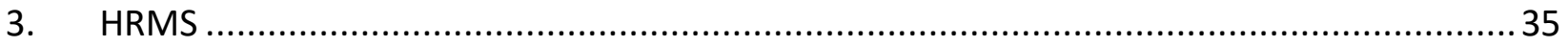

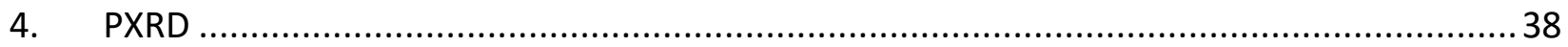

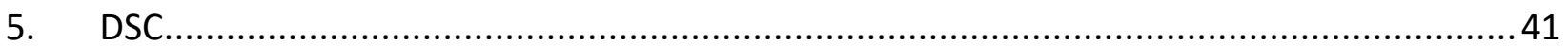

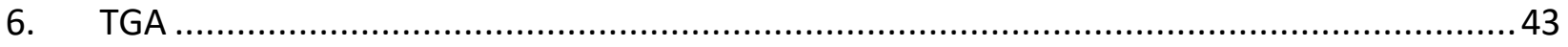

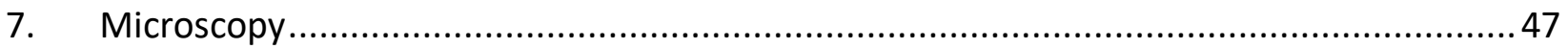

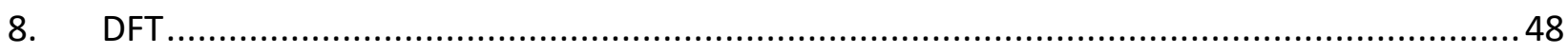




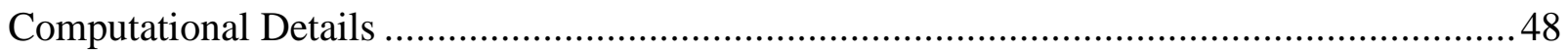

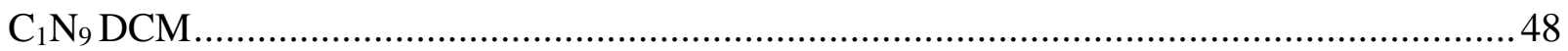

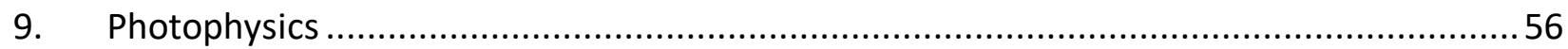

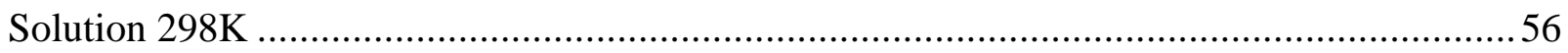

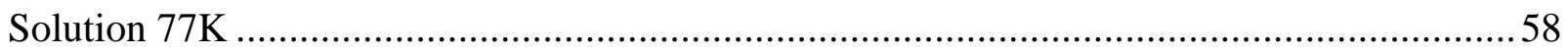

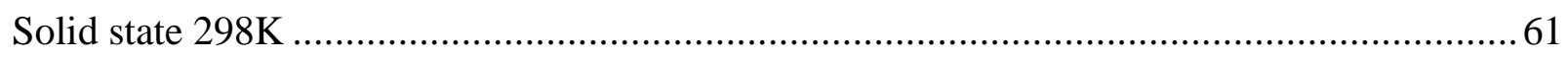

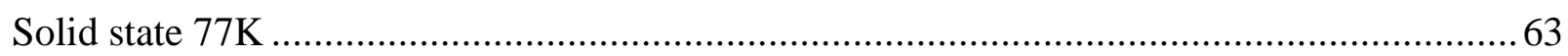

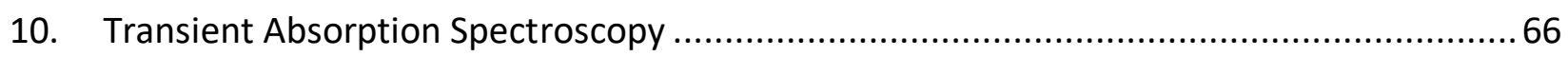

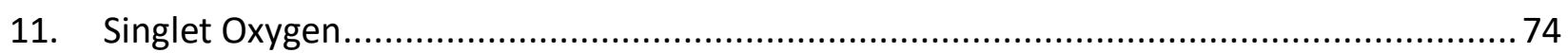

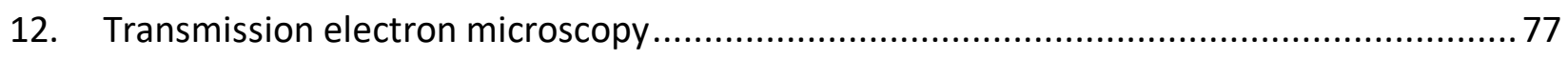

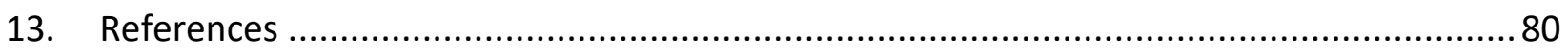

List of Figures

Figure $\mathrm{S} 1:{ }^{1} \mathrm{H}$ NMR spectrum of $\mathbf{N}$-(4-(nonyloxy)phenyl)acetamide in $\mathrm{CDCl}_{3} \ldots \ldots \ldots \ldots \ldots \ldots \ldots . \ldots \ldots$

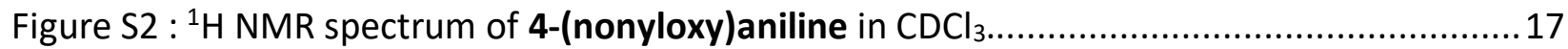

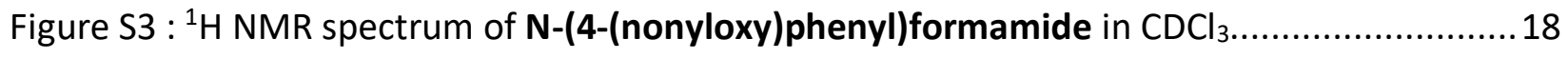

Figure $\mathrm{S} 4:{ }^{1} \mathrm{H}$ NMR spectrum of 1-(nonyloxy)-4-isonitrilebenzene in $\mathrm{CDCl}_{3} \ldots \ldots \ldots \ldots \ldots \ldots \ldots \ldots . . . \ldots \ldots$

Figure S5: ${ }^{1} \mathrm{H}$ NMR spectrum of $\mathbf{N}$-(4-(pentadecyloxy)phenyl)acetamide in $\mathrm{CDCl}_{3} \ldots \ldots \ldots \ldots \ldots . . . . .20$

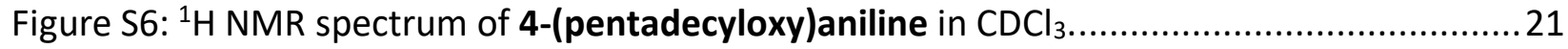

Figure S7: ${ }^{1} \mathrm{H}$ NMR spectrum of $\mathbf{N}$-(4-(pentadecyloxy)phenyl)formamide in $\mathrm{CDCl}_{3} \ldots \ldots \ldots \ldots \ldots . . . . .22$

Figure S8: ${ }^{1} \mathrm{H}$ NMR spectrum of 1-(pentadecyloxy)-4-isonitrilebenzene in $\mathrm{CDCl}_{3} \ldots \ldots \ldots \ldots \ldots \ldots . . . \ldots . . . .23$

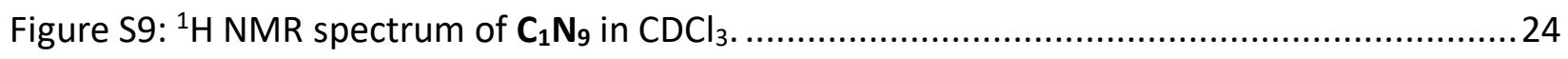

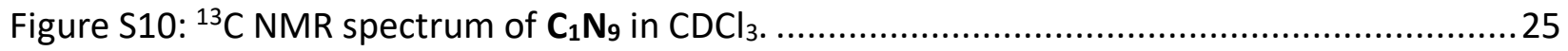

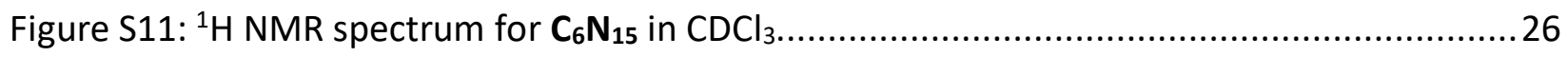

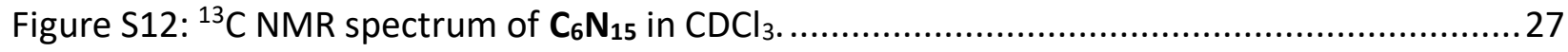

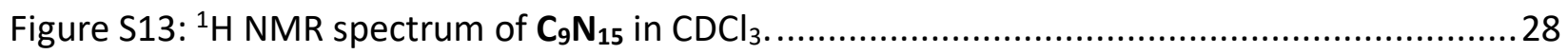

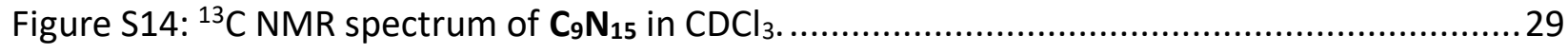




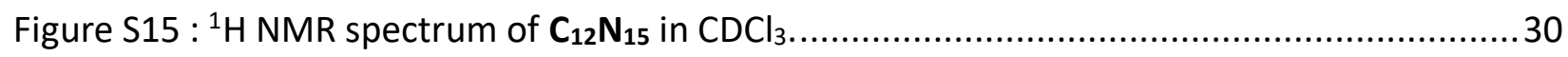

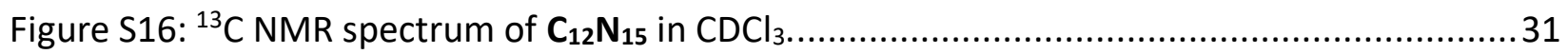

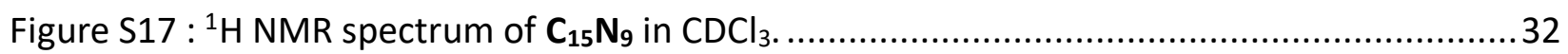

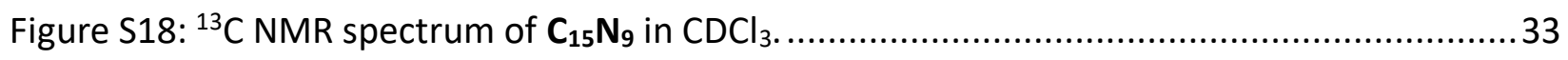

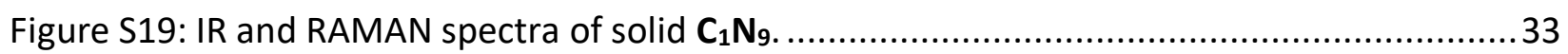

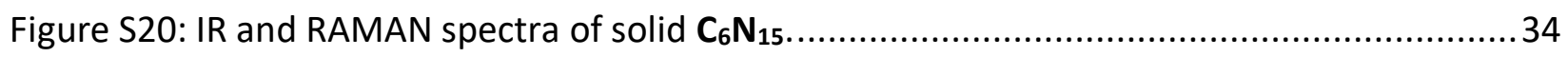

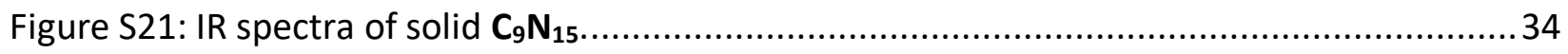

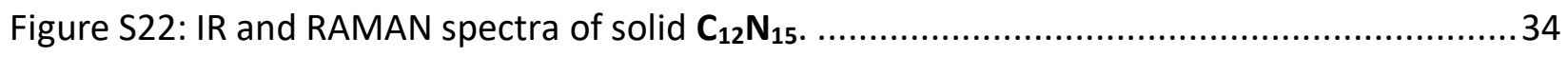

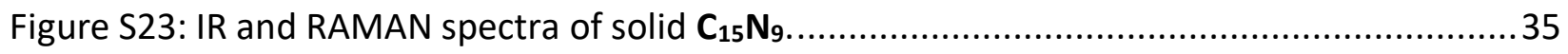

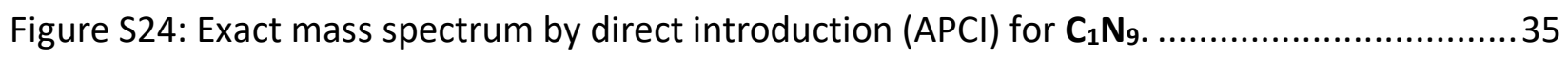

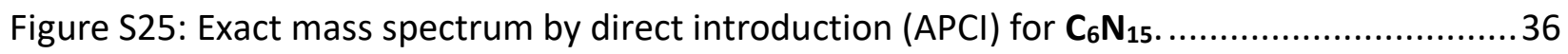

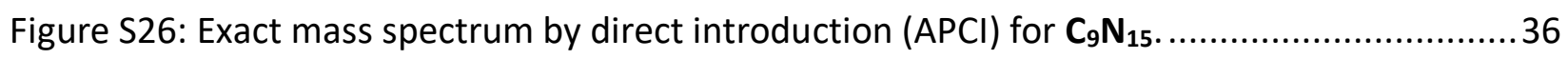

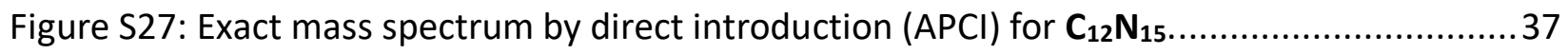

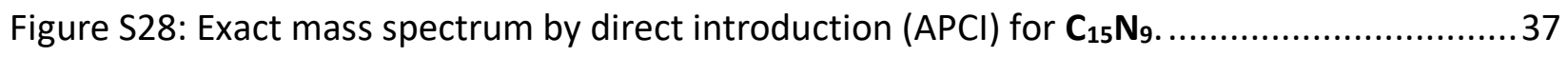

Figure S29 : Experimental powder XRD diffractrograms of $\mathbf{C}_{1} \mathbf{N}_{9}$ at $25{ }^{\circ} \mathrm{C}$ (left) and $125{ }^{\circ} \mathrm{C}$ (right).

Figure S30: Experimental powder XRD diffractrograms of $\mathbf{C}_{6} \mathbf{N}_{15}$ at $25^{\circ} \mathrm{C}$ (left) and $125{ }^{\circ} \mathrm{C}$ (right).

Figure S31: Experimental powder XRD diffractrograms of $\mathrm{C}_{9} \mathrm{~N}_{15}$ at $25^{\circ} \mathrm{C}$ (left) and $125{ }^{\circ} \mathrm{C}$ (right).

Figure S32: Experimental powder XRD diffractrograms of $\mathbf{C}_{12} \mathbf{N}_{15}$ at $25^{\circ} \mathrm{C}$ (left) and $125^{\circ} \mathrm{C}$ (right).

Figure S33: Experimental powder XRD diffractrograms of $\mathrm{C}_{15} \mathrm{~N}_{9}$ at $25^{\circ} \mathrm{C}$ (left) and $125{ }^{\circ} \mathrm{C}$ (right).

Figure S34: Hypothetical packing structure of solid $\mathrm{C}_{15} \mathrm{~N}_{9}$ at $25{ }^{\circ} \mathrm{C}$ based on curve fitting of the powder XRD patterns.

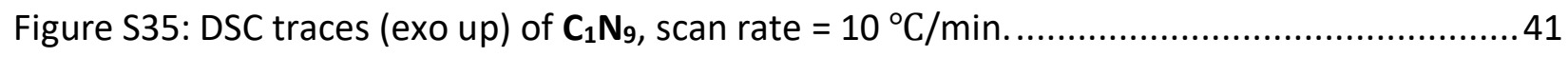

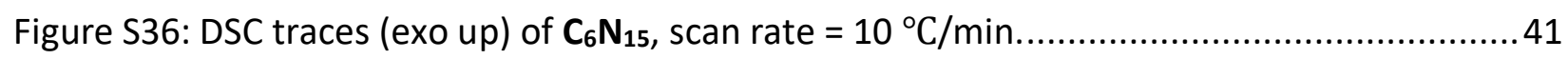

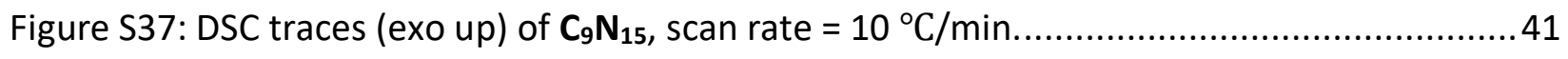


Figure S38: DSC traces (exo up) of $\mathbf{C}_{\mathbf{1 2}} \mathbf{N}_{15}$, scan rate $=10^{\circ} \mathrm{C} / \mathrm{min}$

Figure S39: DSC traces (exo up) of $\mathbf{C}_{15} \mathbf{N}_{9}$, scan rate $=10^{\circ} \mathrm{C} / \mathrm{min}$

Figure S40: Thermogravimetric analysis (black line) and corresponding first derivative (grey line) of $\mathbf{C}_{1} \mathbf{N}_{\mathbf{g}}$ under argon atmosphere from 20 to $950^{\circ} \mathrm{C}$.

Figure S41: Thermogravimetric analysis (black line) and corresponding first derivative (grey line) of $\mathbf{C}_{6} \mathbf{N}_{15}$ under argon atmosphere from 20 to $950{ }^{\circ} \mathrm{C}$.

Figure S42: Thermogravimetric analysis (black line) and corresponding first derivative (grey line) of $\mathbf{C}_{9} \mathbf{N}_{15}$ under argon atmosphere from 20 to $950{ }^{\circ} \mathrm{C}$.

Figure S43: Thermogravimetric analysis (black line) and corresponding first derivative (grey line) of $\mathbf{C}_{\mathbf{1 2}} \mathbf{N}_{\mathbf{1 5}}$ under argon atmosphere from 20 to $950{ }^{\circ} \mathrm{C}$.

Figure S44: Thermogravimetric analysis (black line) and corresponding first derivative (grey line) of $\mathbf{C}_{15} \mathbf{N}_{9}$ under argon atmosphere from 20 to $950{ }^{\circ} \mathrm{C}$. .45

Figure S45: TGA analysis of the residual at $950^{\circ} \mathrm{C}$ as a function of mass percent of carbon. .......46

Figure S46: TGA analysis of the residual at $950^{\circ} \mathrm{C}$ as a function of number of carbon atoms......46 Figure S47: Polarized light microscopy images of $\mathbf{C}_{1} \mathbf{N}_{9}$ at $298 \mathrm{~K}$ (left), at $398 \mathrm{~K}$ (middle) and at $408 \mathrm{~K}$ (right). Note that the image with the yellow back ground is without polarized light.

Figure S48: Polarized light microscopy images of $\mathbf{C}_{1} \mathbf{N}_{9}$ upon cooling at $388 \mathrm{~K}$ (left), at $383 \mathrm{~K}$ (middle) and 298K (right)

Figure S49: Polarized light microscopy images of $\mathbf{C}_{9} \mathbf{N}_{15}$ at $298 \mathrm{~K}$ (left), heated at $403 \mathrm{~K}$ (right) and cooled down to $392 \mathrm{~K}$ (right). Note that the image with the yellow back ground is without polarized light.

Figure S50: Polarized light microscopy images of $\mathbf{C}_{12} \mathbf{N}_{15}$ at $298 \mathrm{~K}$ (left), heated at $403 \mathrm{~K}$ (right) and heated at to $418 \mathrm{~K}$ (right). Note that the image with the yellow back ground is without polarized light.

Figure S51: Polarized light microscopy images of $\mathbf{C}_{12} \mathbf{N}_{15}$ cooled down to 298K. Note that the image with the yellow back ground is without polarized light. .48

Figure S52: Structure (optimized geometry) of $\mathbf{C}_{\mathbf{1}} \mathbf{N}_{\mathbf{9}}$ in the ground state. .48

Figure S53: Representations of the frontier MOs of $\mathbf{C}_{1} \mathbf{N}_{9}$ in the ground state. .50

Figure S54: Optimized geometry of $\mathbf{C}_{\mathbf{1}} \mathbf{N}_{\mathbf{9}}$ in the triplet state. .51 
Figure S55: Representation of the frontier MOs of $\mathbf{C}_{\mathbf{1}} \mathbf{N}_{\mathbf{9}}$ in the triplet state.

Figure S56 : Bar graph of the calculated positions of the spin-allowed electronic transition (blue) of $\mathbf{C}_{1} \mathbf{N}_{\mathbf{9}}$ vs their oscillator strength (the simulated spectrum (black) is generated by assigning an arbitrary thickness of $1500 \mathrm{~cm}^{-1}$ for each bar) ........................................................... 52

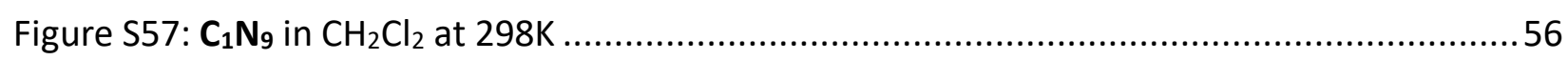

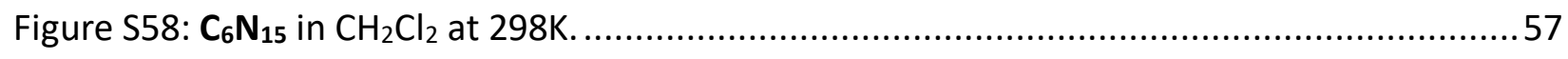

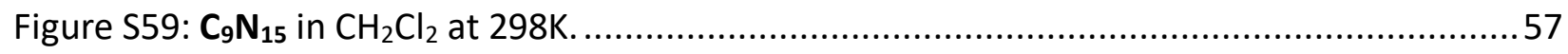

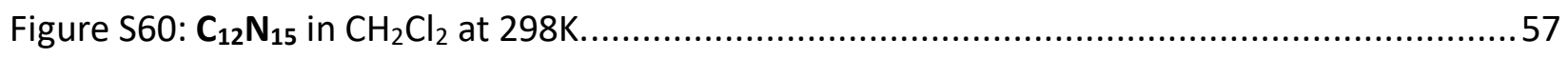

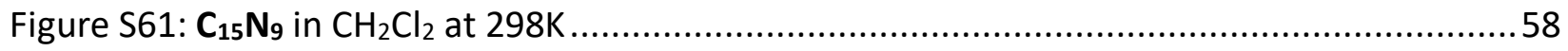

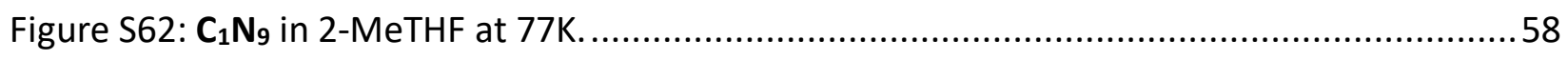

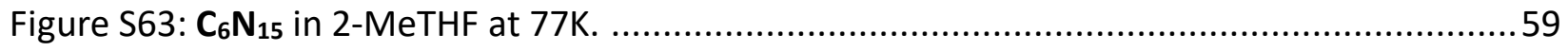

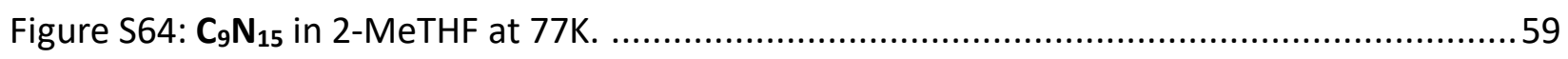

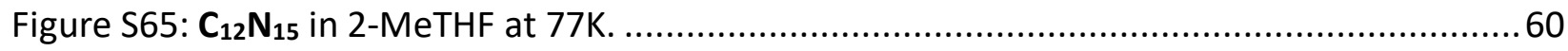

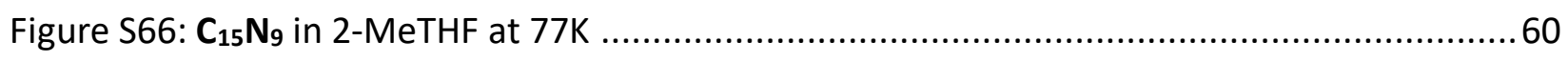

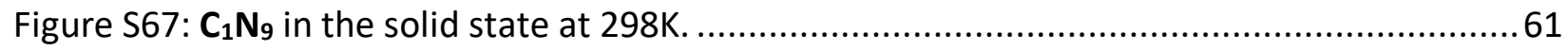

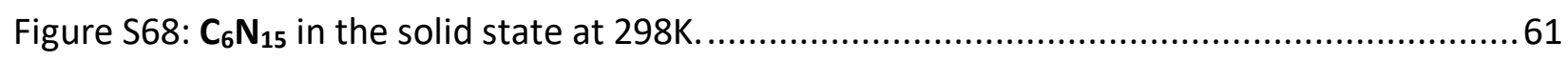

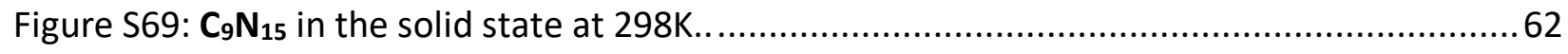

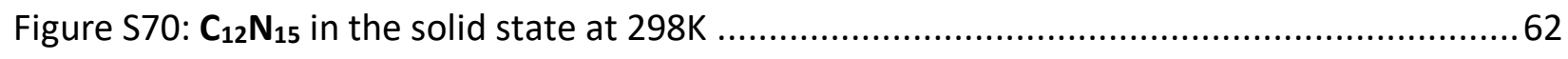

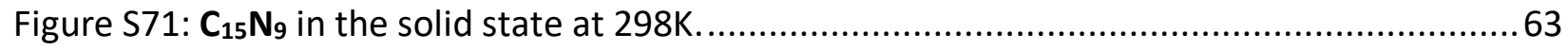

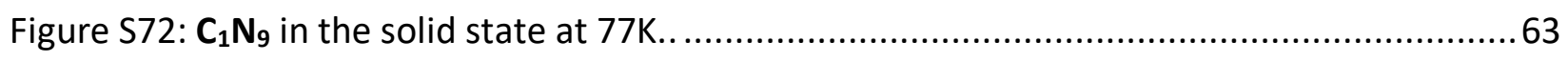

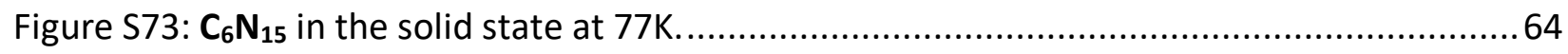

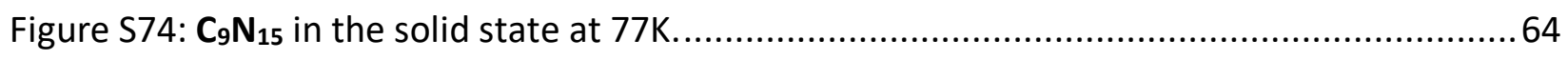

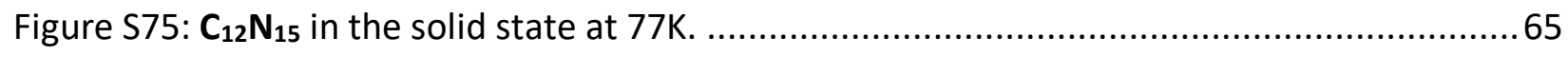

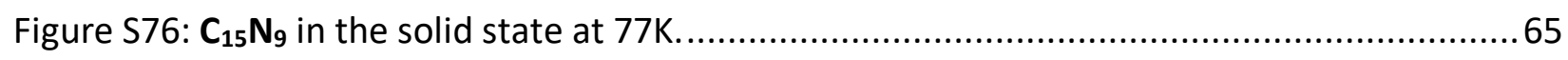

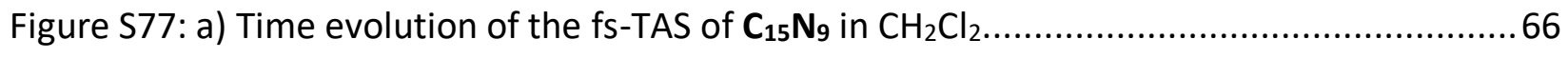

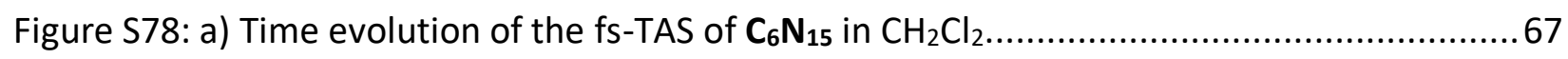

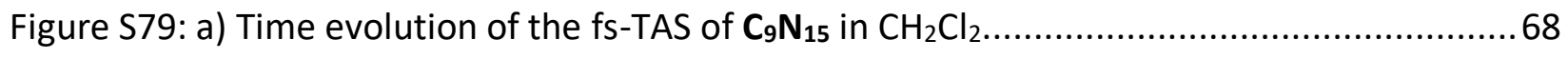

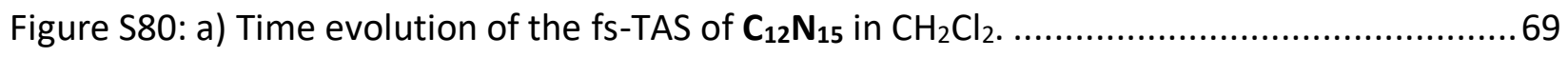


Figure S81: a) Time evolution of the fs-TAS of Au NPs generated upon the photodecomposition of $\mathrm{C}_{15} \mathrm{~N}_{9}$ in $\mathrm{CH}_{2} \mathrm{Cl}_{2}$.

Figure S82: Time evolution of the fs-TAS of Au NPs generated upon the photodecomposition of $\mathrm{C}_{6} \mathrm{~N}_{15}$ in $\mathrm{CH}_{2} \mathrm{Cl}_{2}$.

Figure S83: Time evolution of the fs-TAS of Au NPs generated upon the photodecomposition of $\mathrm{C}_{9} \mathrm{~N}_{15}$ in $\mathrm{CH}_{2} \mathrm{Cl}_{2}$.

Figure S84: Time evolution of the fs-TAS of Au NPs generated upon the photodecomposition of $\mathrm{C}_{12} \mathrm{~N}_{15}$

Figure S85: Experimental setup for near-infrared singlet oxygen steady state detection and lifetime measurements.

Figure S86: Emission decay of singlet oxygen photosensitized by gold complexes upon excitation at $300 \mathrm{~nm}$ in $\mathrm{CH}_{2} \mathrm{Cl}_{2}$ (DCM) at $298 \mathrm{~K}$.

Figure S87: Emission decay of singlet oxygen photosensitized by gold complexes upon excitation at $300 \mathrm{~nm}$ in $\mathrm{CH}_{2} \mathrm{Cl}_{2}$ (DCM) at $298 \mathrm{~K}$. .76

Figure S88: Setup for the irradiation of the gold complexes. .77

Figure S89: TEM images of $\mathbf{C}_{\mathbf{1}} \mathbf{N}_{\mathbf{9}}$. .77

Figure S90: TEM images of $\mathbf{C}_{6} \mathbf{N}_{15}$. 78

Figure S91: TEM images of $\mathbf{C}_{9} \mathbf{N}_{15}$. .78

Figure S92: TEM images of $\mathbf{C}_{\mathbf{1 2}} \mathbf{N}_{\mathbf{1 5}}$. .78

Figure S94: Evolution of the absorption spectra of $\mathbf{C}_{\mathbf{1}} \mathbf{N}_{\mathbf{9}}$ in in the solid state upon photolysis.....79 Figure S94: Evolution of the absorption spectra of $\mathrm{C}_{1} \mathrm{~N}_{9}$ in $\mathrm{CH}_{2} \mathrm{Cl}_{2}$ upon photolysis 79

\section{List of Tables}

Table S1: Atomic contributions of the frontier MOs of $\mathbf{C}_{\mathbf{1}} \mathbf{N}_{\mathbf{9}}$. $(\mathrm{H}=\mathrm{HOMO} ; \mathrm{L}=\mathrm{LUMO}) . . . . . . . . . . . .50$

Table S2: Atomic contributions of the frontier MOs of $\mathbf{C}_{\mathbf{1}} \mathbf{N}_{\mathbf{9}}$ in the triplet state.

Table S3: Calculated positions, oscillator strengths and major contributions of the 100 first spinallowed electronic transitions of $\mathbf{C}_{\mathbf{1}} \mathbf{N}_{\mathbf{9}}$. 


\section{Experimental Section}

\section{Instruments.}

The ${ }^{1} \mathrm{H}(300 \mathrm{MHz})$ and ${ }^{13} \mathrm{C}(76 \mathrm{MHz})$ NMR spectra were recorded on a Bruker Avance 300 Ultrashield NMR spectrometer. The chemical shifts are given in ppm relative to the residual peaks of $\mathrm{CDCl}_{3}$.The IR spectra were recorded at $4 \mathrm{~cm}^{-1}$ on an ABB Bomem, MB series FTIR spectrometer equipped with an ATR module from Specac from 600 to $4000 \mathrm{~cm}^{-1}$. The FT-Raman spectra were recorded from 0 to $4000 \mathrm{~cm}^{-1}$, at $5 \mathrm{~cm}^{-1}$ resolution using a Bruker RFS 100/S spectrometer with the $1064 \mathrm{~nm}$ excitation and a light power equal to $250 \mathrm{~mW}$ equipped with a photomultiplier Ge-diode, cooled at liquid nitrogen temperature $(77 \mathrm{~K})$. The peak centred between 83 and $85 \mathrm{~cm}^{-1}$ is considered as residual artefact from the instrument and should not be considered. The elemental analyses were performed by the analytical service of the University of Lorraine in Nancy, France. The solid-state UV-visible spectra were recorded on a Varian Cary 300 Bio UV-Vis spectrophotometer at $298 \mathrm{~K}$ using raised-angle transmittance apparatus and a homemade $77 \mathrm{~K}$ sample-holder. Samples were dispersed between two quartz plates. Solid-state emission, excitation, emission lifetimes and CIE 1931 charts (chromaticity coordinates) were acquired on a phosphorimeter FLS980 from Edinburgh Instruments equipped with single monochromators. Samples were introduced in a capillary or dispersed between two quartz plates and spectra obtained were corrected for instrument response. The emission lifetime measurements were performed using a "flash" pulsed lamp. Lifetimes values were obtained using a time correlated single photon counting (TCSPC) system and data were treated from both deconvolution of multi-exponential analysis and exponential series methods. Solid state emission quantum yields were recorded using a Quanta- $\varphi$ F-3029 integration sphere from Horiba plugged into a Horiba Fluorolog III (the power at the sample is $0.53 \mathrm{~W} / \mathrm{cm}^{2}$ at the sample $\left(\lambda_{\mathrm{exc}}=300 \mathrm{~nm}\right)$. The thermal analysis (TGA) traces were measured on a Perkin Elmer TGA 7 apparatus between 25 and $950{ }^{\circ} \mathrm{C}$ at a scanning rate of $10^{\circ} \mathrm{C} \cdot \mathrm{min}^{-1}$ under argon atmosphere. The differential scanning calorimetry (DSC) plots were measured on a DSC Q200 instrument equipped with a cooling system RCS 90 both from TA Instruments at a scanning rate of $10^{\circ} \mathrm{C} \cdot \mathrm{min}^{-1}$. The samples for powder X-ray diffraction measurements were mixed with a small amount of paratone oil, cut to approximately $0.3 \times 0.3 \times$ $0.3 \mathrm{~mm}^{3}$, and placed on a sample holder mounted at $173.2 \mathrm{~K}$ on a Bruker APEX DUO X-ray diffractometer. Six correlated runs per sample with Phi Scan of 360 degrees and exposure times of 
270 s were collected with the $\mathrm{Cu}$ micro-focus anode $(1.54184 \AA$ ) and the CCD APEX II detector at a $150 \mathrm{~mm}$ distance. These runs, from -12 to $-72^{\circ} 2 \theta$ and 6 to $36 \omega$, were then treated and integrated with the XRW2 Eval Bruker software to produce WAXD diffraction patterns from 2.5 to $82^{\circ} 2 \theta$. The patterns were streated with Diffrac.Eva version 2.0 from Bruker.

\section{Optical microscope.}

The optical monitoring of the solid-to-solid phase transitions were performed using an Olympus BX51-P polarizing microscope using a $360^{\circ}$ rotary polarizing filter. Images were recorded using a Diagnosticinstruments, inc. 14.2 Color Mosaic CCD camera fitted on the extension tube. The temperature control was performed by a Instec HCS402 temperature-controlled stage.

\section{Transmission electron microscopy.}

Transmission electron microscopy (TEM) images were taken using a Hitachi H-7500, the NP diameters were measures at a 80000x zoom. Carbon film grids from Electron Microscopy Sciences were used for all measurements. Particle dispersity was determined using the software imageJ. The photo- and thermally generated nanoparticles were removed from the substract using dichloromethane and $\mathrm{EtOH}$. Dichloromethane was evaporated under reduced pressure to afford a nanoparticle dispersion in EtOH. The same procedure was used to obtain suspension of thermally generated NPs. Each suspension was deposited on a 200-mesh carbon film grid using a micropipette set for $20 \mu \mathrm{l}$. Each sample was analysed for NP size and size dispersity.

\section{Photolysis apparatus.}

Photochemical decomposition of the complexes was tested using a $405 \mathrm{~nm}$ LED fitted with an NBK7 homogenizer with a calculated power output of $1300 \mathrm{~mW}$ and surface power density of 14.5 $\mathrm{Wm}^{-2}$. The compounds were drop casted onto microscope slides and placed in front of the light source for 3 hours. The distance was set to allow most of the sample to be illuminated while staying within $1 \mathrm{~cm}$ of the homogenizer.

For the fs-TAS measurements of the photogenerated gold nanoparticles (Au NPs), the Au NPs were photogenerated in situ using solutions containing the gold complexes in $\mathrm{CH}_{2} \mathrm{Cl}_{2}$. The excitation was carried out using the THG of the fundamental output of a Soltice (Spectra Physics) 
Ti-sapphire laser $\left(\lambda_{\text {exc }}=266 \mathrm{~nm}\right.$, rep. rate $=500 \mathrm{~Hz}$; and spot size $\left.\approx 300 \mu \mathrm{m}\right)$. The irradiation proceeded for 1 hour $(300 \mathrm{~nJ} / \mathrm{pulse}$ at $500 \mathrm{~Hz})$ and the fs-TAS signal was monitored until it did not change anymore. This was ensured by continuously measuring the transient signal at a fixed pumpprobe delay (5ps) with respect to the exposure time.

\section{Near-Infrared Singlet Oxygen steady state detection and lifetime measurement}

Photosensitized singlet oxygen emission spectra $\left({ }^{1} \Delta_{\mathrm{g}} \rightarrow{ }^{3} \Sigma_{\mathrm{g}} ; \lambda_{\mathrm{emi}}=1275 \mathrm{~nm}\right)$ of the gold complexes in solution were recorded on a QM-400 spectrofluorometer by PTI equipped with a Ushio $75 \mathrm{~W}$ Xenon Short Arc Lamp and a NIR PMT R5509-43 (300 to $1400 \mathrm{~nm}$ ) from Hamamatsu cooled with liquid nitrogen. Dichloromethane solutions were prepared with a concentration adjusted to match 1.0 in absorbance for the $300 \mathrm{~nm}$ absorption band, placed in sealed quartz cells and purged with oxygen gas for 10 minutes. Diffuse light, scattering and harmonic phenomena were filtered off in the 1225-1325 nm window with a $1200 \mathrm{~nm}$ longpass filter from ThorLabs placed before the emission monochromator. The radiative emission decay monitored at $1275 \mathrm{~nm}$ using dichloromethane and chloroform as the solvents were obtained with a similar set up but a Hamamatsu $15 \mathrm{~W}$ Xenon Flash Lamp was used as an excitation source. The results were fitted with Origin software with a one-phase exponential decay function with time constant parameter model $\left(\mathrm{I}(\lambda, \mathrm{t})=\mathrm{I}_{0}+\mathrm{A} \exp \{-\mathrm{t} / \tau\}\right)$.

\section{Ultrafast transient absorption spectroscopy (fs-TAS).}

The fs transient spectra were acquired on a homemade system using a Soltice (Spectra Physics) Tisapphire laser. Excitation was carried out using the THG of the fundamental output of the laser $\left(\lambda_{\text {exc }}=266 \mathrm{~nm}\right.$, rep. rate $=500 \mathrm{~Hz}$; and spot size $\left.\approx 300 \mu \mathrm{m}\right)$. The white light continuum (probe) is generated inside a $\mathrm{CaF} 2$ window and a custom-made dual CCD camera of $64 \times 1024$ pixels sensitive between 200 and $1100 \mathrm{~nm}$ (S7030, Spectronic Devices) is used for signal and reference detection. The delay line permitted us to probe up to $8 \mathrm{~ns}$ with an accuracy of $\sim 4 \mathrm{fs}$. The results were obtained by global analysis using the open source software Glotaran (http://glotaran.org) permitting extraction of a sum of independent exponentials $(I(\lambda, t)=$ $\left.C_{1}(\lambda) \times e^{-\frac{t_{1}}{\tau}}+C_{2}(\lambda) \times e^{-\frac{t_{2}}{\tau}}+\cdots\right)$. that fits the whole 3D transient map. 


\section{Density functional theory computations.}

All density functional theory (DFT) calculations were performed with Gaussian $16^{1}$ at the Université de Sherbrooke with the Mammouth supercomputer supported by Calcul Quebec. The DFT ground state calculations were carried out using the wb97xd/gen functional. A 6-31g(d, p) basis set was used for $\mathrm{C}, \mathrm{H}, \mathrm{N}$ and $\mathrm{O}$ atoms,${ }^{2-7}$ while a LANL2DZ basis set was used for the Au atom. ${ }^{8}$ Starting structures were constructed on GaussView 5.0 then geometry optimization was performed without any solvent field. The structure was then re-optimized in a dichloromethane solvent field. TDDFT computations were performed on both the optimized singlet and triplet state structures using a dichloromethane solvent field. The MO representations use red and blue color as positive isosurface and negative isosurface, respectively, and a contour value of 0.03 .

\section{Structure resolution from powder $\mathrm{X}$-ray diffraction patterns.}

PXRD data were converted into *.raw format and imported into BIOVIA Material Studio $17 .{ }^{9}$ Patterns were processed via the Reflex module and the diffraction peaks were identified with a low amplitude cut-off of $2 \%$ and a smoothing of maxima of $0.08^{\circ} 2 \theta$. The diffractions peaks were indexed with the DICVOL90 algorithm. ${ }^{10,11}$ Solution were analyzed and unit cells were generated for each. Pre-drawn structures of complexes were randomly placed inside the unit cell, the crystal structure was then rebuilt with the crystal system obtained from DICVOL90 and each available space group was tried. The structures were optimised via the Forcite module with a fine Quality (all other parameters were kept to default). Finally, the resulting structure was refined with the Reflex Powder Refinement, with Pawley refinement type and fine convergence quality (all other parameters were kept to default). The results were compared and stacked to the experimental data.

\section{Materials.}

The chemicals used in this investigation were acquired from Sigma-Aldrich, Anachemia and Alfa Aesar and were used as received without further purification. Palladium catalysts were prepared according to a previously published method. ${ }^{12}$ Solvents used for the photophysical measurements and for reactions involving metals were distilled shortly prior to usage and kept under inert atmosphere.

\section{Synthesis.}

Synthesis of dimethylsulfidechlorogold(I): $\mathrm{HAuCl}_{4}(0.15 \mathrm{mmol})$ was solubilized in a minimal amount of degassed EtOH. The solution was further degassed with argon and the vessel was sealed. 
Dimethyl sulfide (DSM) (0.31 mmol) was slowly injected into the flask, a white precipitated formed and the yellow solution turned colorless, the mixture was stirred for an additional 5 minutes. The solid was isolated by filtration and washed with a small amount of cold EtOH. The solid was then quickly transferred into a flask and kept under argon atmosphere. The product was used as is.

Synthesis of 4-alkoxyiodobenzene: Iodophenol (33.3 mmol), halogenoalkane (30.3 mmol), potassium carbonate $(33.3 \mathrm{mmol})$ and 2-butanone were added to a round bottom flask and the mixture was refluxed overnight. Upon completion, the solid was filtered off and the filtrate was evaporated under vacuum. The resulting oily substance was solubilized in diethyl ether and was washed twice with $50 \mathrm{ml}$ of $\mathrm{NaOH} 5 \%$ solution and once with a $50 \mathrm{ml}$ of a saturated $\mathrm{NaHCO}_{3}$ solution. The organic layer was dried over magnesium sulfate and the solvent was evaporated under vacuum. The crude product was further purified by column chromatography, using hexanes as the eluent, to afford the desired product. 4-hexyloxyiodobenzene: transparent liquid, yield $=87 \%$. ${ }^{1} \mathrm{H}$ NMR (300 MHz, CDCl3) $\delta 7.68-7.40(\mathrm{~m}, 2 \mathrm{H}), 6.87-6.57(\mathrm{~m}, 2 \mathrm{H}), 3.93(\mathrm{t}, \mathrm{J}=6.6 \mathrm{~Hz}, 2 \mathrm{H}), 1.95$ - $1.68(\mathrm{~m}, 2 \mathrm{H}), 1.46(\mathrm{ddd}, \mathrm{J}=15.7,11.7,7.7 \mathrm{~Hz}, 2 \mathrm{H}), 1.40-1.29(\mathrm{~m}, 4 \mathrm{H}), 0.95$ (t, J = 6.7 Hz, 3H). 4-nonyloxyiodobenzene: transparent liquid, yield $=49 \% .{ }^{1} \mathrm{H} \mathrm{NMR}(300 \mathrm{MHz}, \mathrm{CDCl} 3) \delta 7.56(\mathrm{~d}$, $\mathrm{J}=9.0 \mathrm{~Hz}, 2 \mathrm{H}), 6.69(\mathrm{~d}, \mathrm{~J}=8.9 \mathrm{~Hz}, 2 \mathrm{H}), 3.93(\mathrm{t}, \mathrm{J}=6.6 \mathrm{~Hz}, 2 \mathrm{H}), 1.86-1.72(\mathrm{~m}, 2 \mathrm{H}), 1.45$ (dd, J $=14.6,6.6 \mathrm{~Hz}, 2 \mathrm{H}), 1.30(\mathrm{~s}, 10 \mathrm{H}), 0.91(\mathrm{t}, \mathrm{J}=6.7 \mathrm{~Hz}, 3 \mathrm{H})$. 4-dodecyloxyiodobenzene: white solid. yield $=78 \%$. ${ }^{1} \mathrm{H}$ NMR $(300 \mathrm{MHz}, \mathrm{CDCl} 3) \delta 7.57(\mathrm{~d}, \mathrm{~J}=9.0 \mathrm{~Hz}, 2 \mathrm{H}), 6.70(\mathrm{~d}, \mathrm{~J}=9.0 \mathrm{~Hz}, 2 \mathrm{H}), 3.93$ $(\mathrm{t}, \mathrm{J}=6.6 \mathrm{~Hz}, 2 \mathrm{H}), 1.98-1.68(\mathrm{~m}, 3 \mathrm{H}), 1.46(\mathrm{q}, \mathrm{J}=6.6 \mathrm{~Hz}, 2 \mathrm{H}), 1.31(\mathrm{~s}, 24 \mathrm{H}), 0.93(\mathrm{t}, \mathrm{J}=6.7 \mathrm{~Hz}$, 9H). ). 4-pentadecyloxyiodobenzene: white solid. Yield $=7469 \%$. ${ }^{1} \mathrm{H}$ NMR $(300 \mathrm{MHz}, \mathrm{CDCl} 3)$ $\delta 7.56(\mathrm{~d}, \mathrm{~J}=8.9 \mathrm{~Hz}, 2 \mathrm{H}), 6.69(\mathrm{~d}, \mathrm{~J}=8.9 \mathrm{~Hz}, 2 \mathrm{H}), 3.93(\mathrm{t}, \mathrm{J}=6.6 \mathrm{~Hz}, 2 \mathrm{H}), 1.86-1.68(\mathrm{~m}, 3 \mathrm{H})$, $1.52-1.40(\mathrm{~m}, 2 \mathrm{H}), 1.28(\mathrm{~s}, 22 \mathrm{H}), 0.91(\mathrm{t}, \mathrm{J}=6.7 \mathrm{~Hz}, 3 \mathrm{H})$.

Synthesis of ((4-(alkoxy)phenyl)ethynyl)trimethylsilane: 1-Alkoxy-4-iodobenzene (10 mmol), $\mathrm{CuI}(0.1 \mathrm{mmmol})$ and $\mathrm{Pd}\left(\mathrm{PPh}_{3}\right)_{2} \mathrm{Cl}_{2}(0.2 \mathrm{mmol})$ were added to torch dried $100 \mathrm{ml}$ 2-neck flask. The system was purged with argon and $40 \mathrm{ml}$ of freshly distilled diethylamine was added. The mixture was brought to reflux for 5 minutes and trimethylsilylacetylene $(15 \mathrm{mmol})$ was injected into the flask, the solution went from yellow to transparent and a black deposit formed. Once the reaction was completed (monitored by TLC) the solvent was removed under reduced pressure. The crude product was solubilized in $50 \mathrm{ml}$ of DCM and washed twice with $30 \mathrm{ml}$ of $\mathrm{HCl} 0.5 \mathrm{~N}$ and once with $30 \mathrm{ml}$ of brine. The organic phase was dried using $\mathrm{MgSO}_{4}$. The resulting solid was purified by 
chromatography column using hexanes as an eluent and progressively switching to DCM. ((4(methoxy)phenyl)ethynyl)trimethylsilane: Yield $=92 \% .{ }^{1} \mathrm{H}$ NMR $(400 \mathrm{MHz}$, Chloroform- $d$ ) $\delta$ $7.43(\mathrm{~d}, J=8.8 \mathrm{~Hz}, 2 \mathrm{H}), 6.84(\mathrm{~d}, J=8.8 \mathrm{~Hz}, 2 \mathrm{H}), 3.83(\mathrm{~s}, 3 \mathrm{H}), 0.26$ (s, 9H). ((4(hexyloxy)phenyl)ethynyl)trimethylsilane: Yield $=68 \% .{ }^{1} \mathrm{H}$ NMR $(300 \mathrm{MHz}, \mathrm{CDCl} 3) \delta 7.43(\mathrm{~d}$, $\mathrm{J}=8.8 \mathrm{~Hz}, 2 \mathrm{H}), 6.83(\mathrm{~d}, \mathrm{~J}=8.9 \mathrm{~Hz}, 2 \mathrm{H}), 3.95(\mathrm{t}, \mathrm{J}=6.6 \mathrm{~Hz}, 2 \mathrm{H}), 1.93-1.69(\mathrm{~m}, 2 \mathrm{H}), 1.56-1.43$ $(\mathrm{m}, \quad 2 \mathrm{H}), \quad 1.42-1.30 \quad(\mathrm{~m}, \quad 4 \mathrm{H}), 0.95 \quad(\mathrm{t}, \quad \mathrm{J}=6.7 \quad \mathrm{~Hz}, \quad 3 \mathrm{H}), 0.28 \quad(\mathrm{~s}, \quad 9 \mathrm{H}) . \quad((4-$ (nonyloxy)phenyl)ethynyl)trimethylsilane: Yield $=37 \% .{ }^{1} \mathrm{H} \mathrm{NMR}(300 \mathrm{MHz}, \mathrm{CDCl} 3) \delta 7.45-$ $7.38(\mathrm{~m}, 2 \mathrm{H}), 6.87-6.79(\mathrm{~m}, 2 \mathrm{H}), 3.96(\mathrm{t}, \mathrm{J}=6.6 \mathrm{~Hz}, 2 \mathrm{H}), 1.78(\mathrm{~d}, \mathrm{~J}=8.0 \mathrm{~Hz}, 2 \mathrm{H}), 1.57-1.24$ $(\mathrm{m}, 12 \mathrm{H}), 0.92(\mathrm{t}, \mathrm{J}=6.7 \mathrm{~Hz}, 3 \mathrm{H}), 0.27(\mathrm{~s}, 9 \mathrm{H})$. ((4-(dodecyloxy)phenyl)ethynyl)trimethylsilane: Yield $=31 \% .{ }^{1} \mathrm{H}$ NMR $(300 \mathrm{MHz}, \mathrm{CDCl} 3) \delta 7.42(\mathrm{~d}, \mathrm{~J}=8.9 \mathrm{~Hz}, 2 \mathrm{H}), 6.83(\mathrm{~d}, \mathrm{~J}=8.9 \mathrm{~Hz}, 2 \mathrm{H})$, $3.96(\mathrm{t}, \mathrm{J}=6.6 \mathrm{~Hz}, 2 \mathrm{H}), 1.79(\mathrm{dd}, \mathrm{J}=14.5,6.7 \mathrm{~Hz}, 3 \mathrm{H}), 1.48(\mathrm{~s}, 2 \mathrm{H}), 1.32(\mathrm{~s}, 22 \mathrm{H}), 0.94(\mathrm{t}, \mathrm{J}=6.7$ $\mathrm{Hz}, 8 \mathrm{H}), 0.29$ (s, 9H). ((4-(pentadecyloxy)phenyl)ethynyl)trimethylsilane: Yield $=55 \% .{ }^{1} \mathrm{H}$ NMR (300 MHz, CDCl3) $\delta 7.41(\mathrm{~d}, \mathrm{~J}=8.8 \mathrm{~Hz}, 2 \mathrm{H}), 6.83(\mathrm{~d}, \mathrm{~J}=8.8 \mathrm{~Hz}, 2 \mathrm{H}), 3.96(\mathrm{t}, \mathrm{J}=6.6 \mathrm{~Hz}$, 2H), $1.78(\mathrm{dd}, \mathrm{J}=14.6,6.7 \mathrm{~Hz}, 2 \mathrm{H}), 1.46(\mathrm{~s}, 3 \mathrm{H}), 1.31(\mathrm{~d}, \mathrm{~J}=12.8 \mathrm{~Hz}, 27 \mathrm{H}), 1.00$ (d, J = 6.6 Hz, $1 \mathrm{H}), 0.91(\mathrm{t}, \mathrm{J}=6.6 \mathrm{~Hz}, 6 \mathrm{H}), 0.27(\mathrm{~s}, 9 \mathrm{H})$.

Synthesis of 1-(alkoxy)-4-ethynylbenzene: The desired amount of ((4(alkoxy)phenyl)ethynyl)trimethylsilane was solubilised in THFTHD and a large excess of TBAF $1 \mathrm{M}$ in THF was slowly added and the solution was stirred for 5 minutes. The reaction was monitored by TLC. The solvent was removed under reduced pressure and the product was purified by column chromatography using hexanes and progressively switching to DCM. The resulting product was used without further characterization. 1-(methoxy)-4-ethynylbenzene: Yield $=54 \%$. ${ }^{1} \mathrm{H}$ NMR (300 MHz, Chloroform-d) $\delta 7.44$ (d, $\left.J=7.7 \mathrm{~Hz}, 2 \mathrm{H}\right), 6.85$ (d, $\left.J=7.7 \mathrm{~Hz}, 2 \mathrm{H}\right), 3.81$ (s, $3 \mathrm{H}), 3.00(\mathrm{~s}, 1 \mathrm{H})$. 1-(hexyloxy)-4-ethynylbenzene: Yield $=21 \% .{ }^{1} \mathrm{H} \mathrm{NMR}(300 \mathrm{MHz}, \mathrm{CDCl} 3) \delta$ $7.45(\mathrm{~d}, \mathrm{~J}=8.6 \mathrm{~Hz}, 2 \mathrm{H}), 6.86(\mathrm{~d}, \mathrm{~J}=8.7 \mathrm{~Hz}, 2 \mathrm{H}), 3.98(\mathrm{~s}, 2 \mathrm{H}), 3.01(\mathrm{~s}, 1 \mathrm{H}), 1.81$ (d, J = $7.5 \mathrm{~Hz}$, 3H), $1.70-1.46$ (m, 4H), 1.33 (s, 17H), 1.13 (ddd, J = 16.7, 12.8, 6.2 Hz, 1H), 0.94 (s, 15H). 1(nonyloxy)-4-ethynylbenzene: Yield $=79 \% .{ }^{1} \mathrm{H}$ NMR $(300 \mathrm{MHz}, \mathrm{CDCl} 3) \delta 7.45(\mathrm{~d}, \mathrm{~J}=8.9 \mathrm{~Hz}$, 2H), $6.86(\mathrm{~d}, \mathrm{~J}=8.9 \mathrm{~Hz}, 2 \mathrm{H}), 3.97$ (t, J = 6.6 Hz, 2H), 3.02 (s, 1H), 1.80 (dd, J = 14.7, 6.6 Hz, 2H), $1.53-1.42(\mathrm{~m}, 2 \mathrm{H}), 1.31(\mathrm{~d}, \mathrm{~J}=4.2 \mathrm{~Hz}, 14 \mathrm{H}), 1.01(\mathrm{~d}, \mathrm{~J}=6.6 \mathrm{~Hz}, 1 \mathrm{H}), 0.93(\mathrm{t}, \mathrm{J}=6.8 \mathrm{~Hz}, 7 \mathrm{H}) .1-$ (dodecyloxy)-4-ethynylbenzene: Yield = 31\%. ${ }^{1} \mathrm{H}$ NMR $(300 \mathrm{MHz}, \mathrm{CDCl} 3) \delta 7.45$ (d, J = 8.8 Hz, 2H), $6.86(\mathrm{~d}, \mathrm{~J}=8.9 \mathrm{~Hz}, 2 \mathrm{H}), 3.97(\mathrm{t}, \mathrm{J}=6.6 \mathrm{~Hz}, 2 \mathrm{H}), 3.02(\mathrm{~s}, 1 \mathrm{H}), 1.88-1.69(\mathrm{~m}, 2 \mathrm{H}), 1.55-$ $1.41(\mathrm{~m}, 3 \mathrm{H}), 1.31(\mathrm{~s}, 18 \mathrm{H}), 0.93(\mathrm{t}, \mathrm{J}=6.7 \mathrm{~Hz}, 4 \mathrm{H})$. 1-(pentadecyloxy)-4-ethynylbenzene: Yield 
$=89 \% .{ }^{1} \mathrm{H}$ NMR $(300 \mathrm{MHz}, \mathrm{CDCl} 3) \delta 7.44(\mathrm{~d}, \mathrm{~J}=8.8 \mathrm{~Hz}, 2 \mathrm{H}), 6.85(\mathrm{~d}, \mathrm{~J}=8.9 \mathrm{~Hz}, 2 \mathrm{H}), 3.97(\mathrm{t}, \mathrm{J}$ $=6.6 \mathrm{~Hz}, 2 \mathrm{H}), 3.01(\mathrm{~s}, 1 \mathrm{H}), 1.96-1.70(\mathrm{~m}, 2 \mathrm{H}), 1.53-1.41(\mathrm{~m}, 3 \mathrm{H}), 1.28(\mathrm{~s}, 26 \mathrm{H}), 1.16-0.97$ $(\mathrm{m}, 1 \mathrm{H}), 0.90(\mathrm{dd}, \mathrm{J}=7.2,6.2 \mathrm{~Hz}, 6 \mathrm{H})$.

Synthesis of N-(4-(alkoxy)phenyl)acetamide: 4-Acetamidophenol $(33.3 \mathrm{mmol})$, halogenoalkane $(30.3 \mathrm{mmol})$ and potassium carbonate $(33.3 \mathrm{mmol})$ were added to a round bottom flask and 2butanone $(100 \mathrm{ml})$ was added and the mixture was refluxed overnight. Upon completion the solid was filtered off and the filtrate was evaporated under vacuum. The resulting oily substance was solubilized in diethyl ether and was washed twice with $50 \mathrm{ml}$ of $\mathrm{NaOH} 5 \%$ solution and once with a $50 \mathrm{ml}$ of a saturated $\mathrm{NaHCO}_{3}$ solution. The organic layer was dried over magnesium sulfate and the solvent was evaporated under vacuum. The crude product was further purified by column chromatography, using hexanes $\rightarrow$ DCM as the eluent, to afford the desired product. N-(4(nonyloxy)phenyl)acetamide: white solid, $57 \%$ yield ${ }^{1} \mathrm{H}$ NMR $(400 \mathrm{MHz}, \mathrm{CDCl} 3) \delta 7.39$ (d, J = $8.9 \mathrm{~Hz}, 2 \mathrm{H}), 7.03$ (s, 1H), 6.87 (d, J = 9.0 Hz, 2H), 3.95 (t, J = 6.6 Hz, 2H), 2.18 (s, 3H), 1.83 $1.70(\mathrm{~m}, 2 \mathrm{H}), 1.47(\mathrm{~d}, \mathrm{~J}=7.2 \mathrm{~Hz}, 1 \mathrm{H}), 1.32(\mathrm{~d}, \mathrm{~J}=12.4 \mathrm{~Hz}, 12 \mathrm{H}), 1.00-0.81(\mathrm{~m}, 2 \mathrm{H}) . \mathbf{N}-(4-$ (pentadecyloxy)phenyl)acetamide: white solid, $74 \%$ yield ${ }^{1} \mathrm{H}$ NMR (400 MHz, Chloroform-d) $\delta$ 7.39 (d, J = 9.0 Hz, 2H), 7.08 (s, 1H), 6.87 (d, J = 9.0 Hz, 2H), 3.95 (t, J = 6.6 Hz, 2H), 2.18 (s, $3 \mathrm{H}), 1.78(\mathrm{dd}, \mathrm{J}=8.2,6.5 \mathrm{~Hz}, 2 \mathrm{H}), 1.46(\mathrm{t}, \mathrm{J}=7.7 \mathrm{~Hz}, 2 \mathrm{H}), 1.28(\mathrm{~s}, 22 \mathrm{H}), 0.95-0.84(\mathrm{~m}, 3 \mathrm{H})$.

Synthesis of 4-(alkoxy)benzenaminium hydrogen sulfate: 4-(alkoxy)phenylacetamide (15 mmol) was suspended in $\mathrm{H}_{2} \mathrm{SO}_{4} 40 \%$ and the solution was refluxed until it forms an homogenous solution. The solution is then slowly cooled to room temperature, as it cools a precipitate forms. The solid was isolated by filtration and then recrystallized in ethanol $70 \%$ to afford a long fibrous pink solid. The products were used without further purification or analysis. 4-(noncyloxy)benzenaminium hydrogen sulfate: $71 \%$ yield. 4-(pentadecyloxy)benzenaminium hydrogen sulfate:: $92 \%$ yield.

Synthesis of 4-(alkoxy)aniline: 4-(alkoxy)phenylammonium hydrogen sulfate (12 mmol) was transferred to a flask with DCM, benzyltriethylammonium chloride and $\mathrm{NaOH} 1 \mathrm{M}$. The mixture was stirred at room temperature until solid had completely solubilized. The organic phase was then separated and evaporated under reduced pressure to afford 4-(alkoxy)aniline. 4-(nonyloxy)aniline: $99 \%$ yield, ${ }^{1} \mathrm{H}$ NMR (400 MHz, Chloroform- $d$ ) $\delta 6.98-6.89(\mathrm{~m}, 2 \mathrm{H}), 6.86-6.79(\mathrm{~m}, 2 \mathrm{H}), 3.99-$ 3.85 (m, 2H), 1.77 (dd, $J=8.3,6.6 \mathrm{~Hz}, 2 \mathrm{H}), 1.46$ (t, $J=7.7 \mathrm{~Hz}, 1 \mathrm{H}), 1.38-1.23(\mathrm{~m}, 13 \mathrm{H}), 1.13-$ $0.74(\mathrm{~m}, 2 \mathrm{H}) .4$-(pentadecyloxy)aniline: $99 \%$ yield, ${ }^{1} \mathrm{H}$ NMR $(300 \mathrm{MHz}$, Chloroform- $d$ ) $\delta 7.02(\mathrm{~d}$, 
$J=8.8 \mathrm{~Hz}, 1 \mathrm{H}), 6.92-6.63(\mathrm{~m}, 1 \mathrm{H}), 4.02-3.74(\mathrm{~m}, 2 \mathrm{H}), 1.77(\mathrm{~s}, 4 \mathrm{H}), 1.28(\mathrm{~s}, 28 \mathrm{H}), 1.00-0.66$ $(\mathrm{m}, 3 \mathrm{H})$.

Synthesis of N-(4-(alkoxy)phenyl)formamide: 4-(alkoxy)aniline $(9.7 \mathrm{mmol})$ was solubilized in toluene and formic acid 70\% (9.7 mmol) was added. The mixture was refluxed and monitored by TLC. Upon completion the solvent was evaporated, and the crude product was recrystallized from chloroform and hexanes. $\mathbf{N}$-(4-(nonyloxy)phenyl)formamide: 90\% yield, ${ }^{1} \mathrm{H}$ NMR $(300 \mathrm{MHz}$, Chloroform- $d$ ) $\delta 8.51(\mathrm{~d}, J=11.6 \mathrm{~Hz}, 0.5 \mathrm{H}), 8.36(\mathrm{~d}, J=1.8 \mathrm{~Hz}, 0.5 \mathrm{H}), 7.45(\mathrm{~d}, J=9.0 \mathrm{~Hz}, 1 \mathrm{H})$, $7.03(\mathrm{~d}, J=8.8 \mathrm{~Hz}, 1 \mathrm{H}), 6.90(\mathrm{dd}, J=8.8,6.1 \mathrm{~Hz}, 2 \mathrm{H}), 3.96(\mathrm{td}, J=6.5,1.1 \mathrm{~Hz}, 2 \mathrm{H}), 1.79(\mathrm{dd}, J$ $=10.0, \quad 4.6 \mathrm{~Hz}, \quad 2 \mathrm{H}), \quad 1.47(\mathrm{~s}, \quad 2 \mathrm{H}), \quad 1.30 \quad(\mathrm{~s}, \quad 8 \mathrm{H}), \quad 0.96-0.68 \quad(\mathrm{~m}, \quad 3 \mathrm{H}) . \quad \mathbf{N}-(4-$ (pentadecyloxy)phenyl)formamide: $99 \%$ yield, ${ }^{1} \mathrm{H}$ NMR $(300 \mathrm{MHz}$, Chloroform- $d$ ) $\delta 8.51$ (d, $J$ $=11.6 \mathrm{~Hz}, 1 \mathrm{H}), 8.36(\mathrm{~d}, J=1.8 \mathrm{~Hz}, 1 \mathrm{H}), 7.45(\mathrm{~d}, J=8.9 \mathrm{~Hz}, 1 \mathrm{H}), 7.03(\mathrm{~d}, J=8.9 \mathrm{~Hz}, 1 \mathrm{H}), 6.90$ $(\mathrm{dd}, J=8.8,6.0 \mathrm{~Hz}, 2 \mathrm{H}), 3.96(\mathrm{t}, J=6.5 \mathrm{~Hz}, 2 \mathrm{H}), 1.93-1.65(\mathrm{~m}, 2 \mathrm{H}), 1.46(\mathrm{~s}, 3 \mathrm{H}), 1.28(\mathrm{~s}, 22 \mathrm{H})$, $1.10-0.61(\mathrm{~m}, 3 \mathrm{H})$.

Synthesis of 1-(alkoxy)-4-isonitrilebenzene: Under an argon atmosphere, 4-(alkoxy)formanilide $(7.5 \mathrm{mmol})$ was solubilized in DCM and triethylamine $(52.3 \mathrm{mmol})$. The flask was transfered to an ice bath for 10 minutes, to allow the solution to reach $0^{\circ} \mathrm{C}$. A solution of triphosgene (2eq) in DCM was added dropwise through a septum using a syringe, the flask needs to be attached to a gas manifold in order to avoid pressure build up. The solution was stirred for 30 minutes to assure completion, the solution turned to a bright yellow cloudy mixture as the triphosgene was added. DCM was added and the mixture was then washed twice with water. The organic layer was dried over sodium sulfate and the solvent was evaporated under reduced pressure. The dark yellow crude product was then purified by column chromatography using silica gel that was treated with triethylamine in order to minimize product decomposition. Hexanes was used as the eluent to afford the desired product. The 4-(alkoxy)phenylisonitrille was stored at $-20^{\circ} \mathrm{C}$ under argon. 1(nonyloxy)-4-isonitrilebenzene: $44 \%$ yield, ${ }^{1} \mathrm{H}$ NMR (300 MHz, Chloroform- $d$ ) $\delta 7.32$ (d, $J=8.9$ $\mathrm{Hz}, 2 \mathrm{H}), 6.87$ (d, $J=8.9 \mathrm{~Hz}, 2 \mathrm{H}), 3.97$ (t, $J=6.5 \mathrm{~Hz}, 2 \mathrm{H}), 2.14-1.69$ (m, 2H), $1.49-1.19$ (m, $12 \mathrm{H}), 1.05-0.58(\mathrm{~m}, 3 \mathrm{H}) .1$-(pentadecyloxy)-4-isonitrilebenzene: $51 \%$ yield, ${ }^{1} \mathrm{H}$ NMR (300 MHz, Chloroform- $d$ ) $\delta 7.32(\mathrm{~d}, J=8.9 \mathrm{~Hz}, 2 \mathrm{H}), 6.87(\mathrm{~d}, J=8.9 \mathrm{~Hz}, 2 \mathrm{H}), 3.97(\mathrm{t}, J=6.5 \mathrm{~Hz}, 2 \mathrm{H})$, $2.03-1.67(\mathrm{~m}, 2 \mathrm{H}), 1.47(\mathrm{~s}, 2 \mathrm{H}), 1.28(\mathrm{~s}, 22 \mathrm{H}), 1.01-0.74(\mathrm{~m}, 3 \mathrm{H})$. 
Synthesis of 1-(alkoxy)-4-ethynylbenzenechlorogold(I): A degassed solution of 1-(alkoxy)-4ethynylbenzene ( $0.15 \mathrm{mmol})$ in DCM was added to the flask containing AuCl(DMS) (0.15 mmol) and $22.3 \mathrm{mg}$ of triethylamine was slowly added. The reaction was stirred under argon at room temperature for 45 minutes. The resulting yellow solid was isolated by filtration and washed with cold acetone. The clean product was dried under vacuum and was used without further purification.

Synthesis of 1-(alkoxy)-4-ethynylbenzene-1'-(alkoxy)-4'-isonitrilebenzenegold(I): Toluene (10 $\mathrm{ml}$ ) was added to $\mathrm{AuCl}$ (ethynyl) $(0.15 \mathrm{mmol})$ and 1 -(alkoxy)-4-isonitrilebenzene $(0.15 \mathrm{mmol})$. The mixture was kept under argon and stirred for $10 \mathrm{~min}$, the solvent was then evaporated under reduced pressure. The resulting solid was purified by column chromatography, using hexanes and gradually changing the eluent for $\mathrm{CH}_{2} \mathrm{Cl}_{2}$, to remove most impurities and then using methanol saturated hexanes to isolate the product. $\mathbf{C}_{\mathbf{1}} \mathbf{N}_{9}: 60 \%$ yield, $1 \mathrm{H} \mathrm{NMR} \mathrm{(300} \mathrm{MHz,} \mathrm{Chloroform-d)} \delta 7.44$ (t, J = $9.2 \mathrm{~Hz}, 4 \mathrm{H}), 6.97-6.89(\mathrm{~m}, 2 \mathrm{H}), 6.85-6.74(\mathrm{~m}, 2 \mathrm{H}), 3.99(\mathrm{t}, \mathrm{J}=6.5 \mathrm{~Hz}, 2 \mathrm{H}), 3.80$ (s, 3H), 1.79 (dt, J = 8.0, 6.5 Hz, 2H), $1.45(\mathrm{q}, \mathrm{J}=6.9 \mathrm{~Hz}, 2 \mathrm{H}), 1.40-1.22(\mathrm{~m}, 11 \mathrm{H}), 0.94-0.85(\mathrm{~m}, 3 \mathrm{H}) . \mathbf{C}_{6} \mathbf{N}_{15}$ : $48 \%$ yield, 1H NMR (300 MHz, Chloroform-d) $\delta 7.44(\mathrm{t}, \mathrm{J}=9.3 \mathrm{~Hz}, 4 \mathrm{H}), 7.02-6.91(\mathrm{~m}, 2 \mathrm{H})$, $6.80(\mathrm{~d}, \mathrm{~J}=8.8 \mathrm{~Hz}, 2 \mathrm{H}), 3.98(\mathrm{dt}, \mathrm{J}=18.8,6.6 \mathrm{~Hz}, 4 \mathrm{H}), 1.81(\mathrm{~d}, \mathrm{~J}=7.1 \mathrm{~Hz}, 2 \mathrm{H}), 1.28(\mathrm{~s}, 18 \mathrm{H})$, 0.90 (t, J $=6.6 \mathrm{~Hz}, 7 \mathrm{H}$ ). $\mathbf{C}_{9} \mathbf{N}_{15}: 23 \%$ yield. $\mathbf{C}_{\mathbf{1 2}} \mathbf{N}_{15}: 27 \%$ yield, $1 \mathrm{H}$ NMR (300 MHz, Chloroformd) $\delta 7.45(\mathrm{t}, \mathrm{J}=9.1 \mathrm{~Hz}, 4 \mathrm{H}), 6.96(\mathrm{~d}, \mathrm{~J}=9.0 \mathrm{~Hz}, 2 \mathrm{H}), 6.80(\mathrm{~d}, \mathrm{~J}=8.8 \mathrm{~Hz}, 2 \mathrm{H}), 3.98(\mathrm{dt}, \mathrm{J}=18.8$, $6.5 \mathrm{~Hz}, 4 \mathrm{H}), 1.80(\mathrm{dt}, \mathrm{J}=13.1,6.7 \mathrm{~Hz}, 4 \mathrm{H}), 1.44(\mathrm{t}, \mathrm{J}=7.3 \mathrm{~Hz}, 2 \mathrm{H}), 1.28(\mathrm{~s}, 27 \mathrm{H}), 0.90$ (t, J = 6.6 $\mathrm{Hz}, 5 \mathrm{H}) . \mathbf{C}_{15} \mathbf{N}_{\mathbf{9}}$ : 24\% yield, $1 \mathrm{H}$ NMR (400 MHz, Chloroform-d) $\delta 7.45$ (dd, J = 12.3, 8.9 Hz, 4H), $6.96(\mathrm{~d}, \mathrm{~J}=9.1 \mathrm{~Hz}, 2 \mathrm{H}), 6.80(\mathrm{~d}, \mathrm{~J}=8.8 \mathrm{~Hz}, 2 \mathrm{H}), 4.01(\mathrm{t}, \mathrm{J}=6.5 \mathrm{~Hz}, 2 \mathrm{H}), 3.95(\mathrm{t}, \mathrm{J}=6.6 \mathrm{~Hz}, 2 \mathrm{H})$, $1.80(\mathrm{dt}, \mathrm{J}=17.3,7.6 \mathrm{~Hz}, 4 \mathrm{H}), 1.54-1.41(\mathrm{~m}, 5 \mathrm{H}), 1.30(\mathrm{~d}, \mathrm{~J}=13.5 \mathrm{~Hz}, 35 \mathrm{H}), 0.94-0.86(\mathrm{~m}$, $7 \mathrm{H})$. 


\section{2. ${ }^{1}$ H NMR}

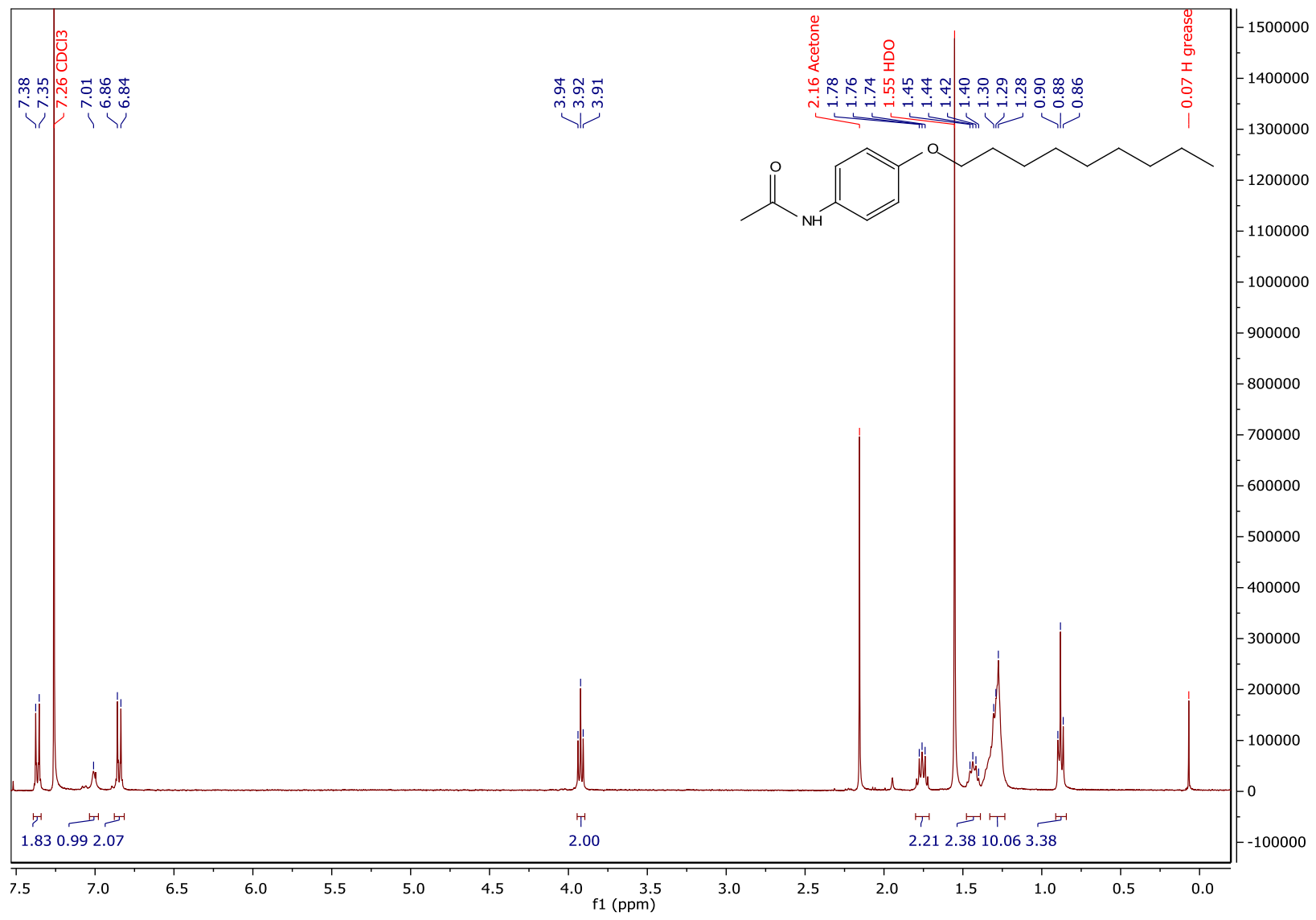

Figure $\mathrm{S} 1:{ }^{1} \mathrm{H}$ NMR spectrum of $\mathbf{N}-\left(4-\left(\right.\right.$ nonyloxy)phenyl)acetamide in $\mathrm{CDCl}_{3}$. 


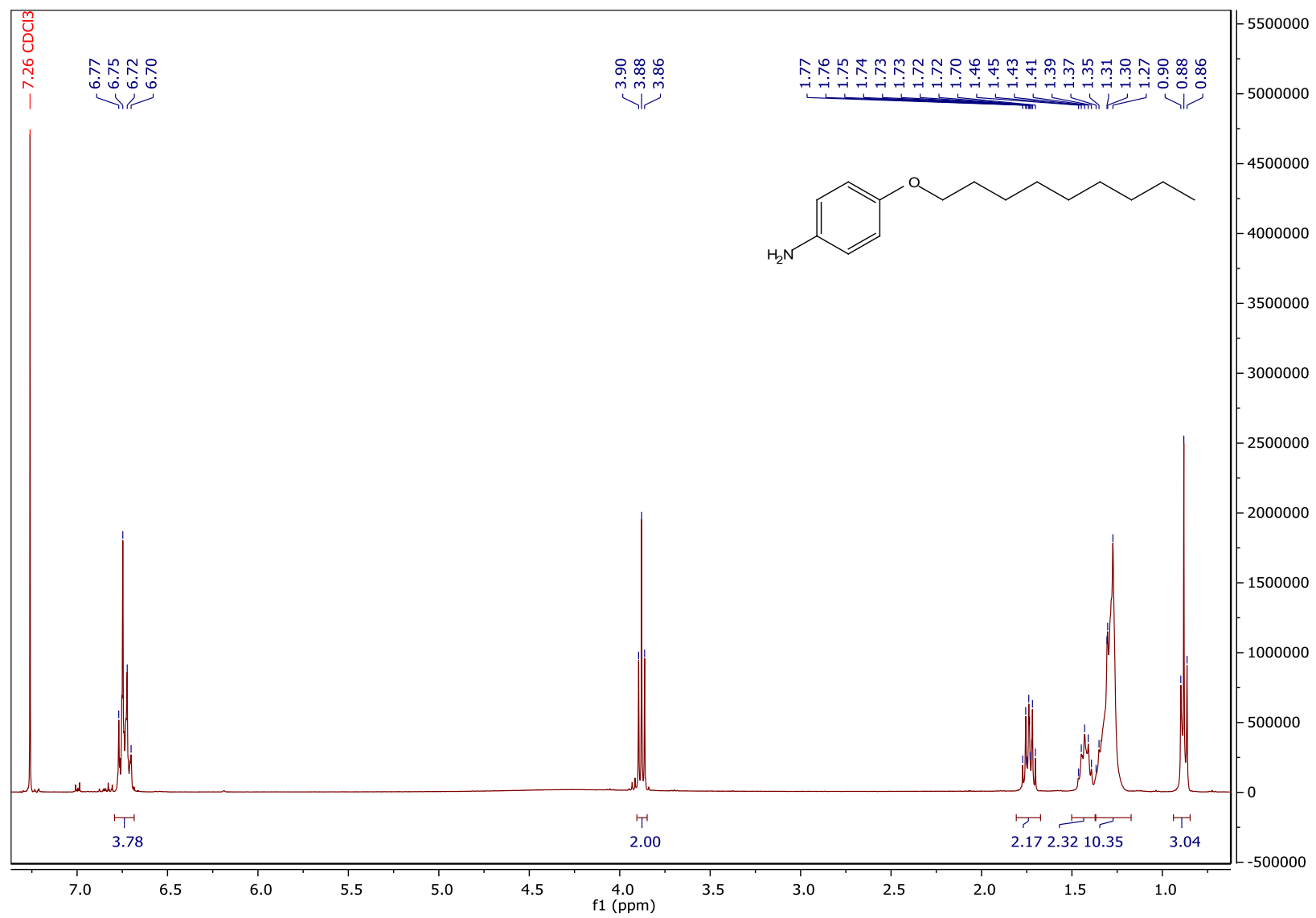

Figure $\mathrm{S} 2:{ }^{1} \mathrm{H}$ NMR spectrum of 4-(nonyloxy)aniline in $\mathrm{CDCl}_{3}$. 


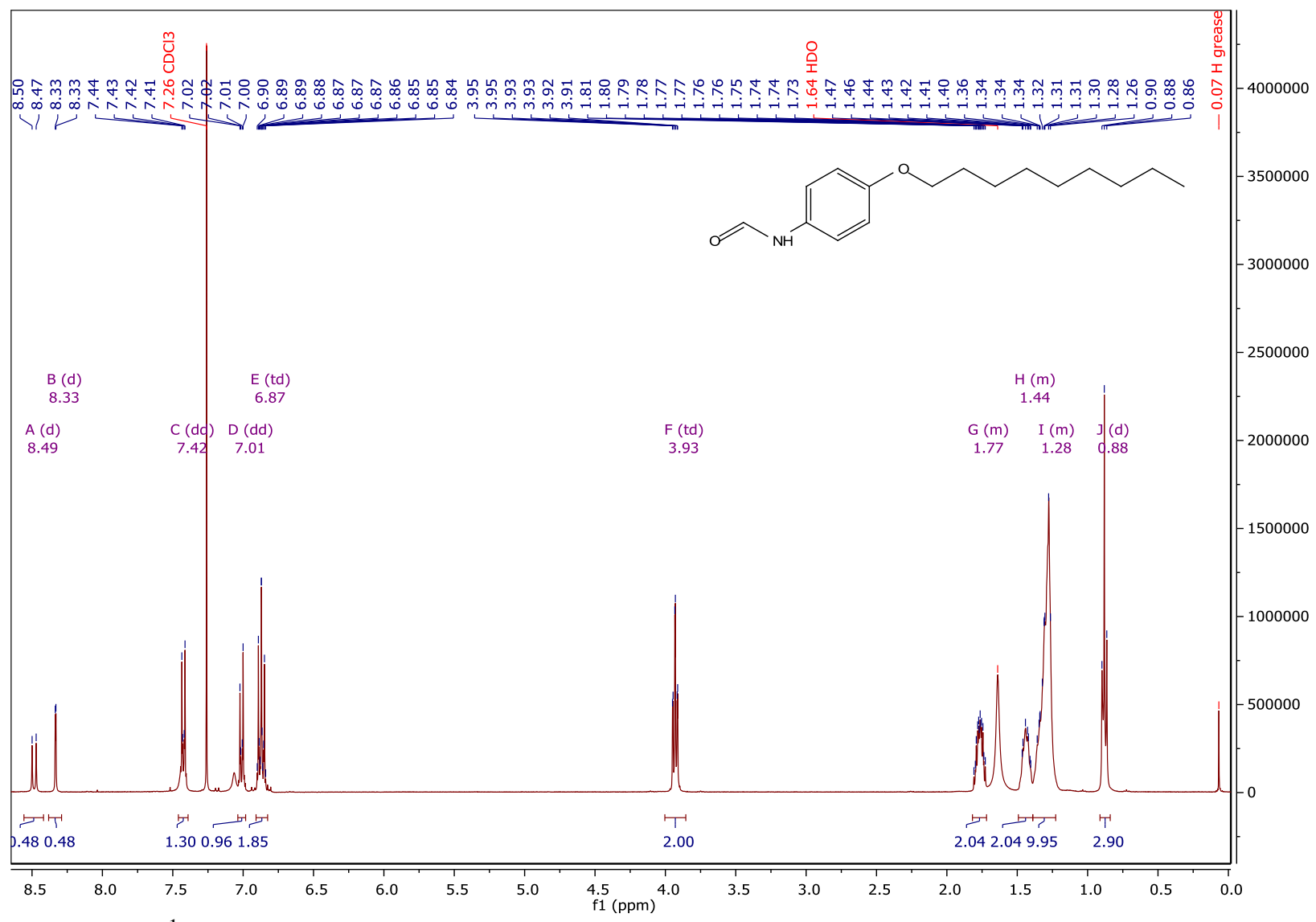

Figure S3 : ${ }^{1} \mathrm{H}$ NMR spectrum of $\mathbf{N}$-(4-(nonyloxy)phenyl)formamide in $\mathrm{CDCl}_{3}$. 


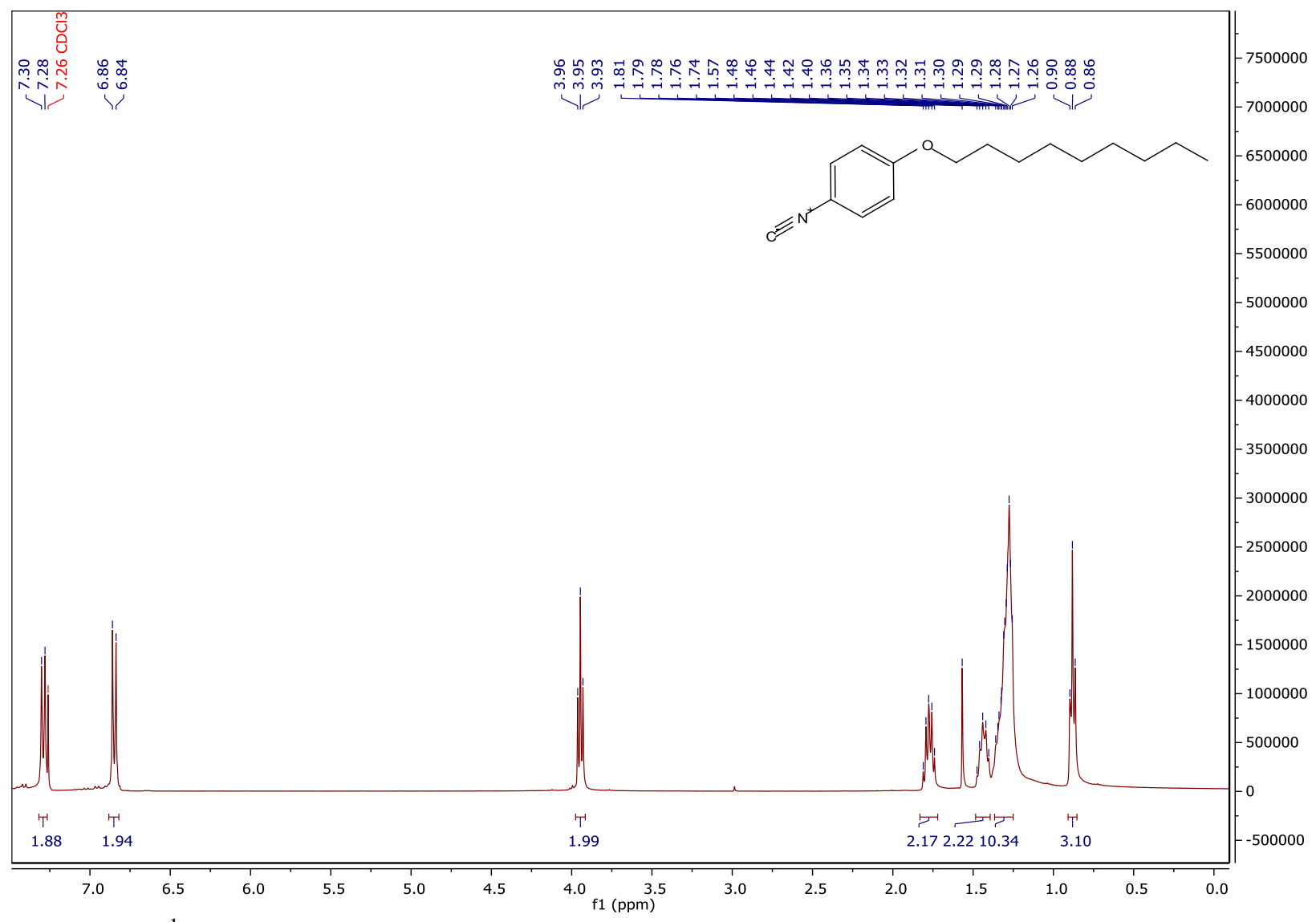

Figure S4 : ${ }^{1} \mathrm{H}$ NMR spectrum of 1-(nonyloxy)-4-isonitrilebenzene in $\mathrm{CDCl}_{3}$. 


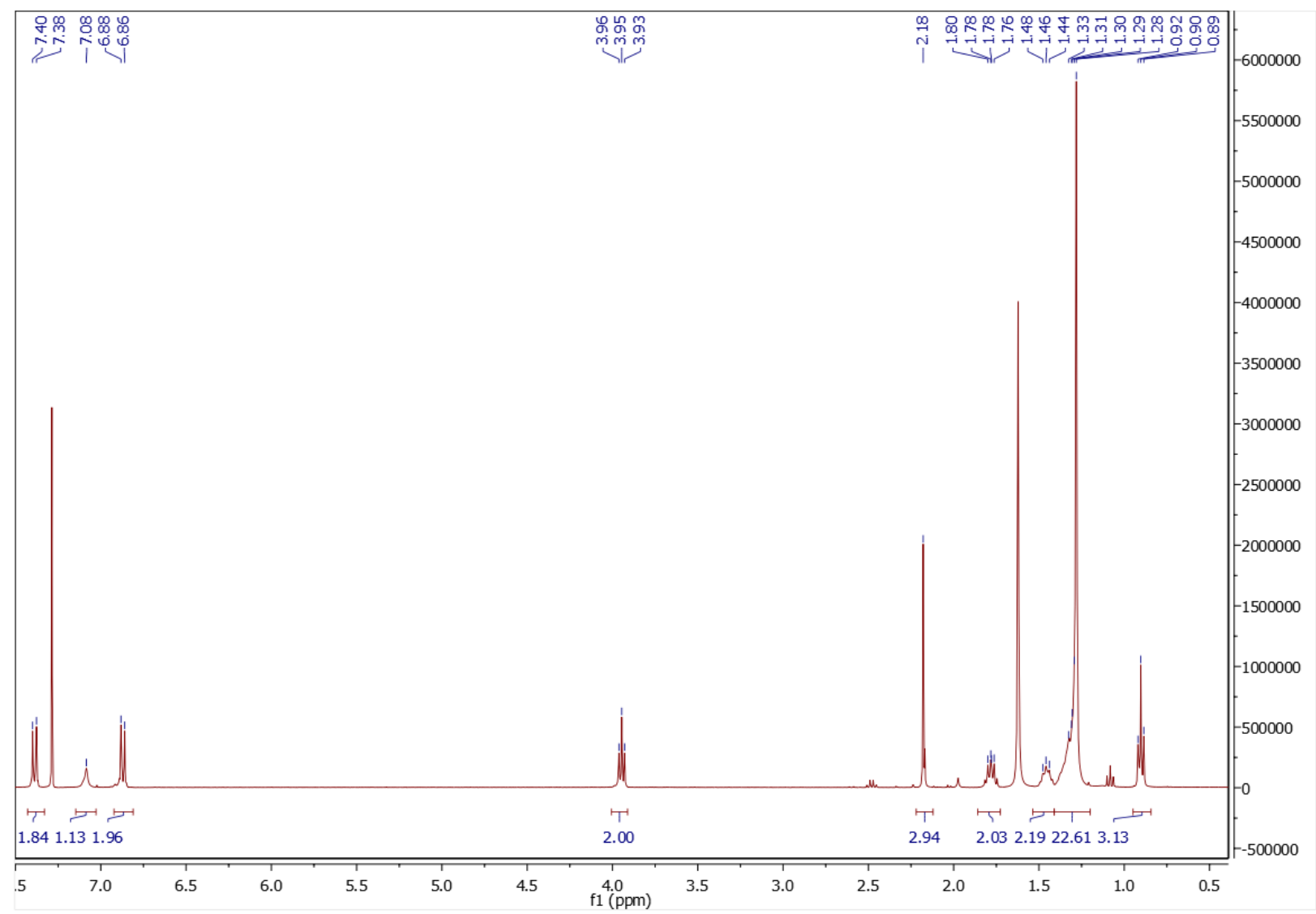

Figure S5: ${ }^{1} \mathrm{H}$ NMR spectrum of $\mathbf{N}$-(4-(pentadecyloxy)phenyl)acetamide in $\mathrm{CDCl}_{3}$. 


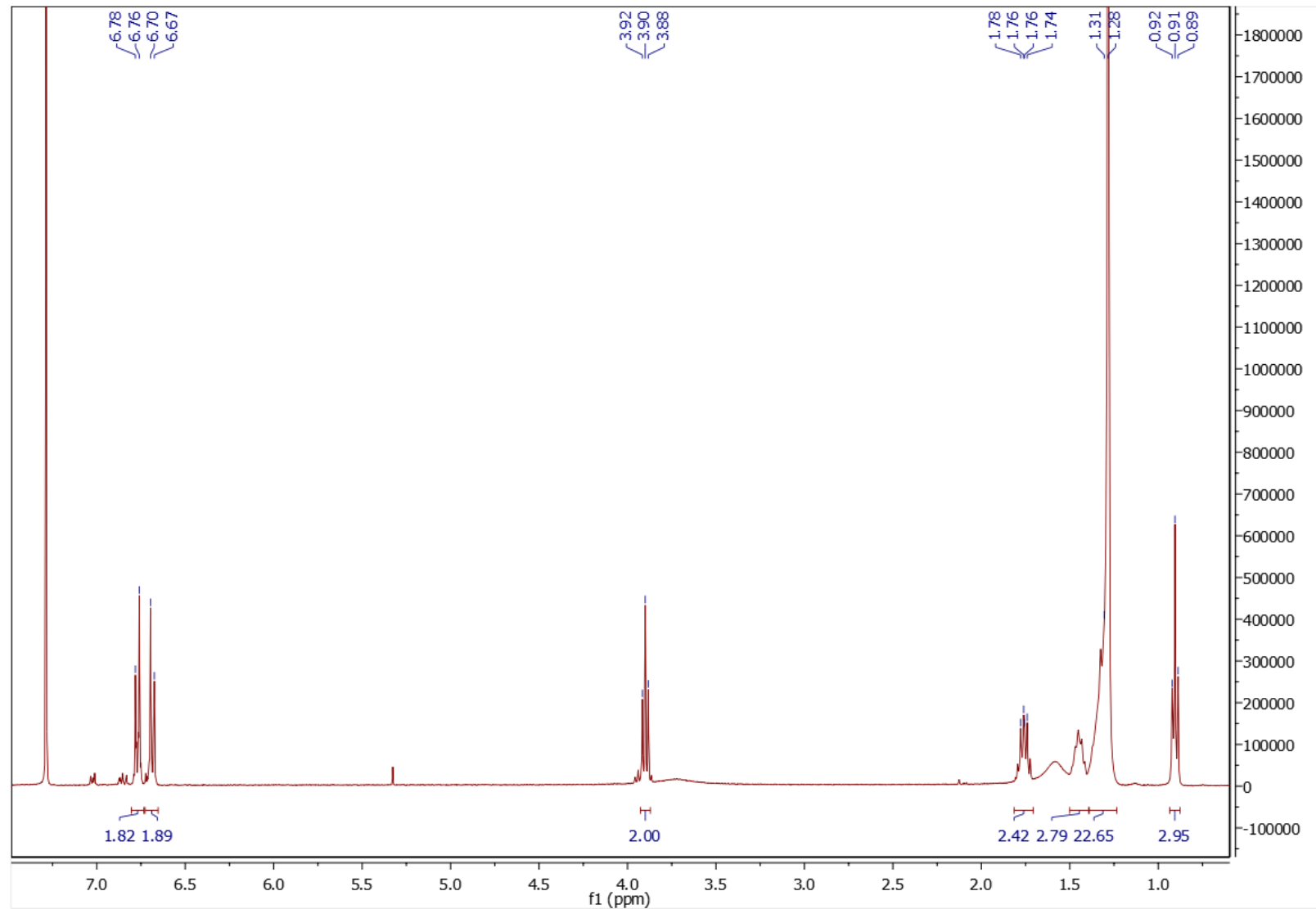

Figure S6: ${ }^{1} \mathrm{H}$ NMR spectrum of 4-(pentadecyloxy)aniline in $\mathrm{CDCl}_{3}$. 


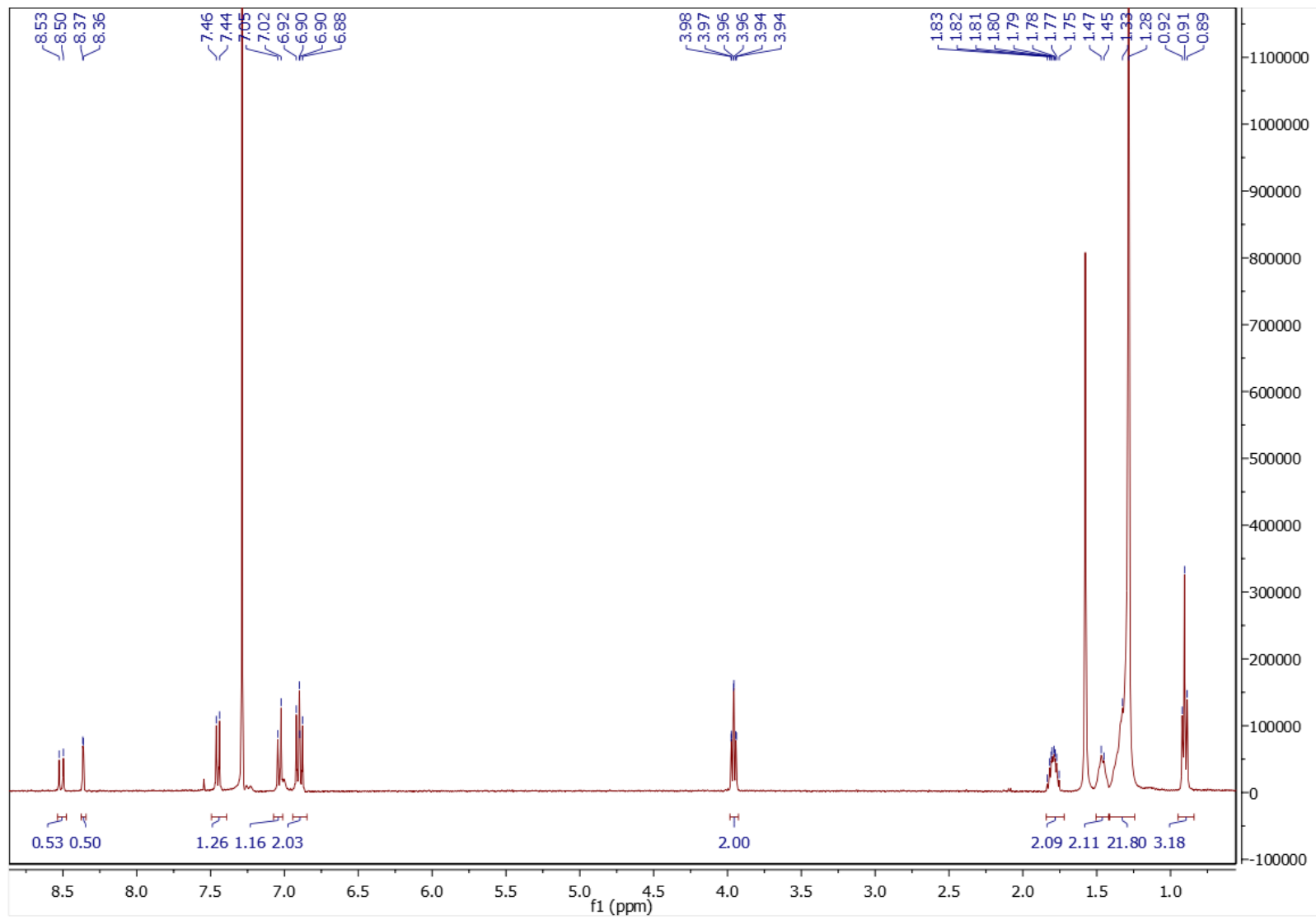

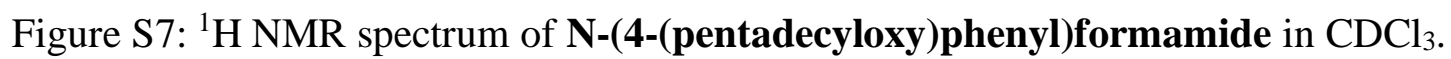




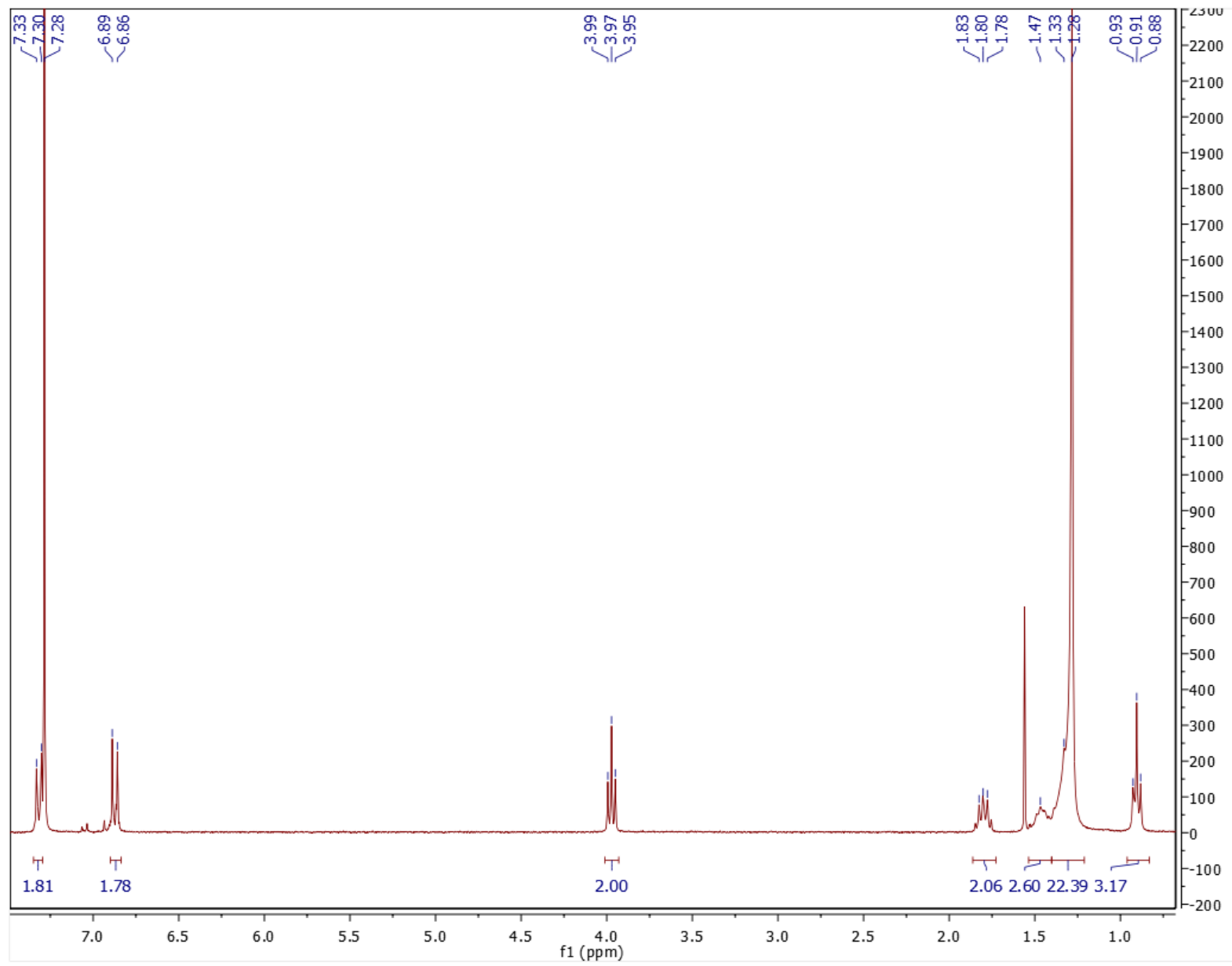

Figure S8: ${ }^{1} \mathrm{H}$ NMR spectrum of 1-(pentadecyloxy)-4-isonitrilebenzene in $\mathrm{CDCl}_{3}$. 


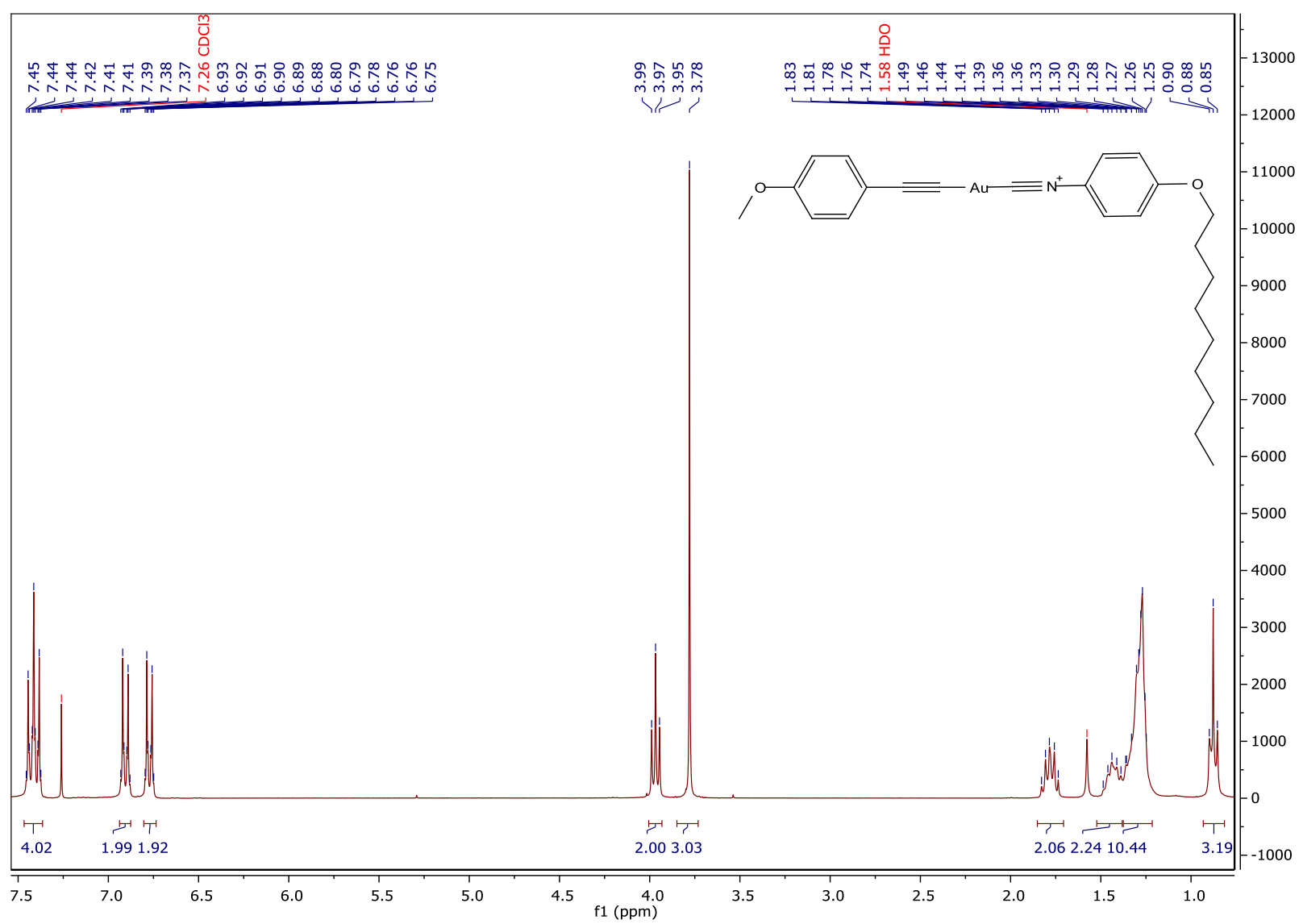

Figure S9: ${ }^{1} \mathrm{H}$ NMR spectrum of $\mathbf{C}_{\mathbf{1}} \mathbf{N}_{9}$ in $\mathrm{CDCl}_{3}$. 


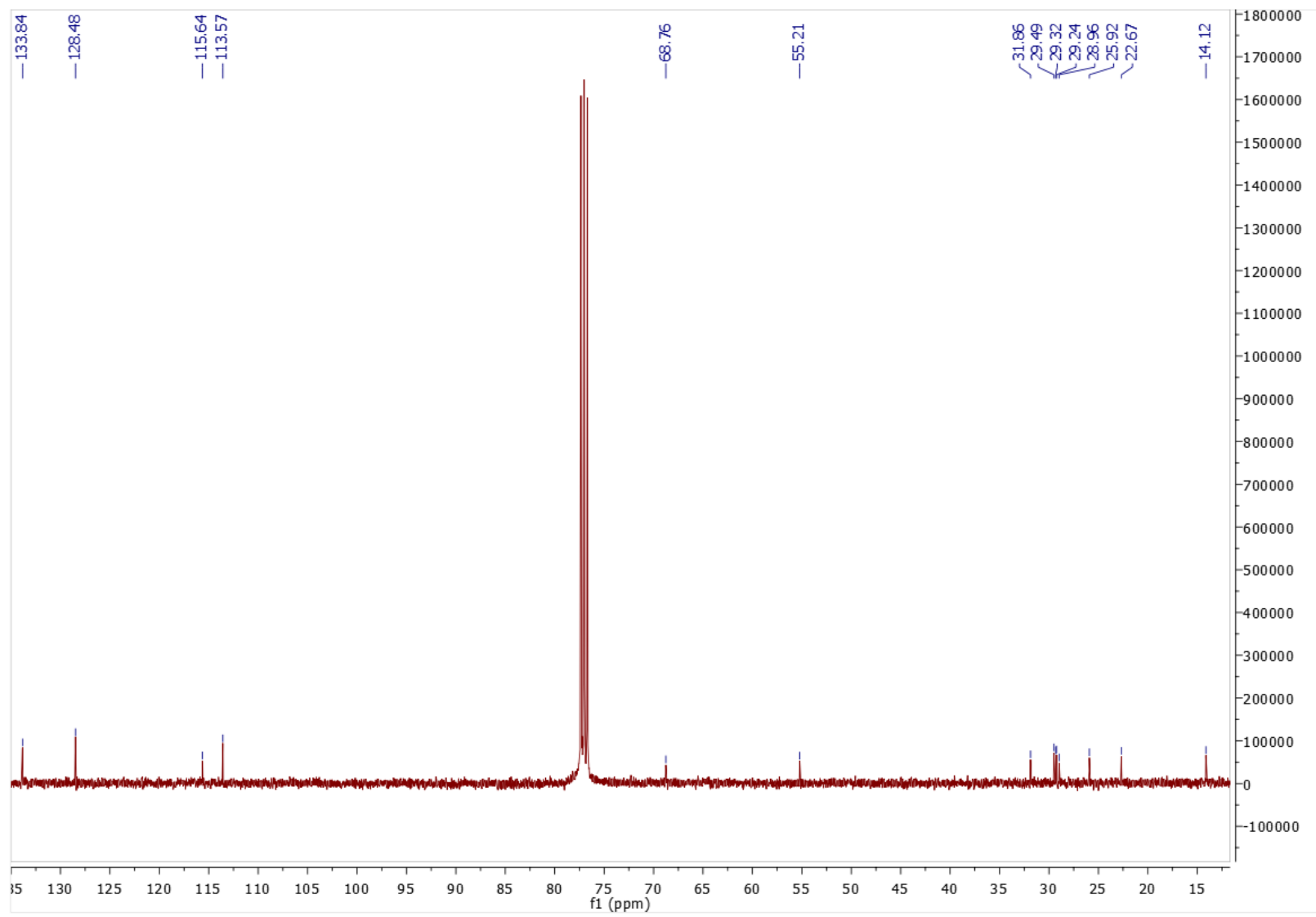

Figure S10: ${ }^{13} \mathrm{C}$ NMR spectrum of $\mathbf{C}_{\mathbf{1}} \mathbf{N}_{\mathbf{9}}$ in $\mathrm{CDCl}_{3}$. 


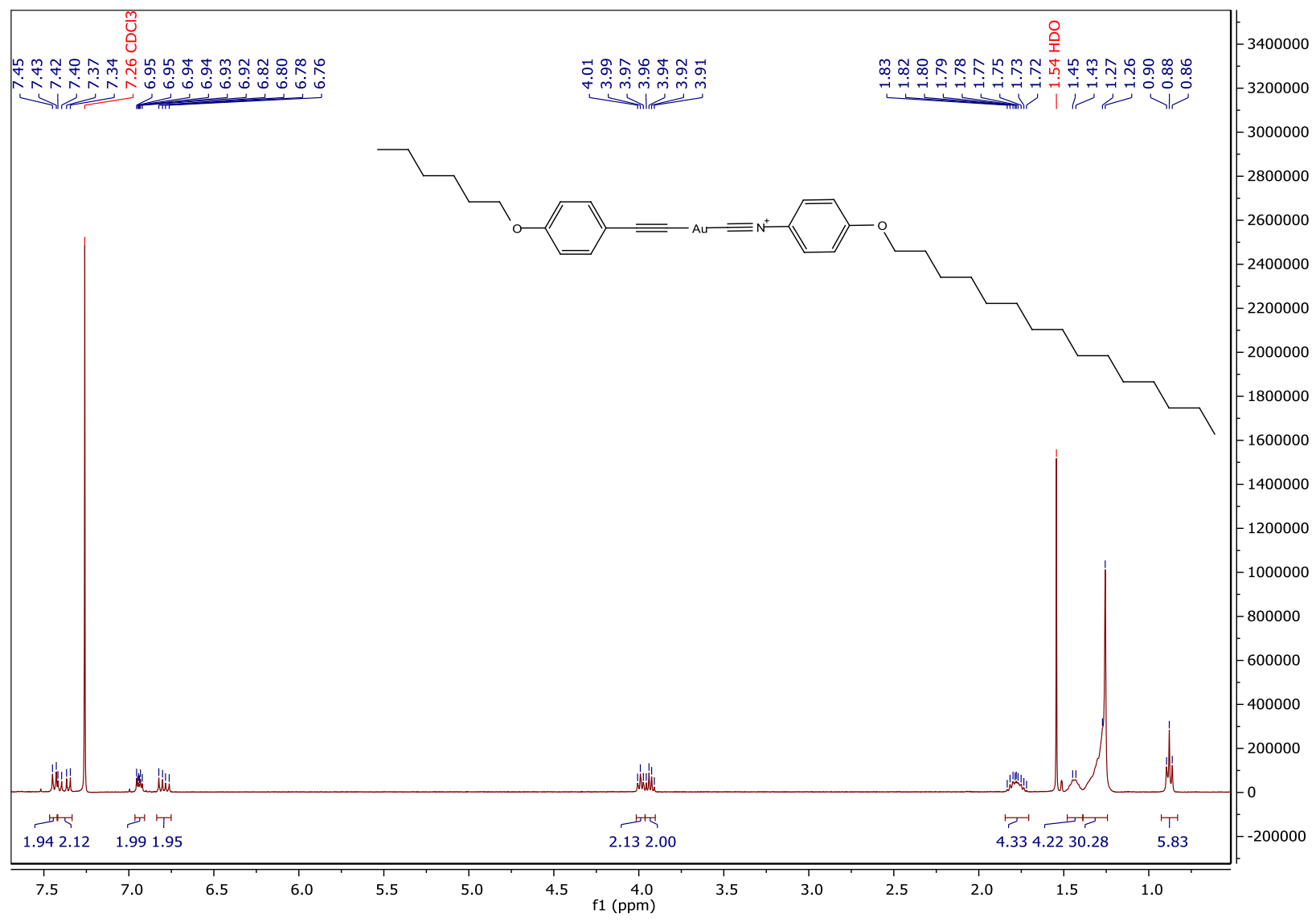

Figure S11: ${ }^{1} \mathrm{H}$ NMR spectrum for $\mathbf{C}_{6} \mathbf{N}_{15}$ in $\mathrm{CDCl}_{3}$. 


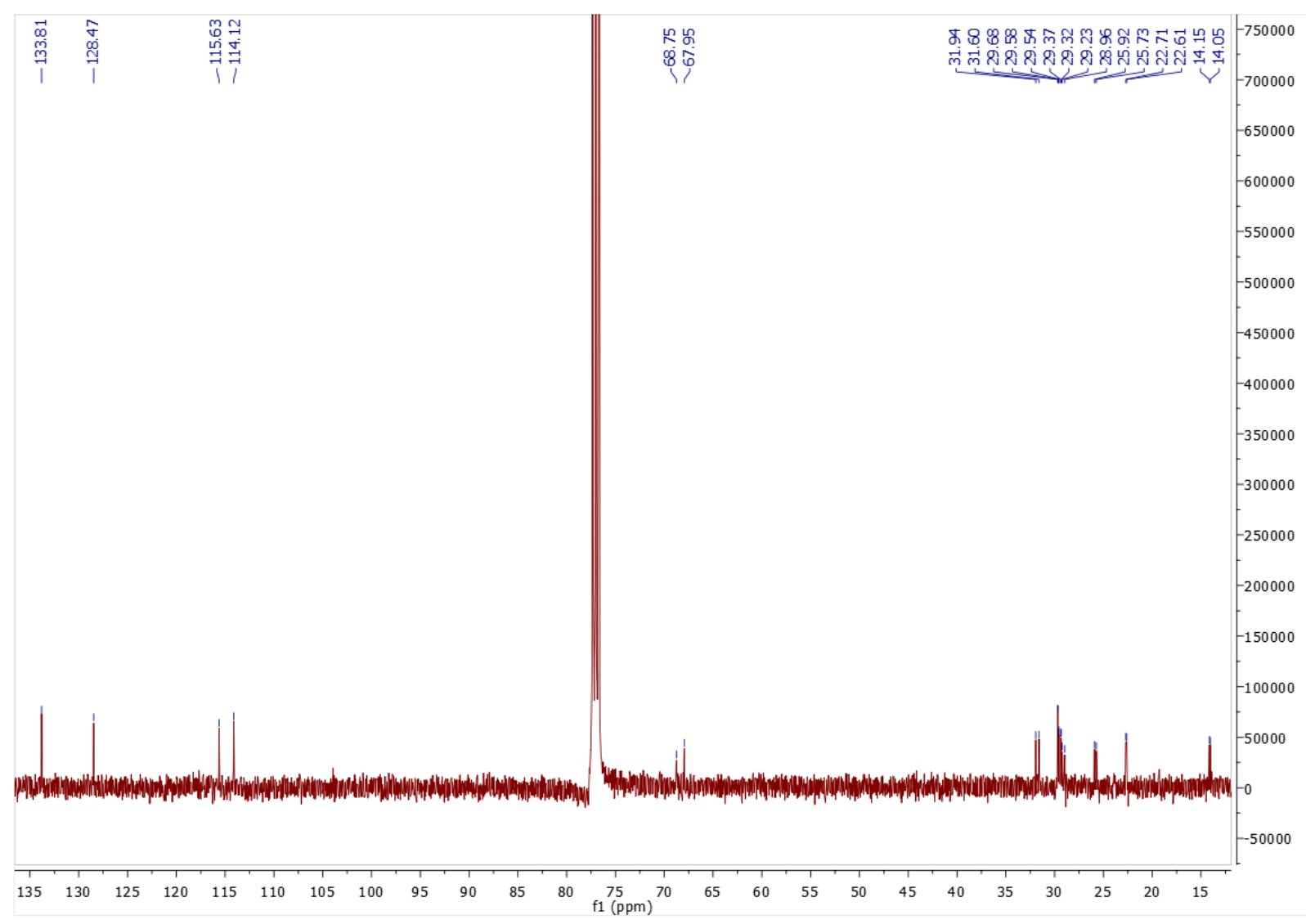

Figure S12: ${ }^{13} \mathrm{C}$ NMR spectrum of $\mathbf{C}_{6} \mathbf{N}_{15}$ in $\mathrm{CDCl}_{3}$. 


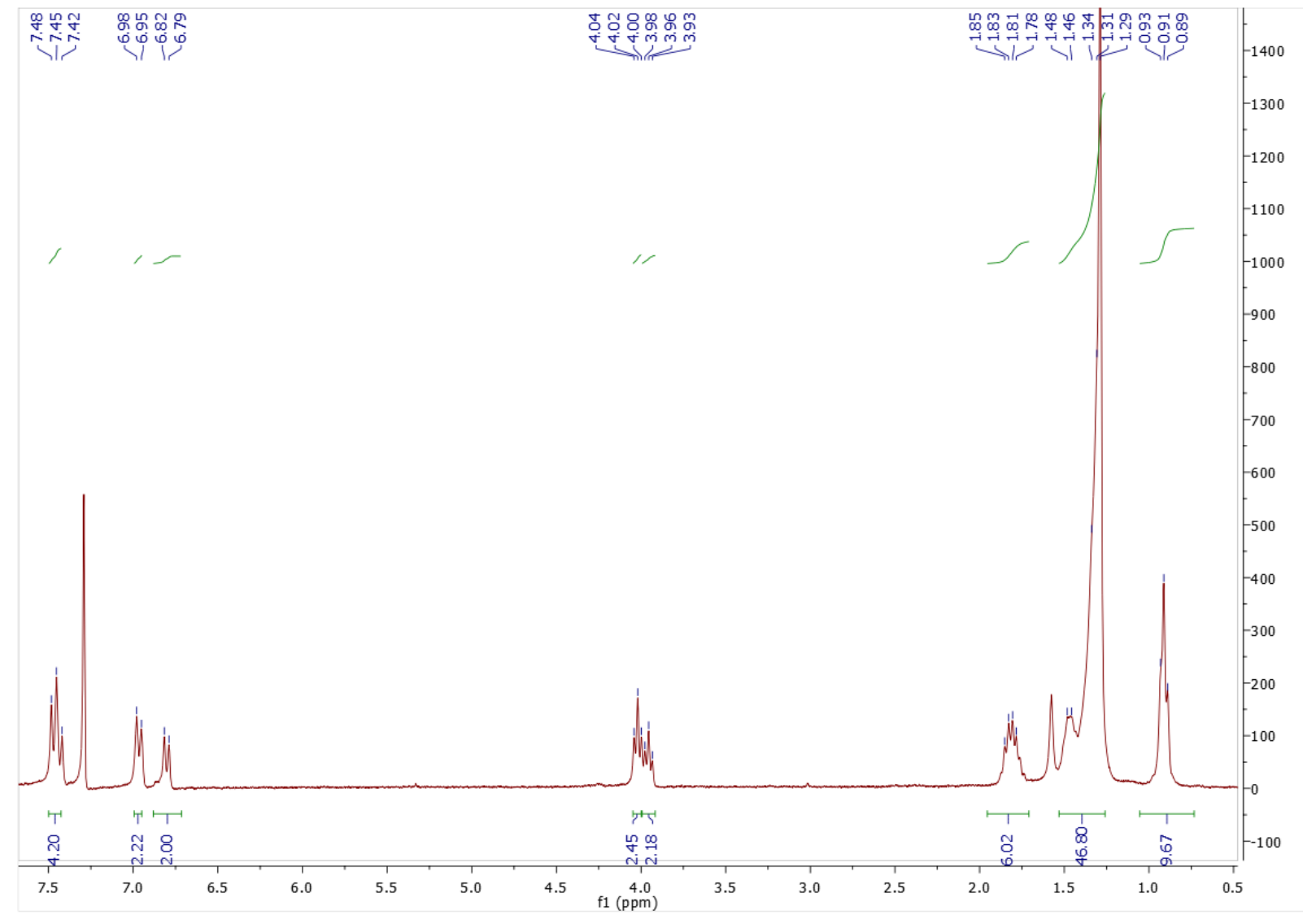

Figure S13: ${ }^{1} \mathrm{H}$ NMR spectrum of $\mathbf{C}_{9} \mathbf{N}_{15}$ in $\mathrm{CDCl}_{3}$. 


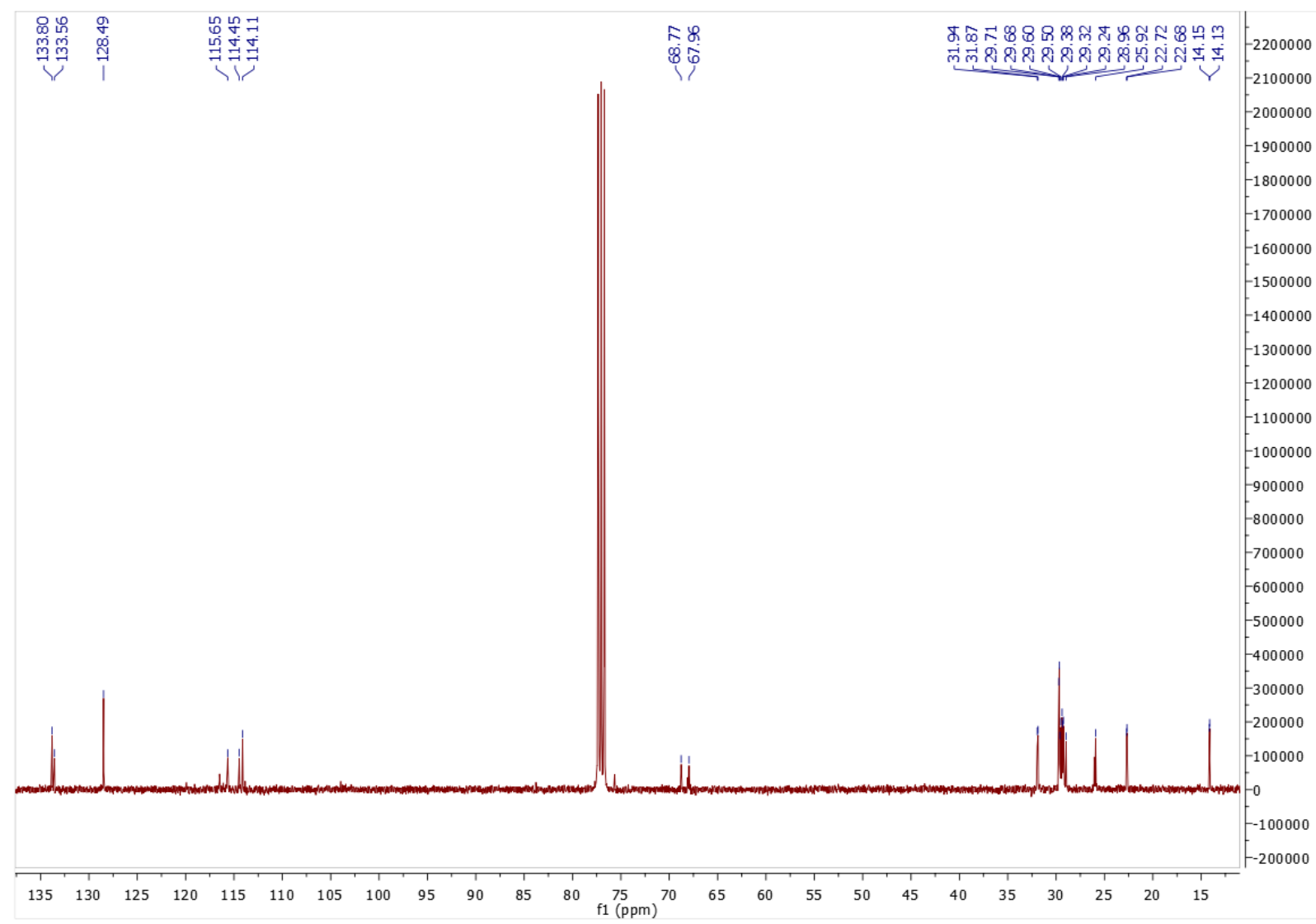

Figure S14: ${ }^{13} \mathrm{C}$ NMR spectrum of $\mathbf{C}_{9} \mathbf{N}_{15}$ in $\mathrm{CDCl}_{3}$. 


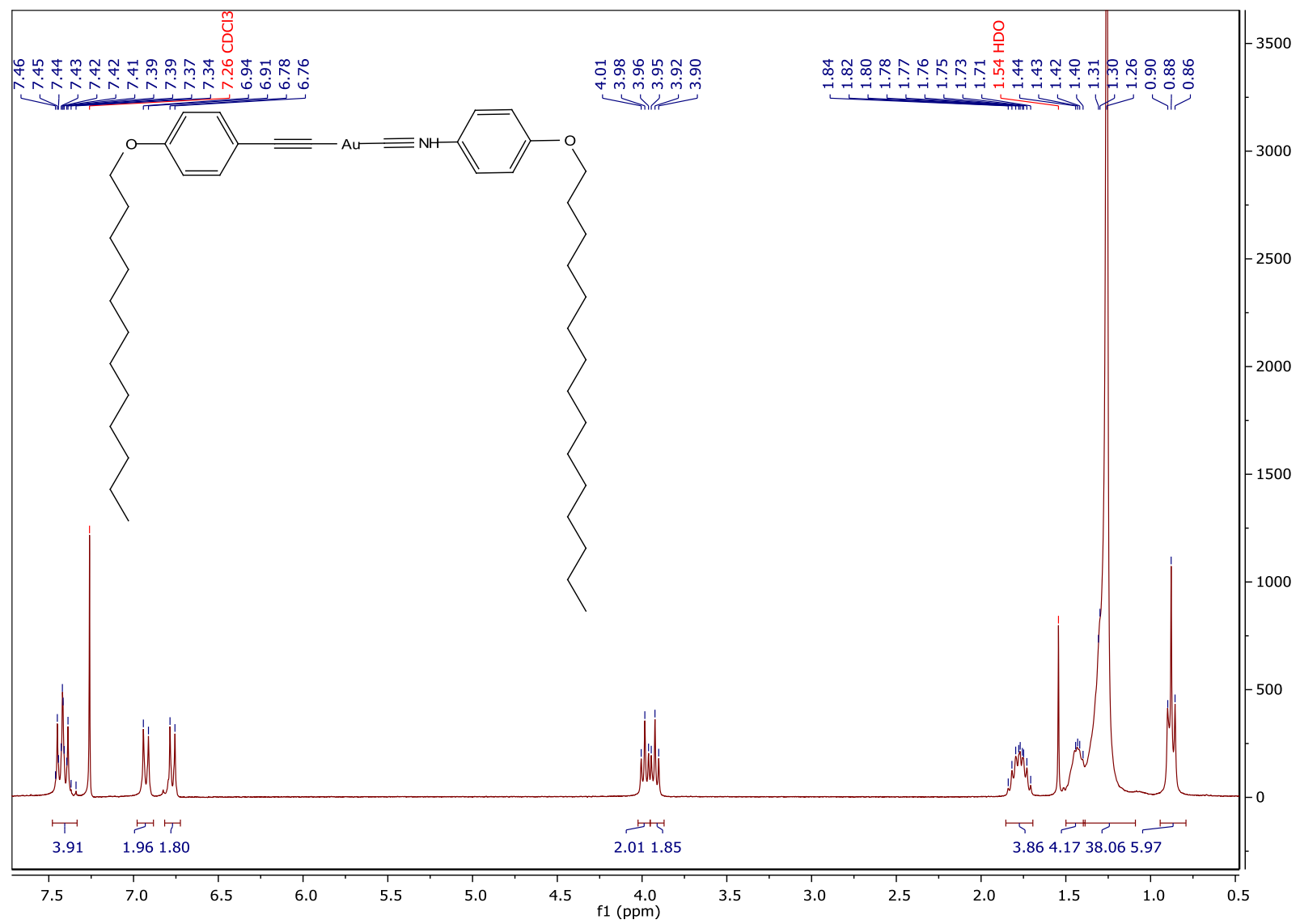

Figure S15 : ${ }^{1} \mathrm{H}$ NMR spectrum of $\mathbf{C}_{12} \mathbf{N}_{15}$ in $\mathrm{CDCl}_{3}$. 


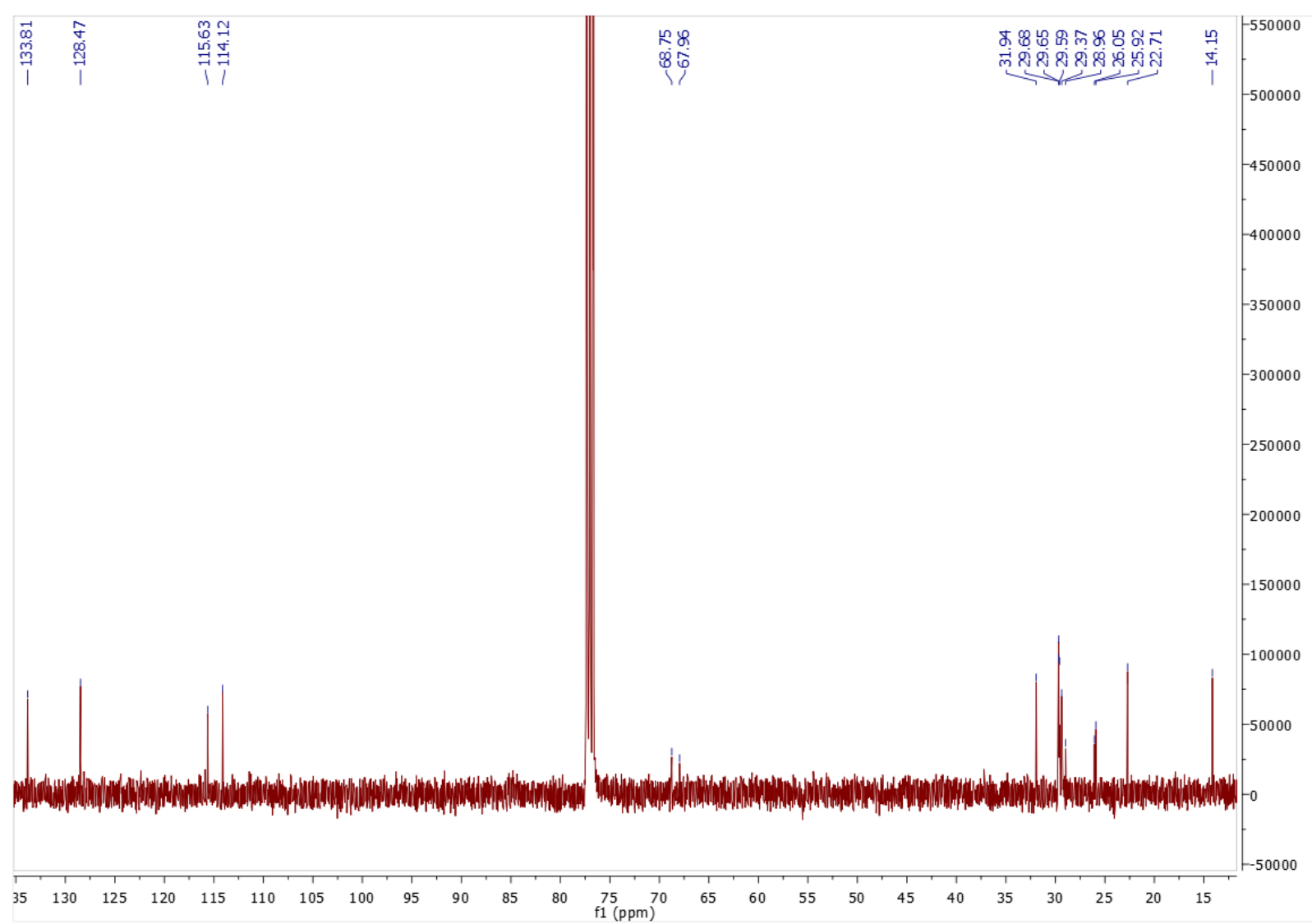

Figure S16: ${ }^{13} \mathrm{C}$ NMR spectrum of $\mathbf{C}_{\mathbf{1 2}} \mathbf{N}_{15}$ in $\mathrm{CDCl}_{3}$. 


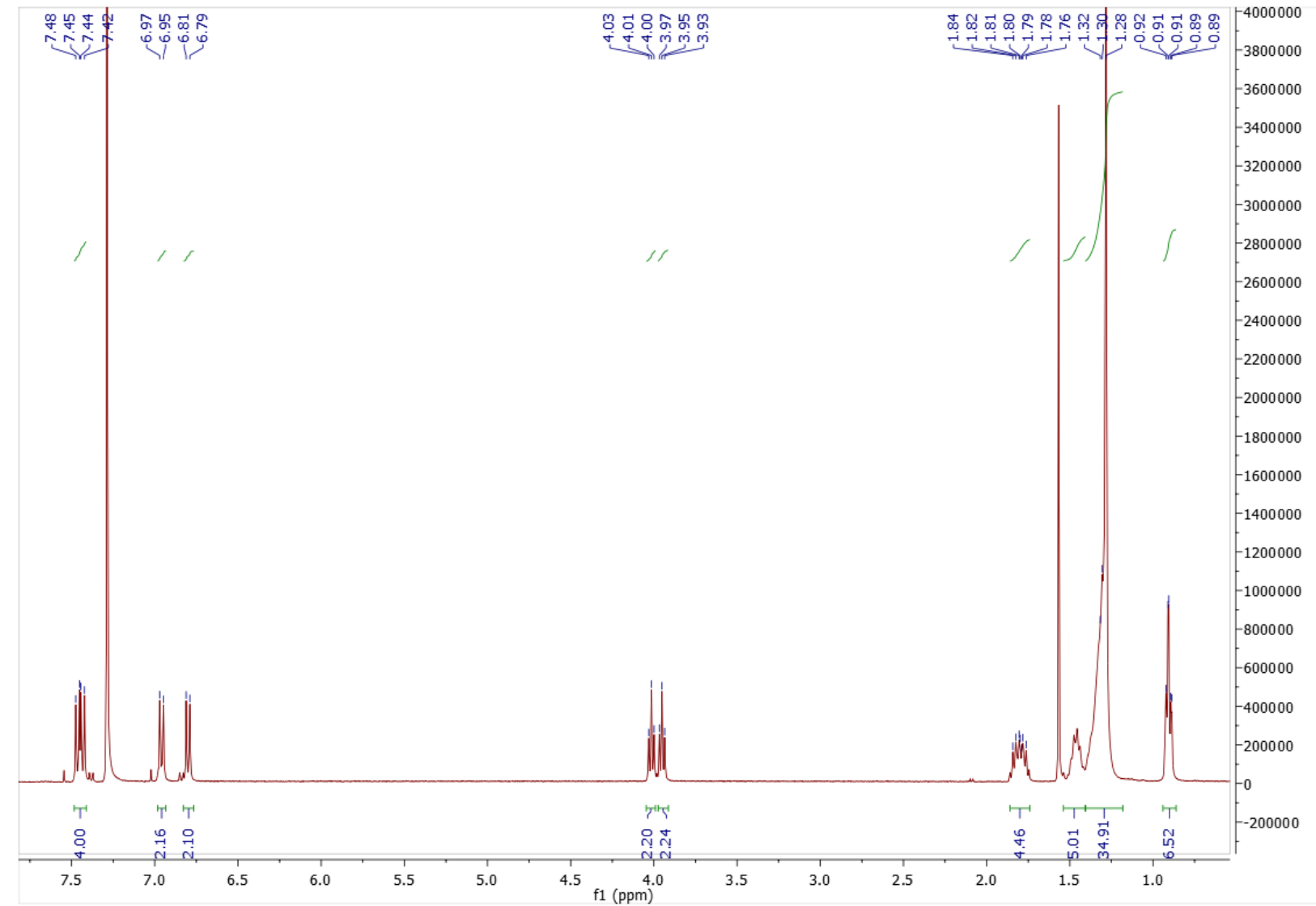

Figure $\mathrm{S} 17:{ }^{1} \mathrm{H}$ NMR spectrum of $\mathbf{C}_{\mathbf{1 5}} \mathbf{N}_{\mathbf{9}}$ in $\mathrm{CDCl}_{3}$. 


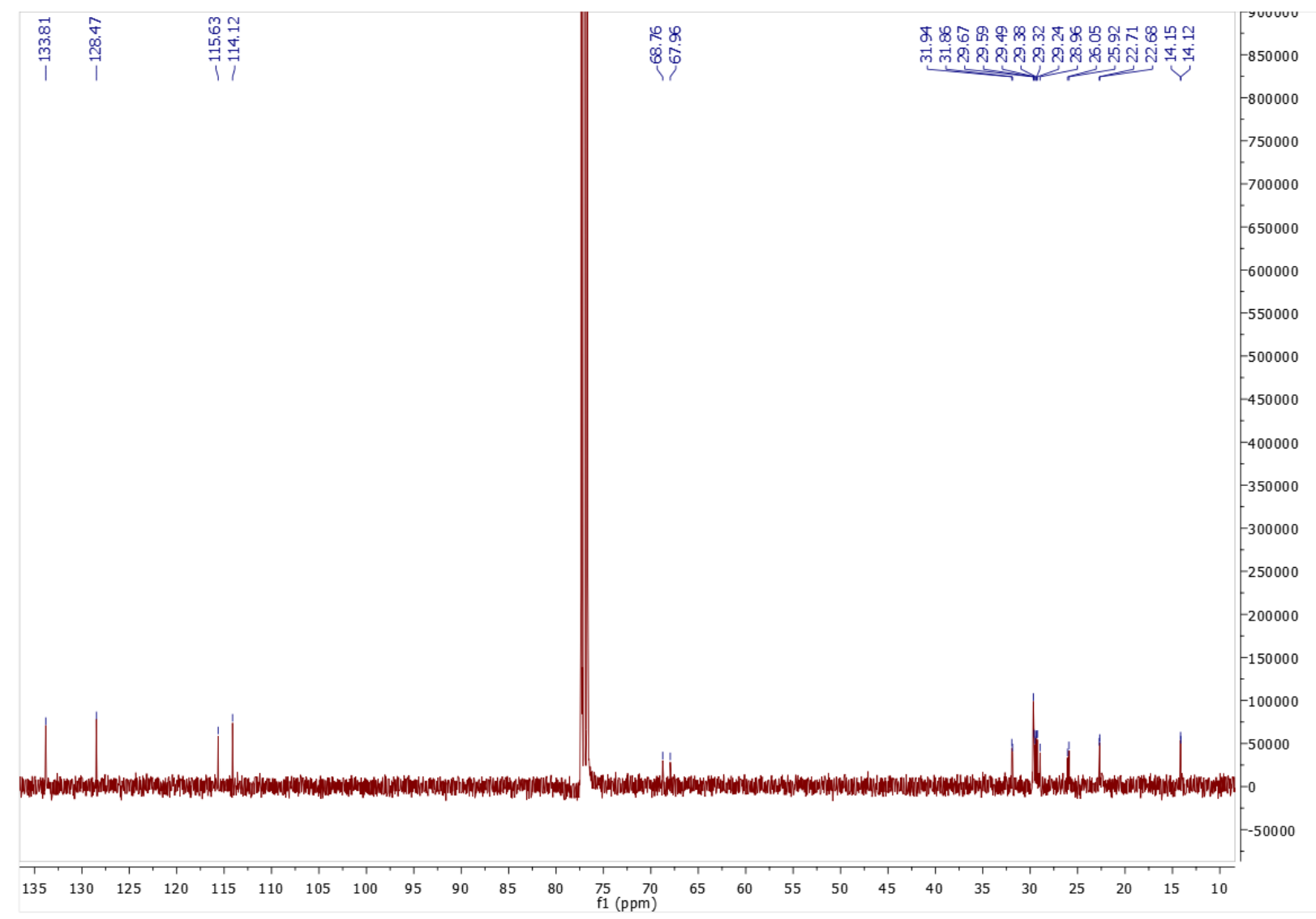

Figure S18: ${ }^{13} \mathrm{C}$ NMR spectrum of $\mathbf{C}_{\mathbf{1 5}} \mathbf{N}_{\mathbf{9}}$ in $\mathrm{CDCl}_{3}$.

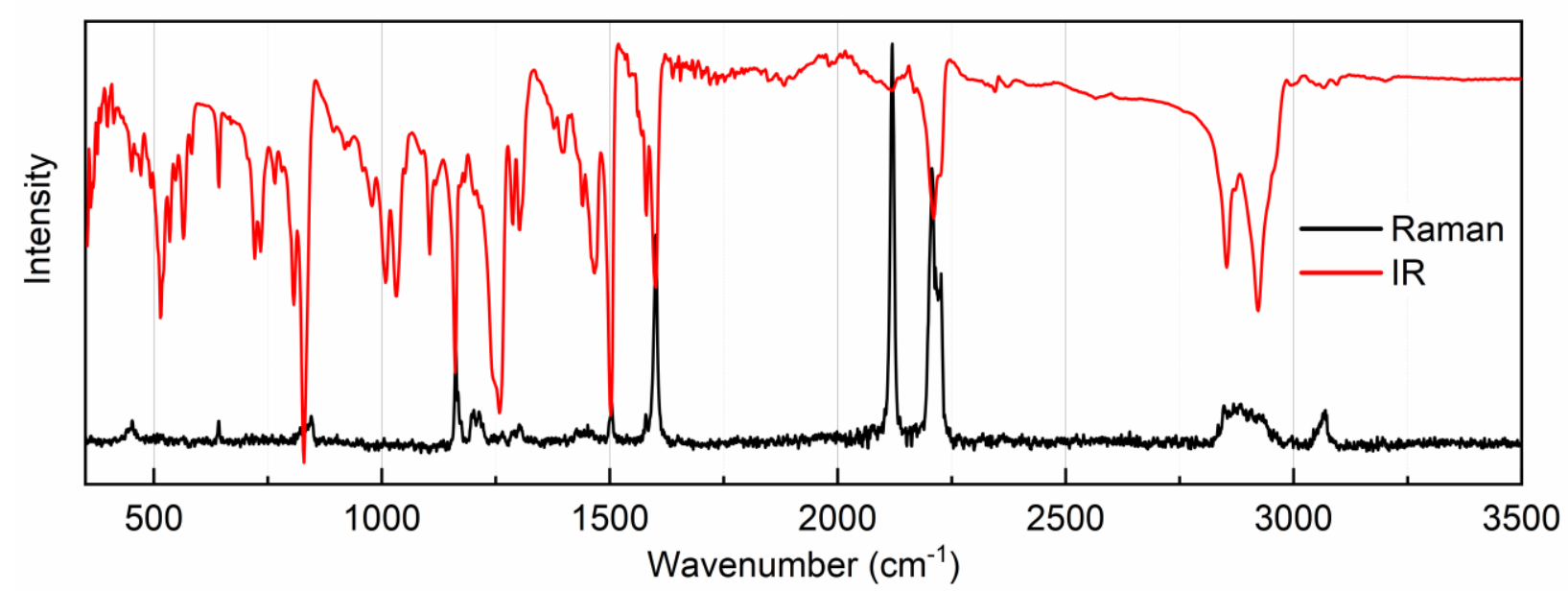

Figure S19: IR and RAMAN spectra of solid $\mathbf{C}_{\mathbf{1}} \mathbf{N}_{\mathbf{9}}$. 


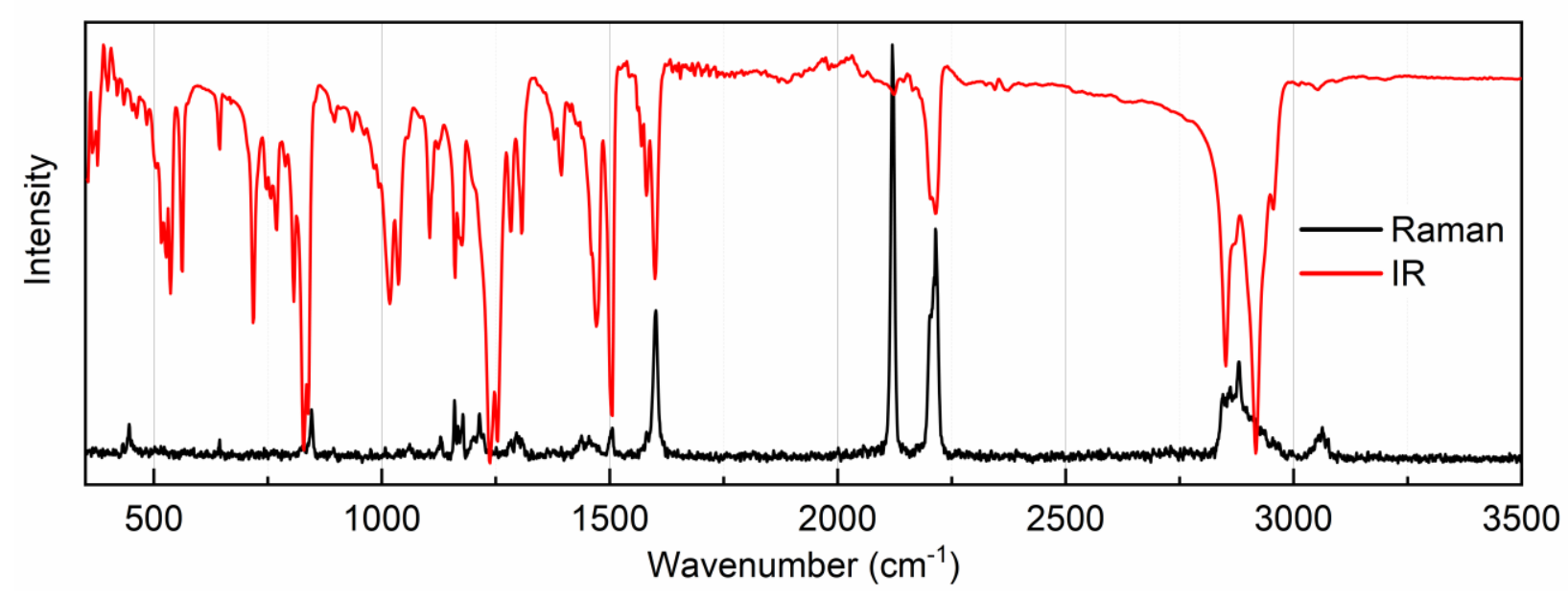

Figure S20: IR and RAMAN spectra of solid $\mathbf{C}_{6} \mathbf{N}_{15}$.

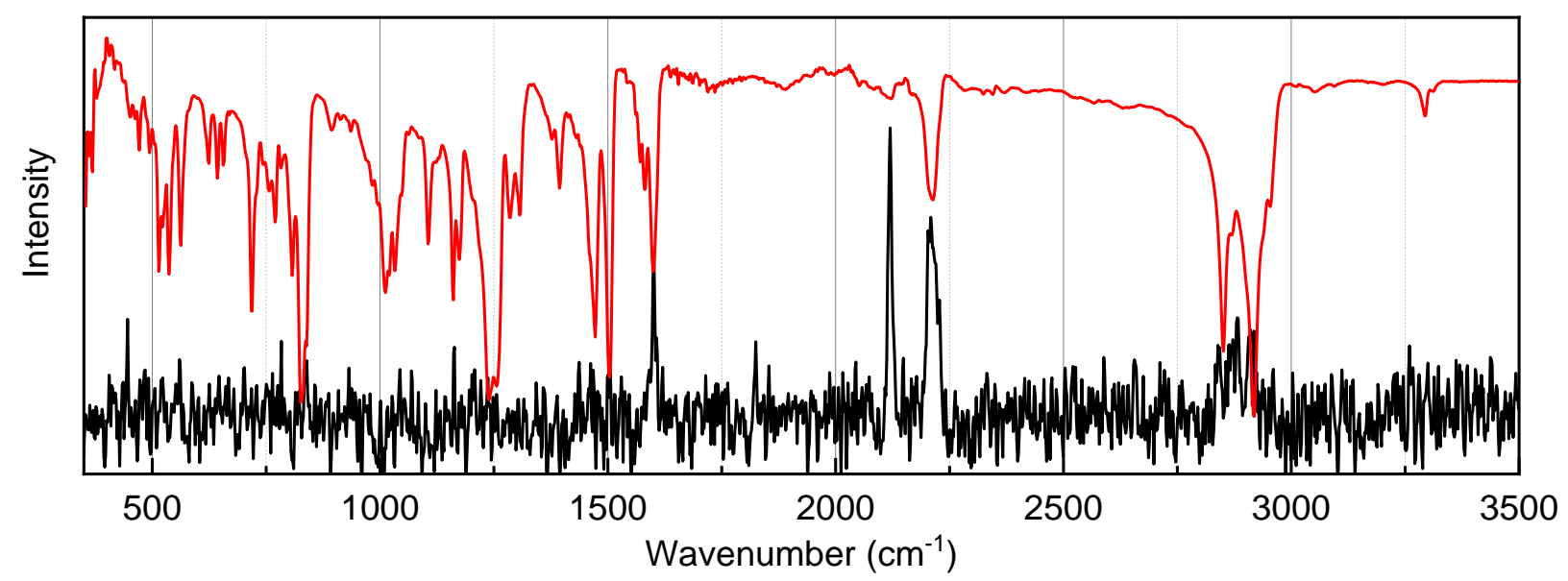

Figure S21: IR spectra of solid $\mathbf{C}_{9} \mathbf{N}_{15}$.

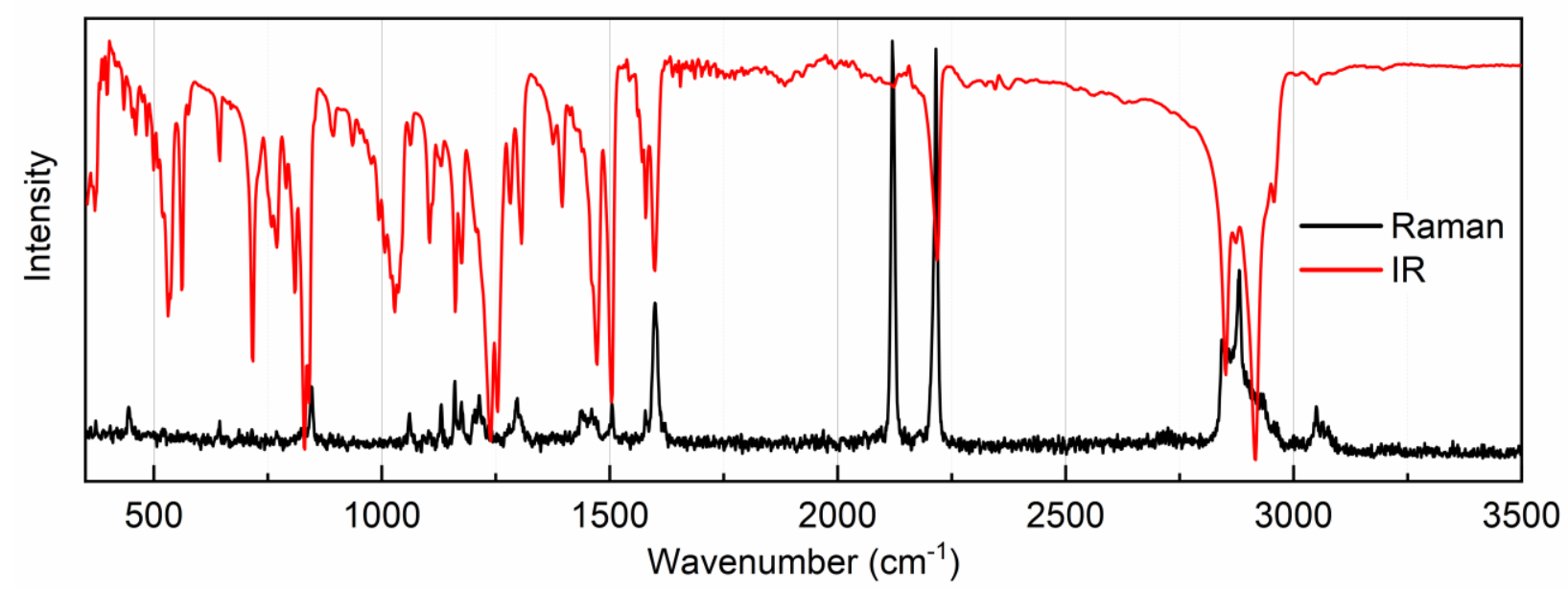

Figure S22: IR and RAMAN spectra of solid $\mathbf{C}_{12} \mathbf{N}_{\mathbf{1 5}}$. 


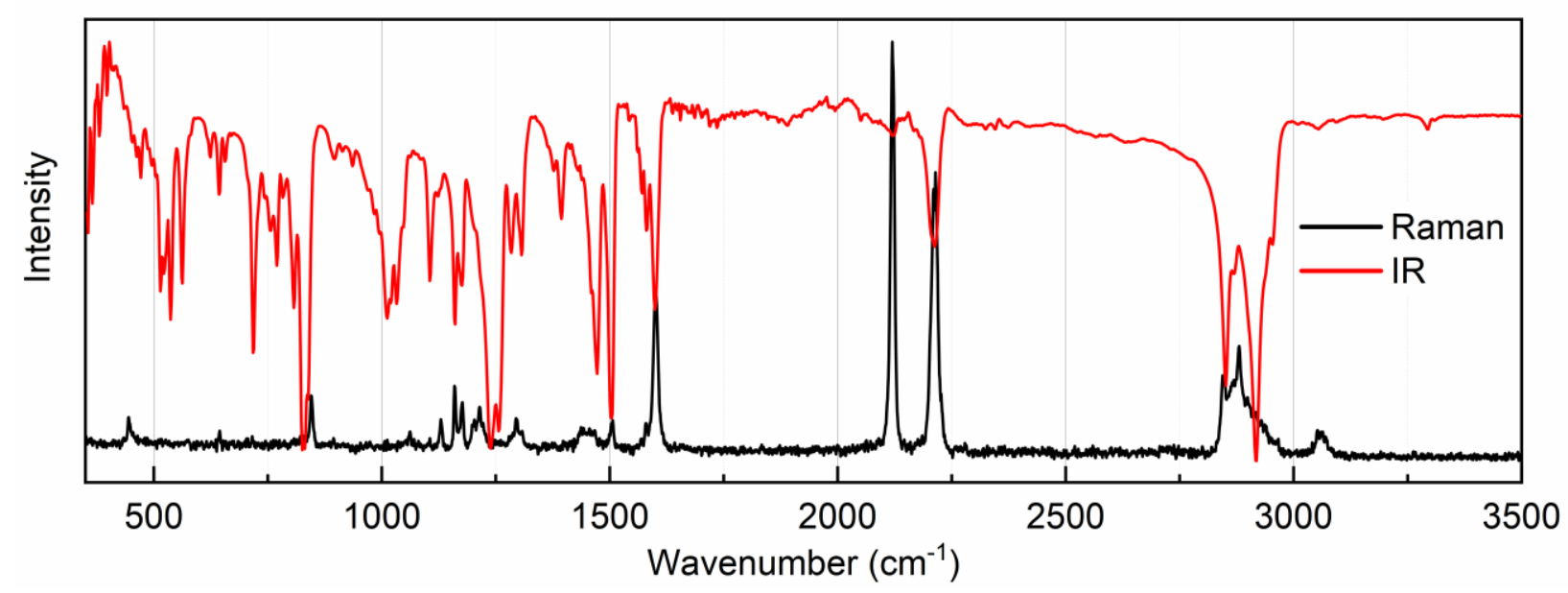

Figure S23: IR and RAMAN spectra of solid $\mathbf{C}_{15} \mathbf{N}_{\mathbf{9}}$.

\section{HRMS}

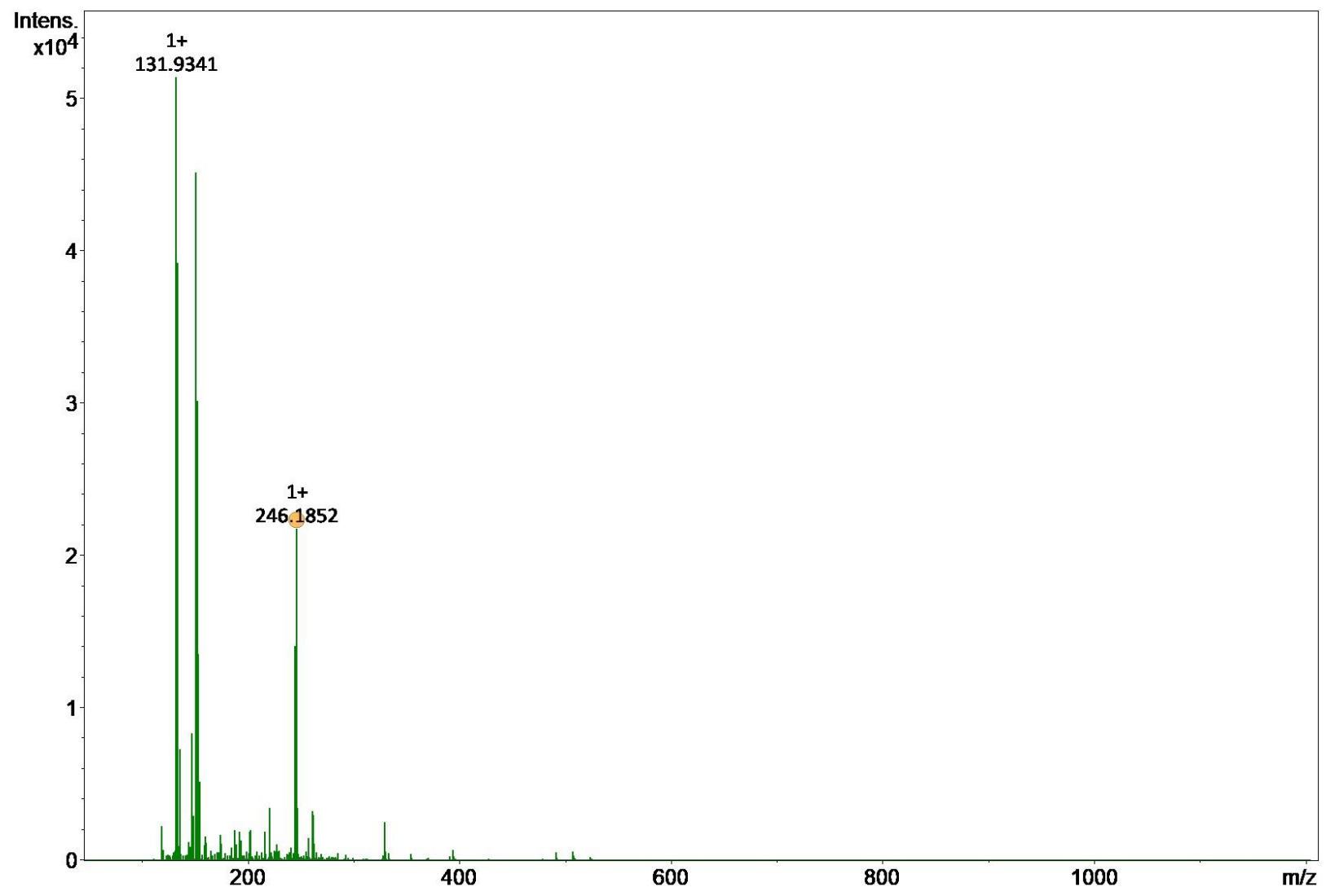

Figure S24: Exact mass spectrum by direct introduction (APCI) for $\mathbf{C}_{\mathbf{1}} \mathbf{N}_{\mathbf{9}}$. 


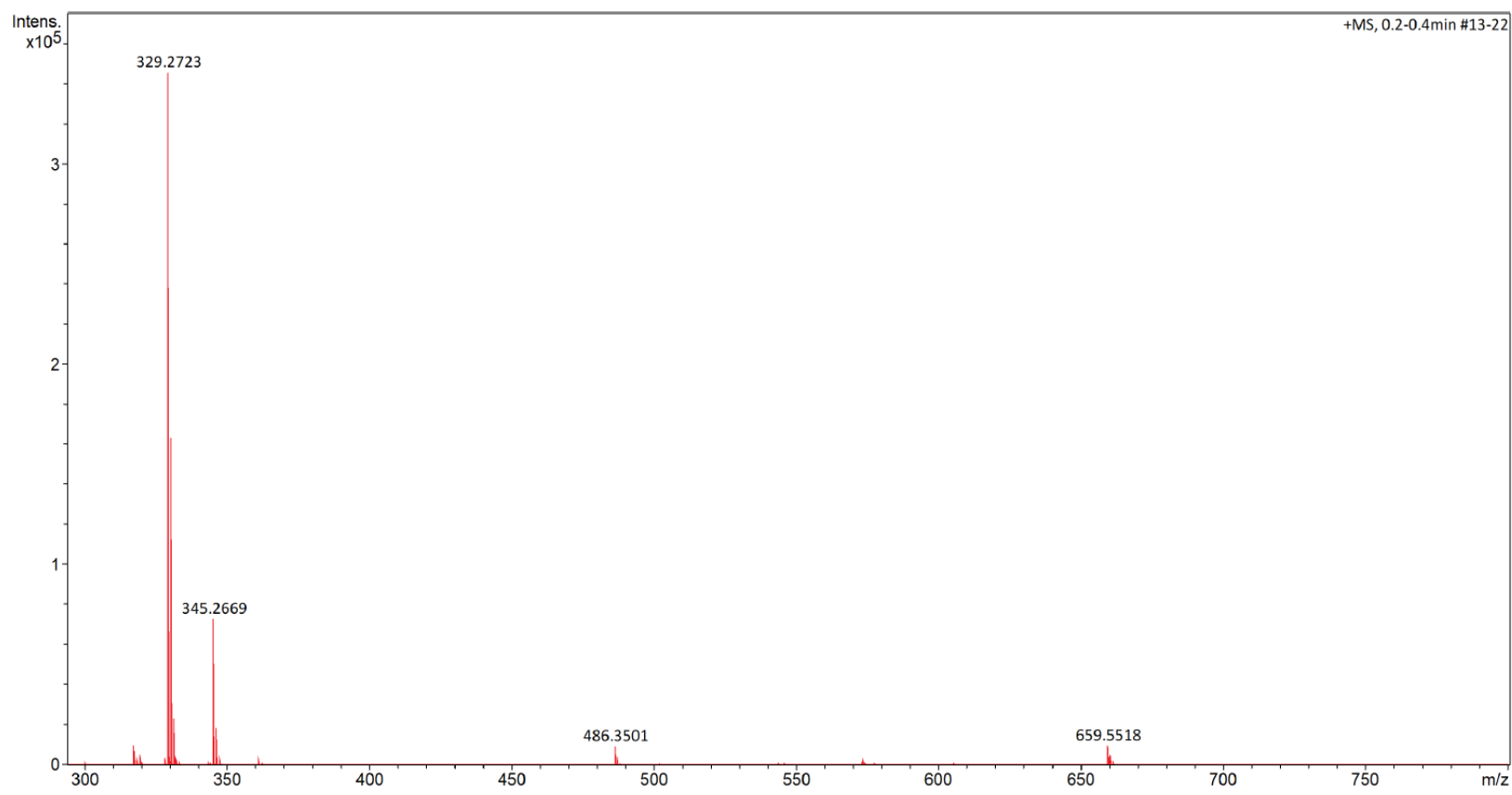

Figure S25: Exact mass spectrum by direct introduction (APCI) for $\mathbf{C}_{\mathbf{6}} \mathbf{N}_{\mathbf{1 5}}$.

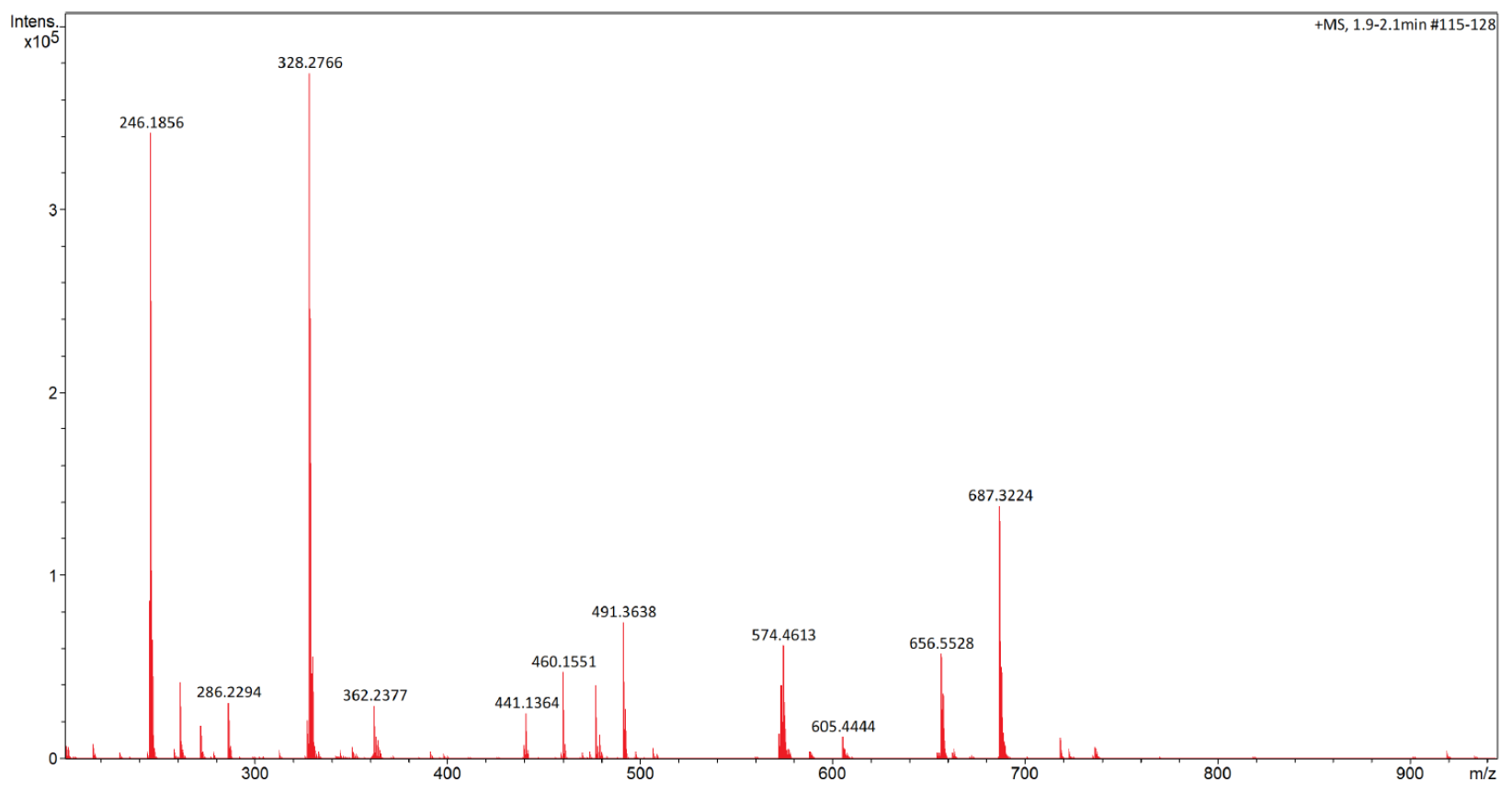

Figure S26: Exact mass spectrum by direct introduction (APCI) for $\mathbf{C}_{9} \mathbf{N}_{\mathbf{1 5}}$. 


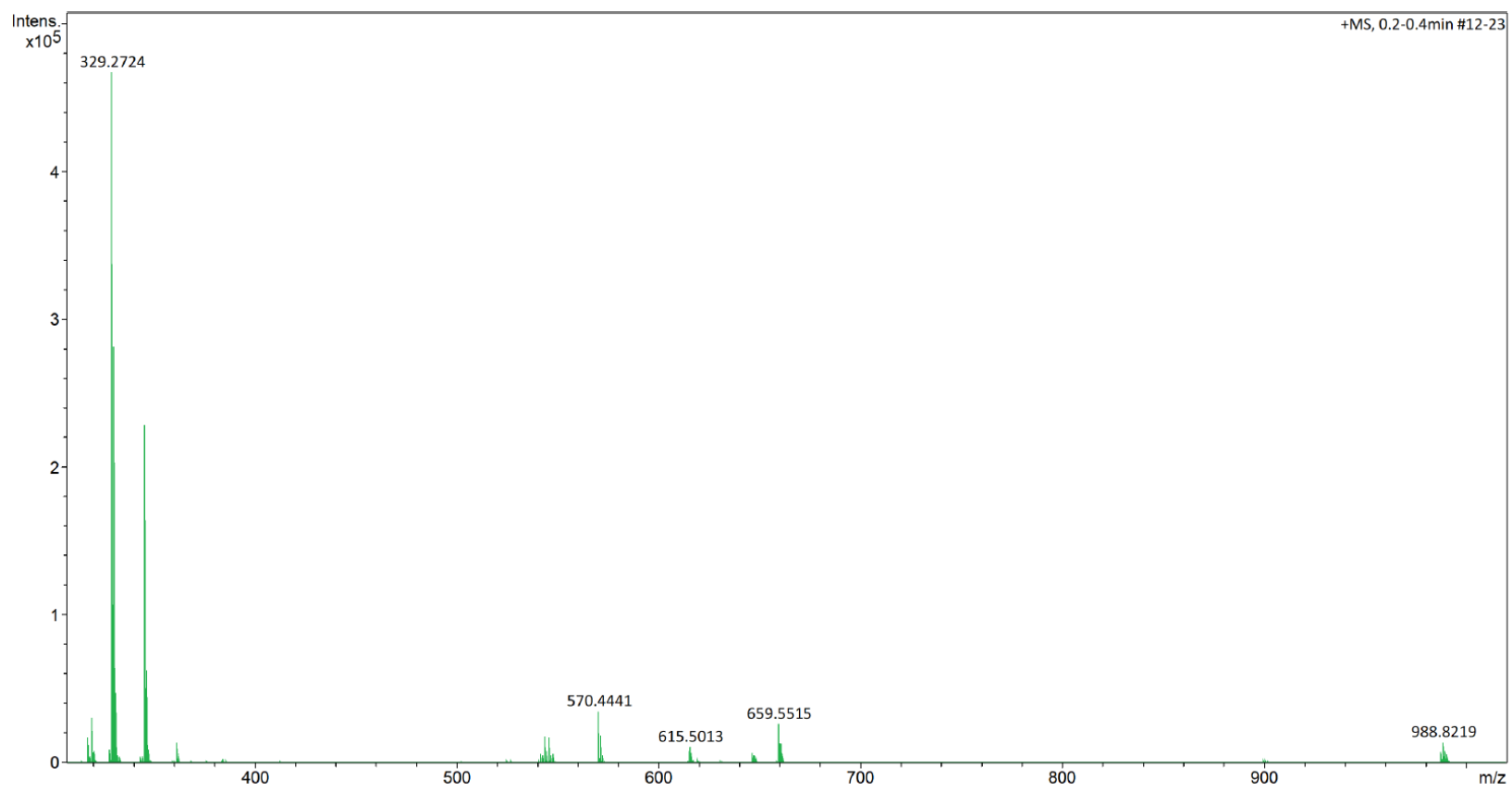

Figure S27: Exact mass spectrum by direct introduction (APCI) for $\mathbf{C}_{\mathbf{1 2}} \mathbf{N}_{\mathbf{1 5}}$.

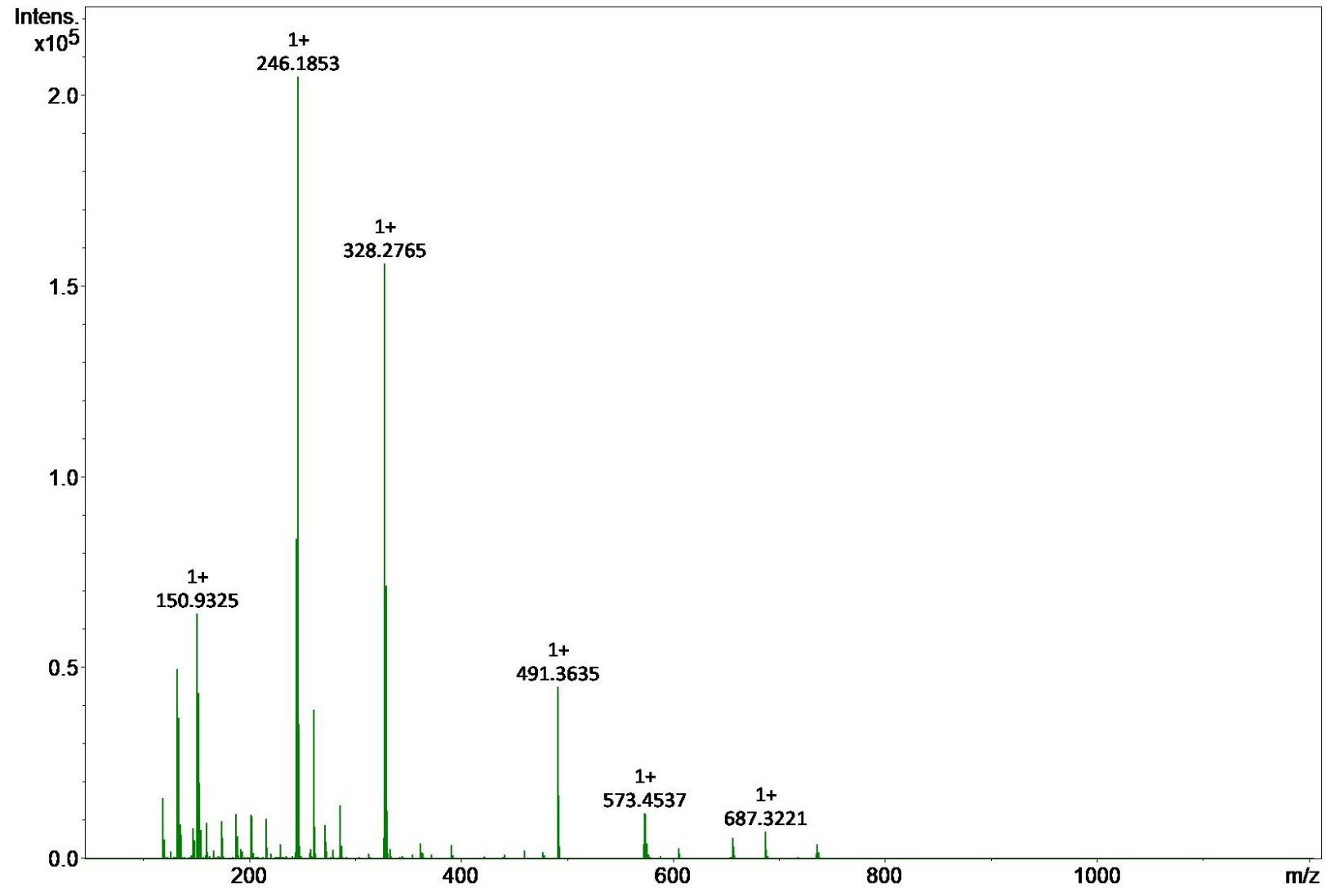

Figure S28: Exact mass spectrum by direct introduction (APCI) for $\mathbf{C}_{15} \mathbf{N}_{\mathbf{9}}$. 
4. PXRD
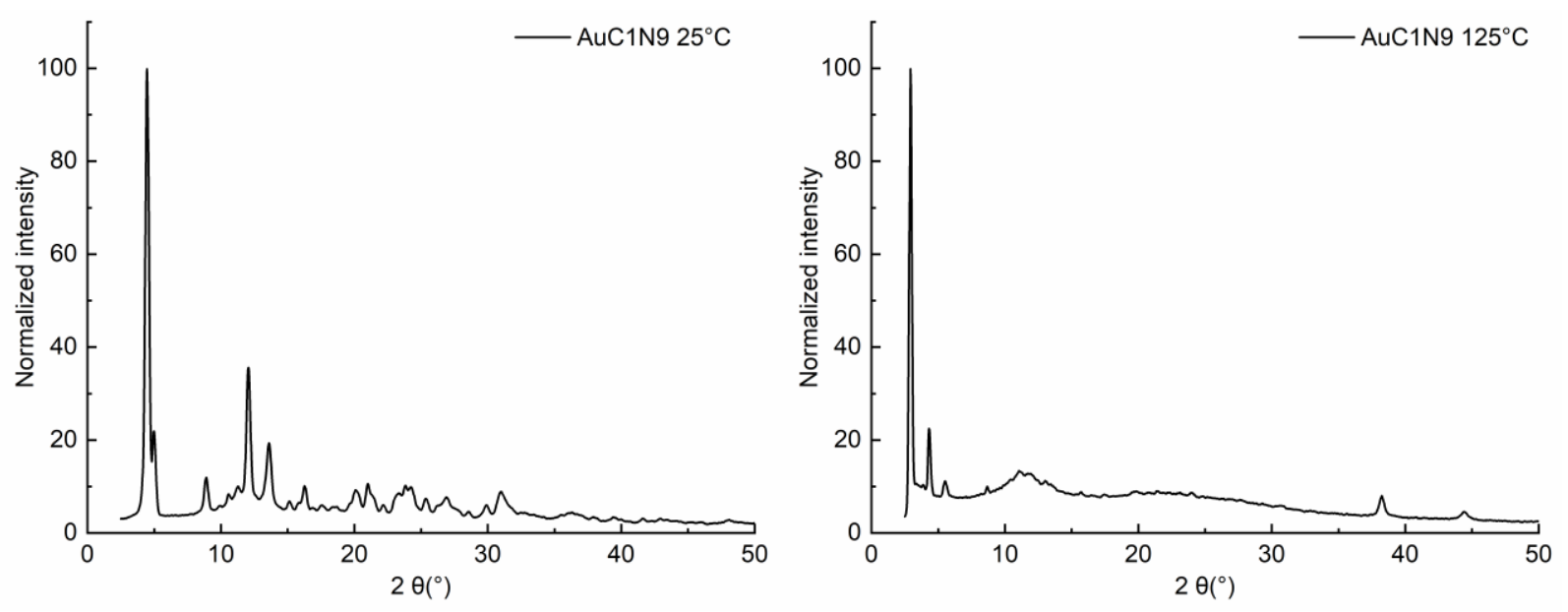

Figure S29 : Experimental powder XRD diffractrograms of $\mathbf{C}_{\mathbf{1}} \mathbf{N}_{9}$ at $25^{\circ} \mathrm{C}$ (left) and $125{ }^{\circ} \mathrm{C}$ (right).
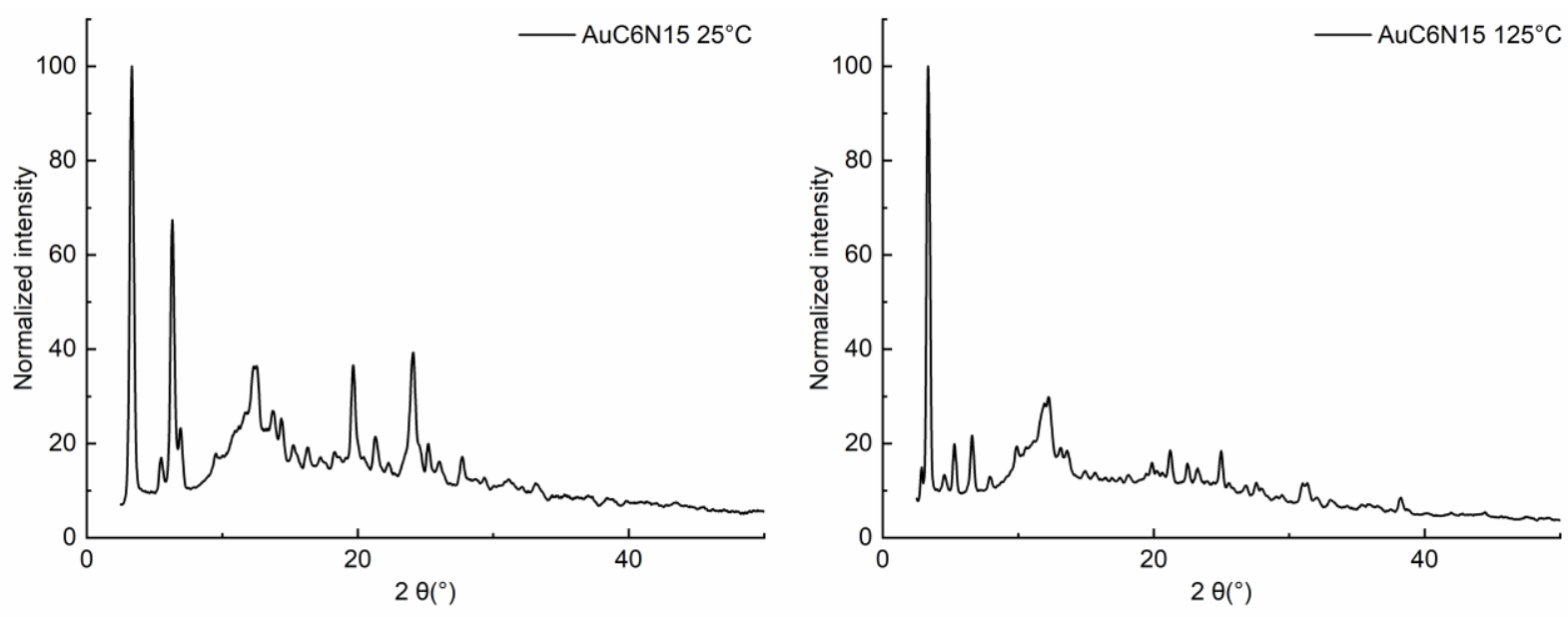

Figure S30: Experimental powder XRD diffractrograms of $\mathbf{C}_{6} \mathbf{N}_{15}$ at $25^{\circ} \mathrm{C}$ (left) and $125{ }^{\circ} \mathrm{C}$ (right). 

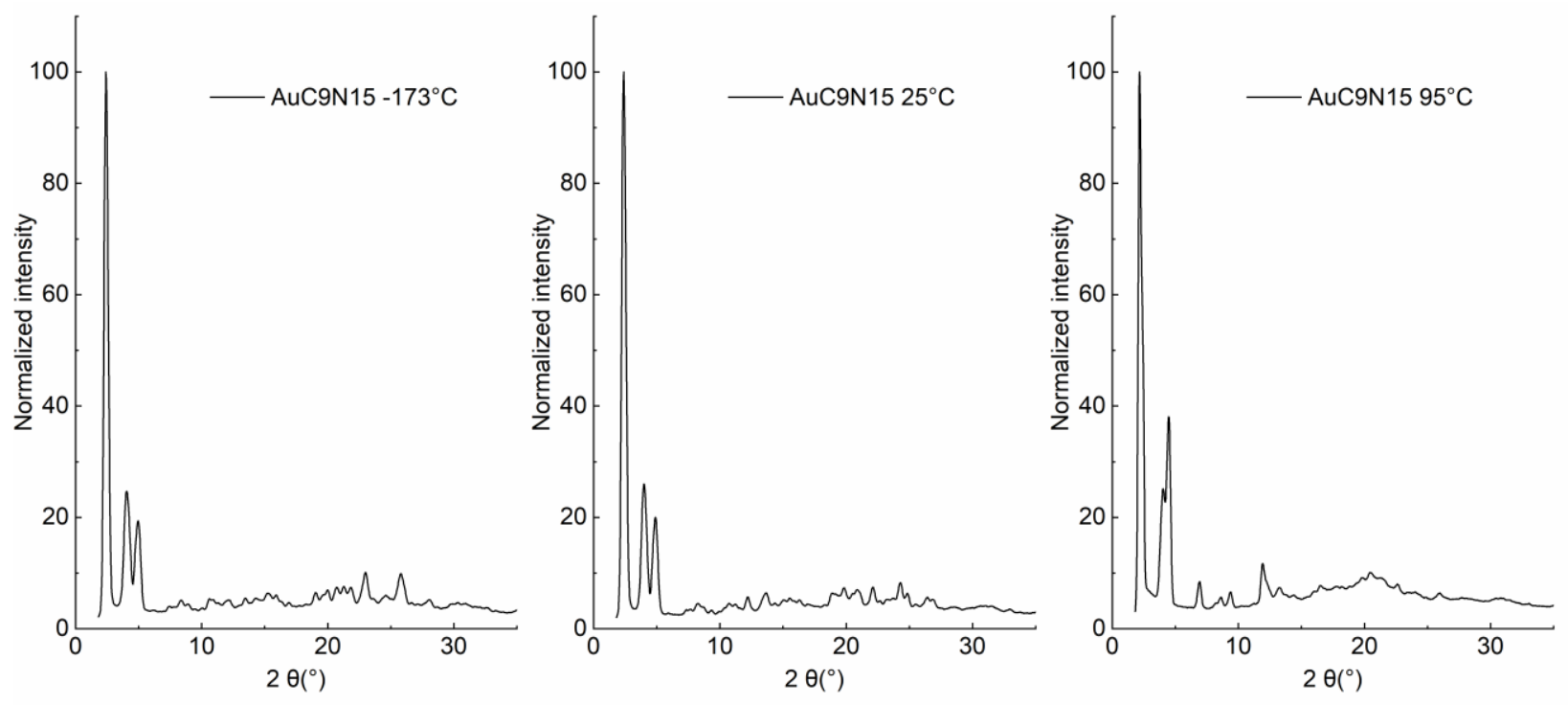

Figure S31: Experimental powder XRD diffractrograms of $\mathbf{C}_{9} \mathbf{N}_{15}$ at $25^{\circ} \mathrm{C}$ (left) and $125^{\circ} \mathrm{C}$ (right).
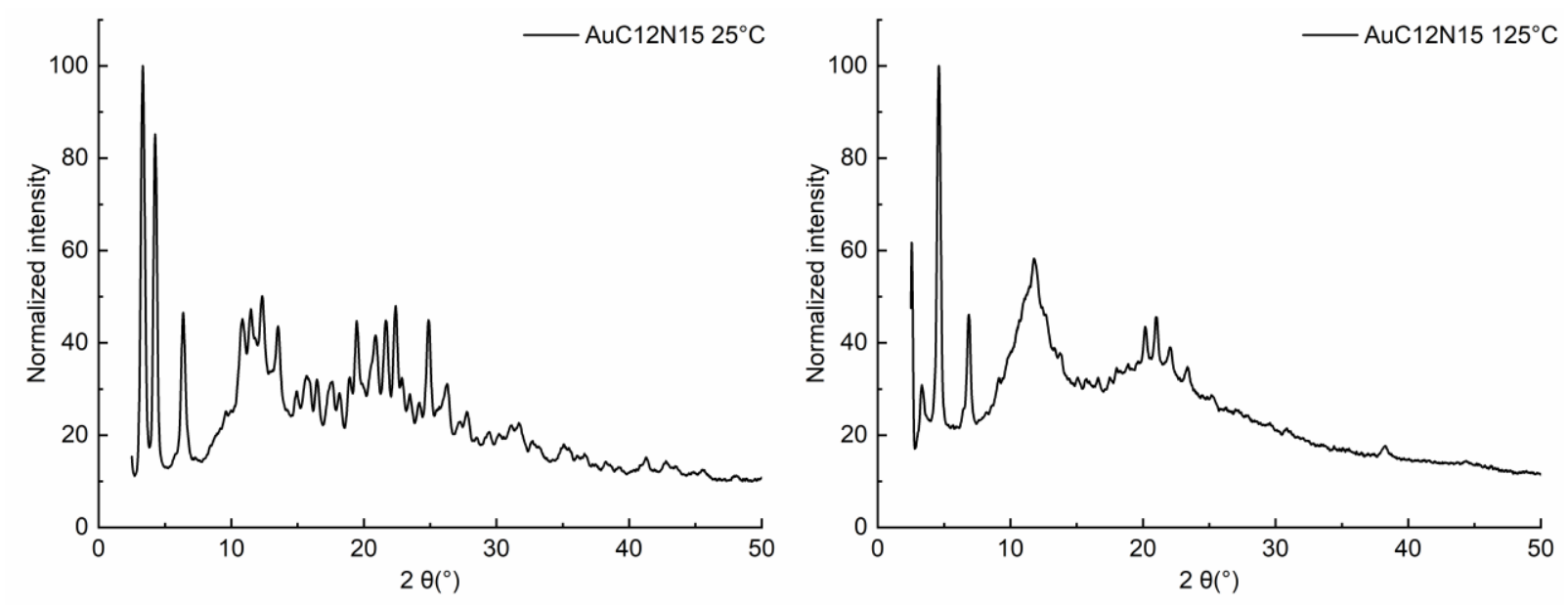

Figure S32: Experimental powder XRD diffractrograms of $\mathbf{C}_{\mathbf{1 2}} \mathbf{N}_{\mathbf{1 5}}$ at $25^{\circ} \mathrm{C}$ (left) and $125^{\circ} \mathrm{C}$ (right). 


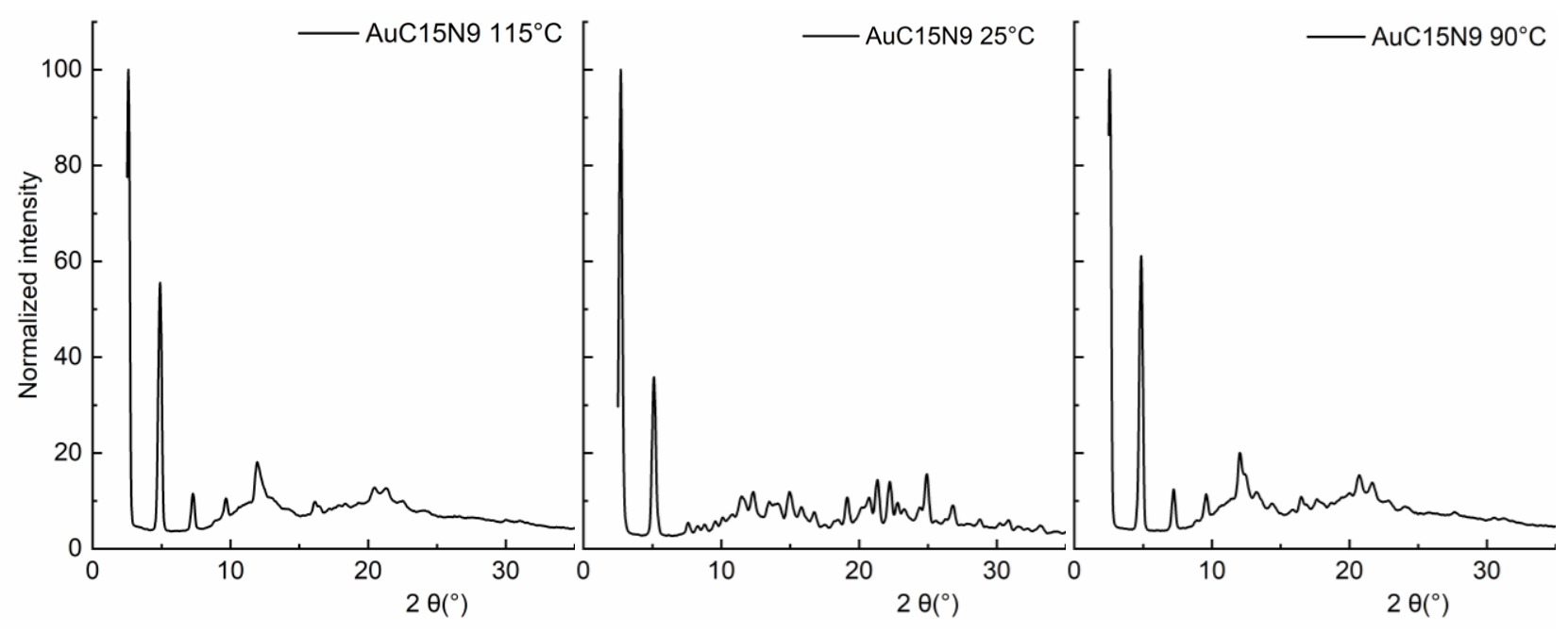

Figure S33: Experimental powder XRD diffractrograms of $\mathbf{C}_{\mathbf{1 5}} \mathbf{N}_{\mathbf{9}}$ at $25^{\circ} \mathrm{C}$ (left) and $125^{\circ} \mathrm{C}$ (right).

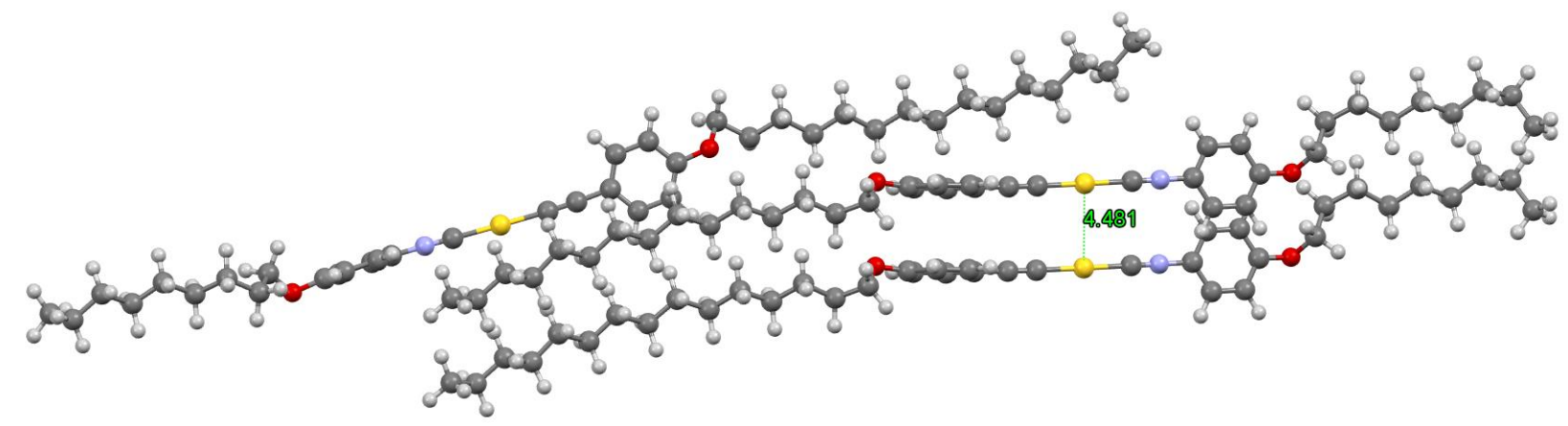

Figure S34: Hypothetical packing structure of solid $\mathbf{C}_{\mathbf{1 5}} \mathbf{N}_{\mathbf{9}}$ at $25^{\circ} \mathrm{C}$ based on curve fitting of the powder XRD patterns. 


\section{DSC}

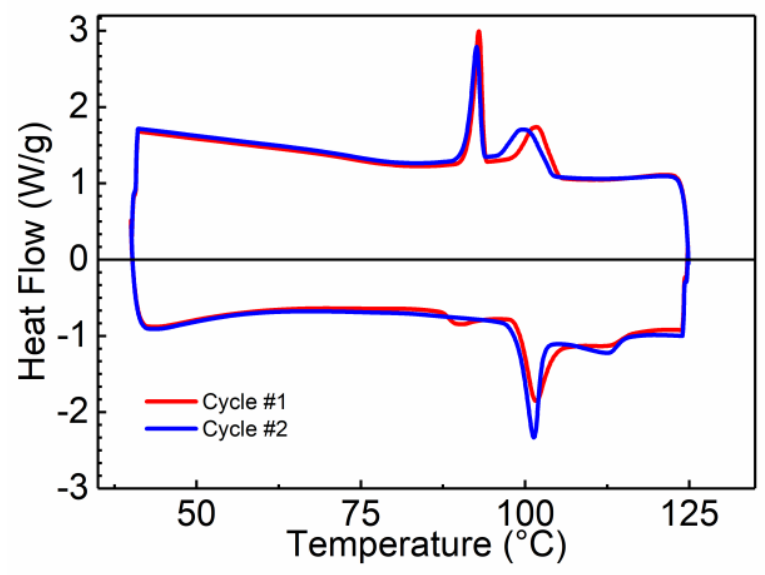

Figure S35: DSC traces (exo up) of $\mathbf{C}_{\mathbf{1}} \mathbf{N} \mathbf{9}$, scan rate $=10^{\circ} \mathrm{C} / \mathrm{min}$.

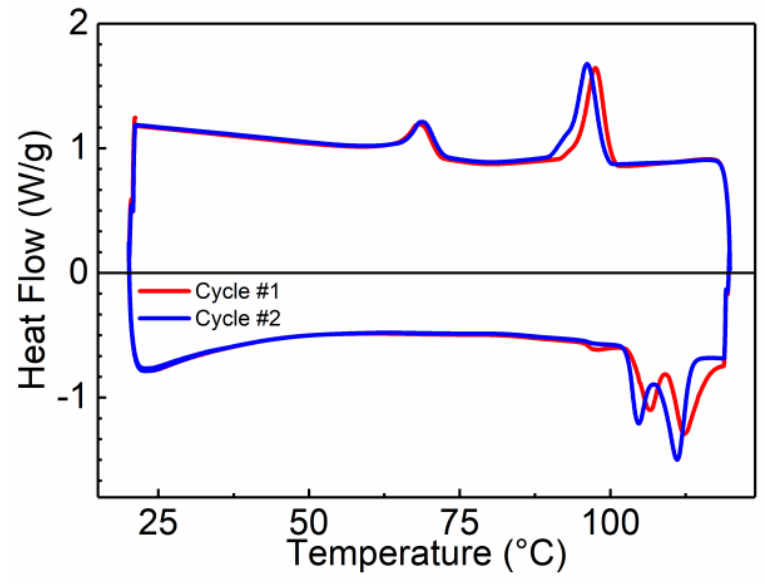

Figure S36: DSC traces (exo up) of $\mathbf{C}_{\mathbf{6}} \mathbf{N}_{\mathbf{1 5}}$, scan rate $=10{ }^{\circ} \mathrm{C} / \mathrm{min}$.

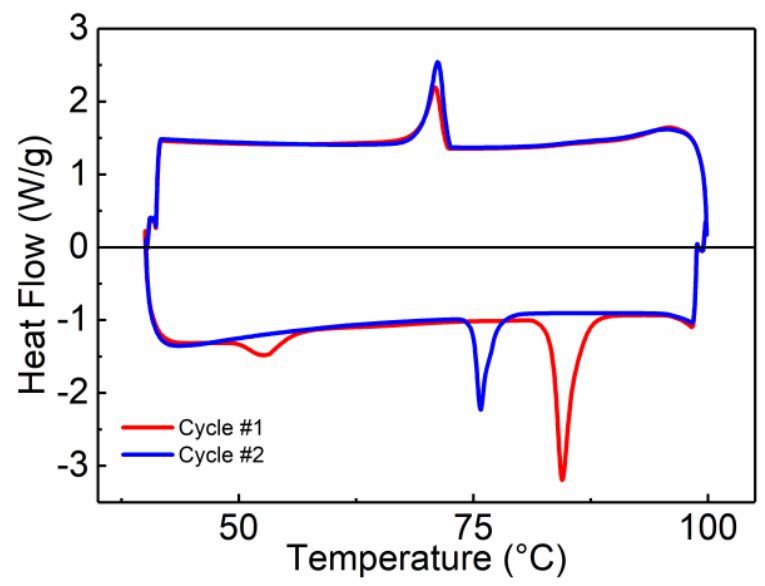

Figure S37: DSC traces (exo up) of $\mathbf{C}_{\mathbf{9}} \mathbf{N}_{\mathbf{1 5}}$, scan rate $=10{ }^{\circ} \mathrm{C} / \mathrm{min}$. 


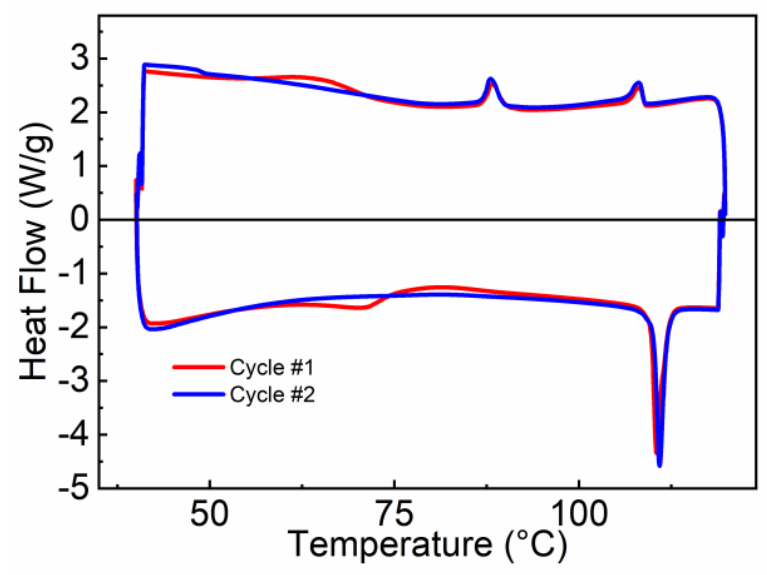

Figure S38: DSC traces (exo up) of $\mathbf{C}_{\mathbf{1 2}} \mathbf{N}_{15}$, scan rate $=10{ }^{\circ} \mathrm{C} / \mathrm{min}$

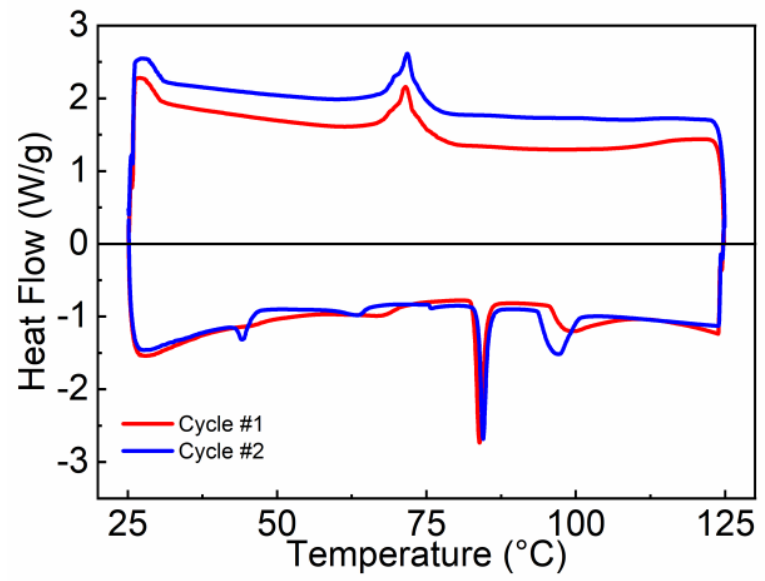

Figure S39: DSC traces (exo up) of $\mathbf{C}_{\mathbf{1 5}} \mathbf{N}_{\mathbf{9}}$, scan rate $=10{ }^{\circ} \mathrm{C} / \mathrm{min}$ 


\section{TGA}

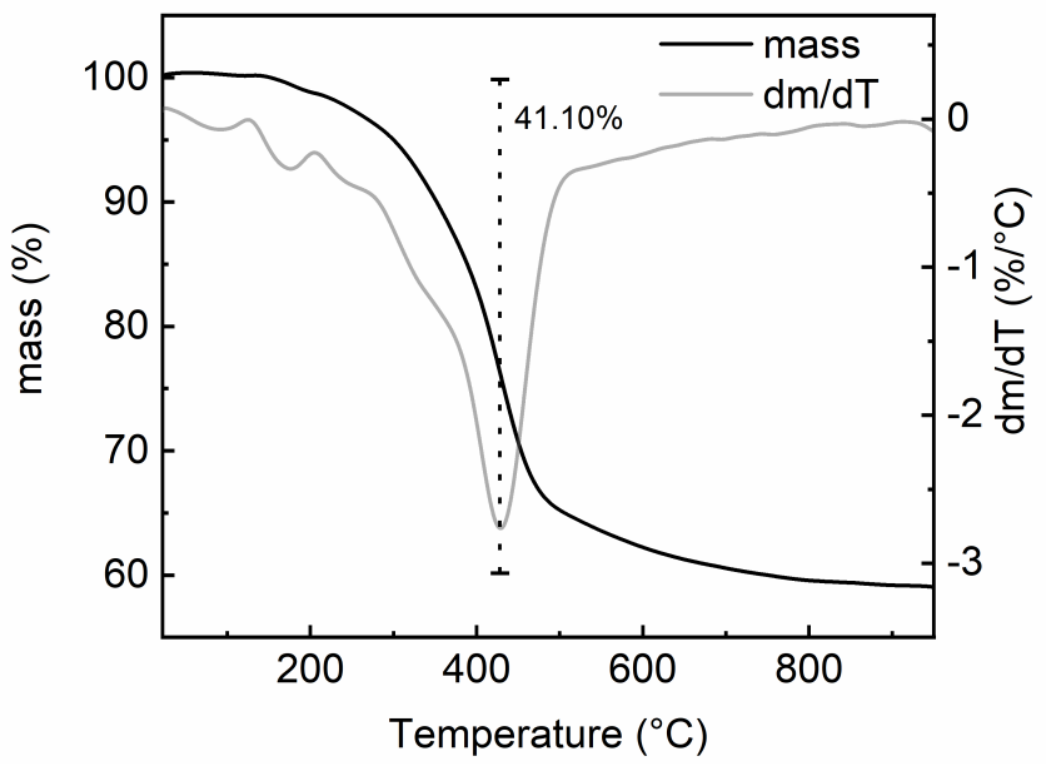

Figure S40: Thermogravimetric analysis (black line) and corresponding first derivative (grey line) of $\mathbf{C}_{\mathbf{1}} \mathbf{N}_{\mathbf{9}}$ under argon atmosphere from 20 to $950{ }^{\circ} \mathrm{C}$.

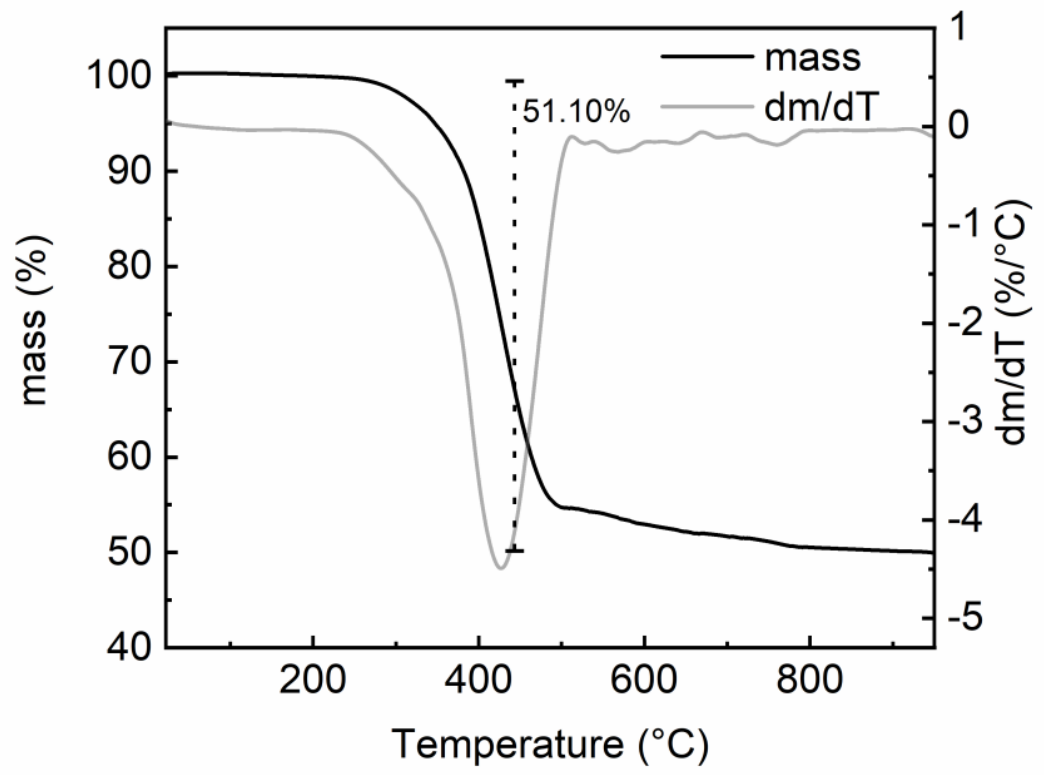

Figure S41: Thermogravimetric analysis (black line) and corresponding first derivative (grey line) of $\mathbf{C}_{6} \mathbf{N}_{15}$ under argon atmosphere from 20 to $950{ }^{\circ} \mathrm{C}$. 


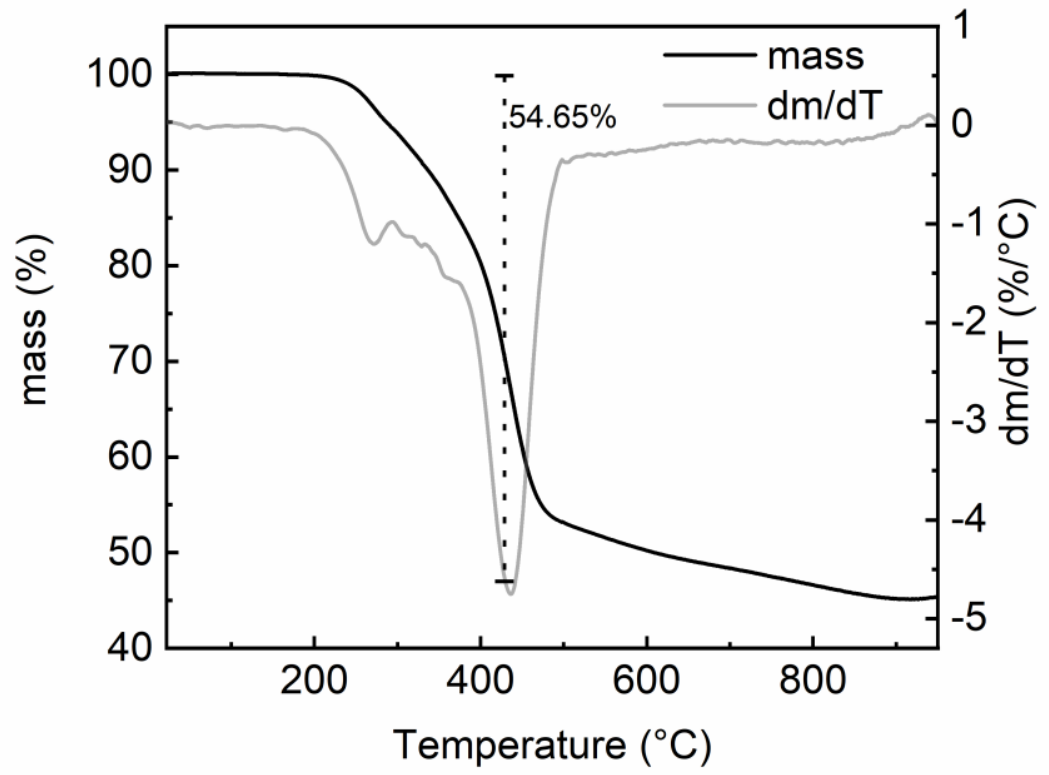

Figure S42: Thermogravimetric analysis (black line) and corresponding first derivative (grey line) of $\mathbf{C}_{9} \mathbf{N}_{15}$ under argon atmosphere from 20 to $950{ }^{\circ} \mathrm{C}$.

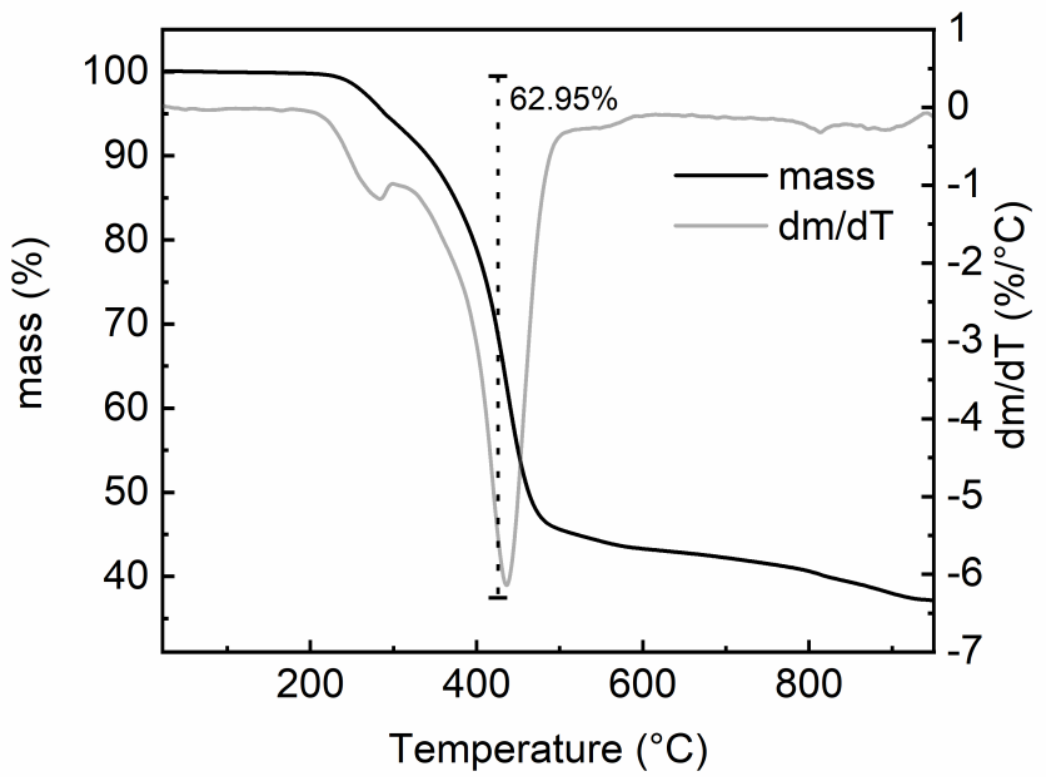

Figure S43: Thermogravimetric analysis (black line) and corresponding first derivative (grey line) of $\mathbf{C}_{12} \mathbf{N}_{15}$ under argon atmosphere from 20 to $950{ }^{\circ} \mathrm{C}$. 


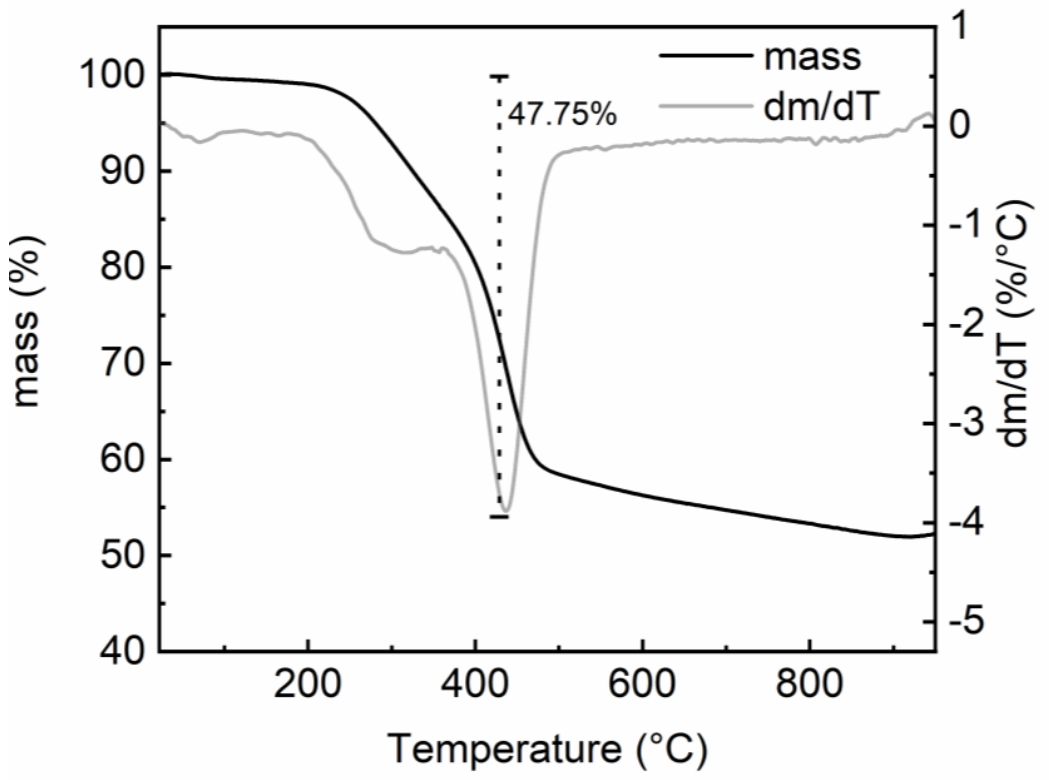

Figure S44: Thermogravimetric analysis (black line) and corresponding first derivative (grey line) of $\mathbf{C}_{15} N_{9}$ under argon atmosphere from 20 to $950{ }^{\circ} \mathrm{C}$. 


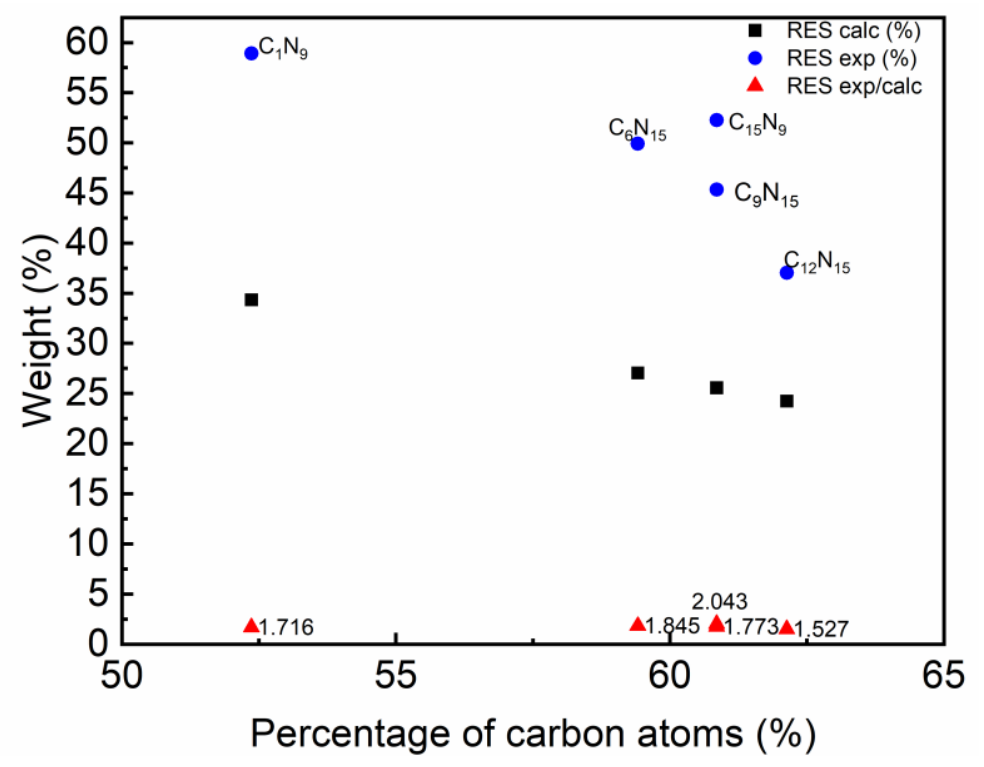

Figure S45: TGA analysis of the residual at $950^{\circ} \mathrm{C}$ as a function of mass percent of carbon.

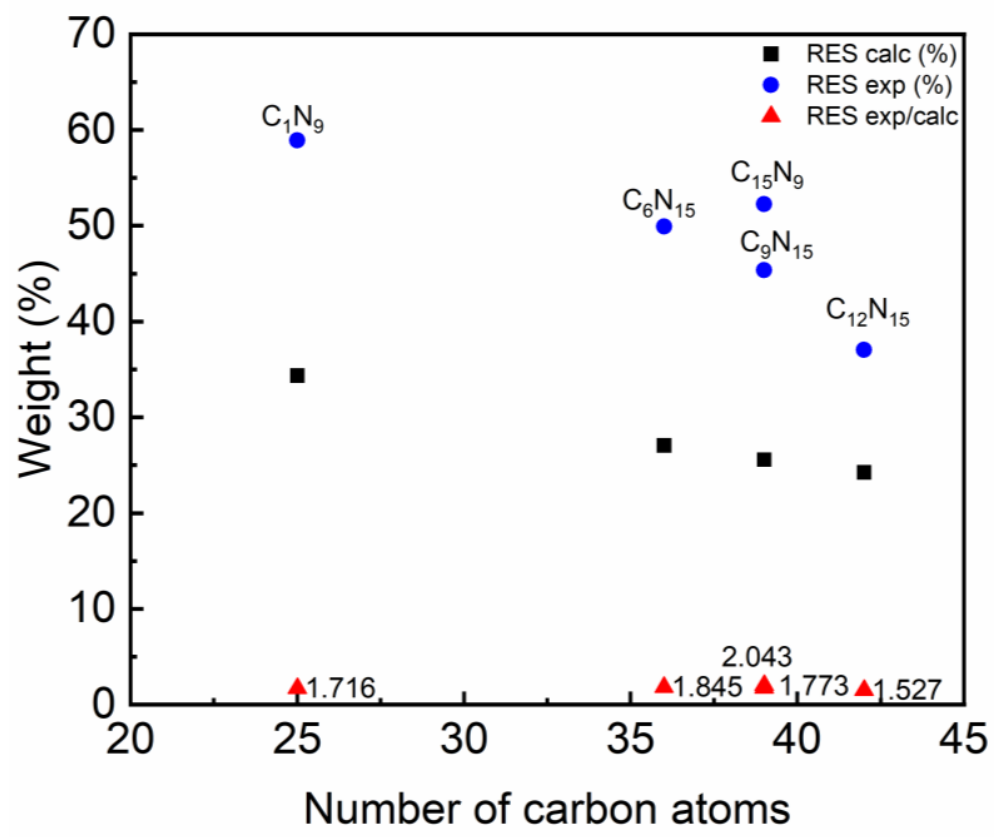

Figure S46: TGA analysis of the residual at $950^{\circ} \mathrm{C}$ as a function of number of carbon atoms. 


\section{Microscopy}

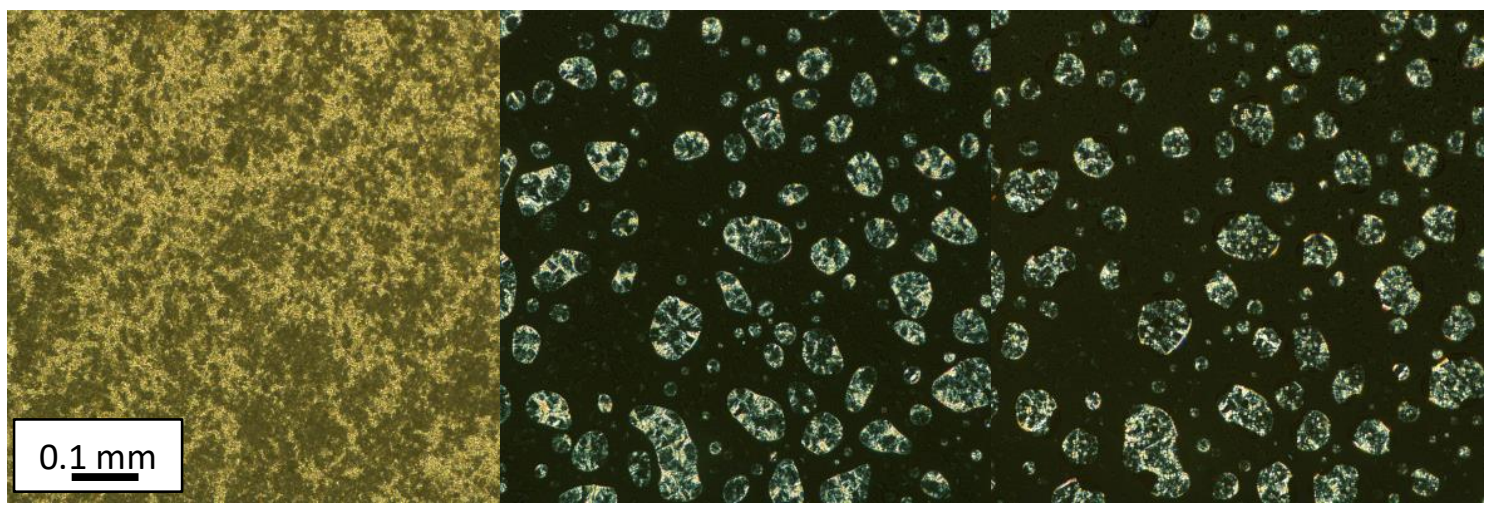

Figure S47: Polarized light microscopy images of $\mathbf{C}_{\mathbf{1}} \mathbf{N}_{\mathbf{9}}$ at $298 \mathrm{~K}$ (left), at $398 \mathrm{~K}$ (middle) and at $408 \mathrm{~K}$ (right). Note that the image with the yellow back ground is without polarized light.
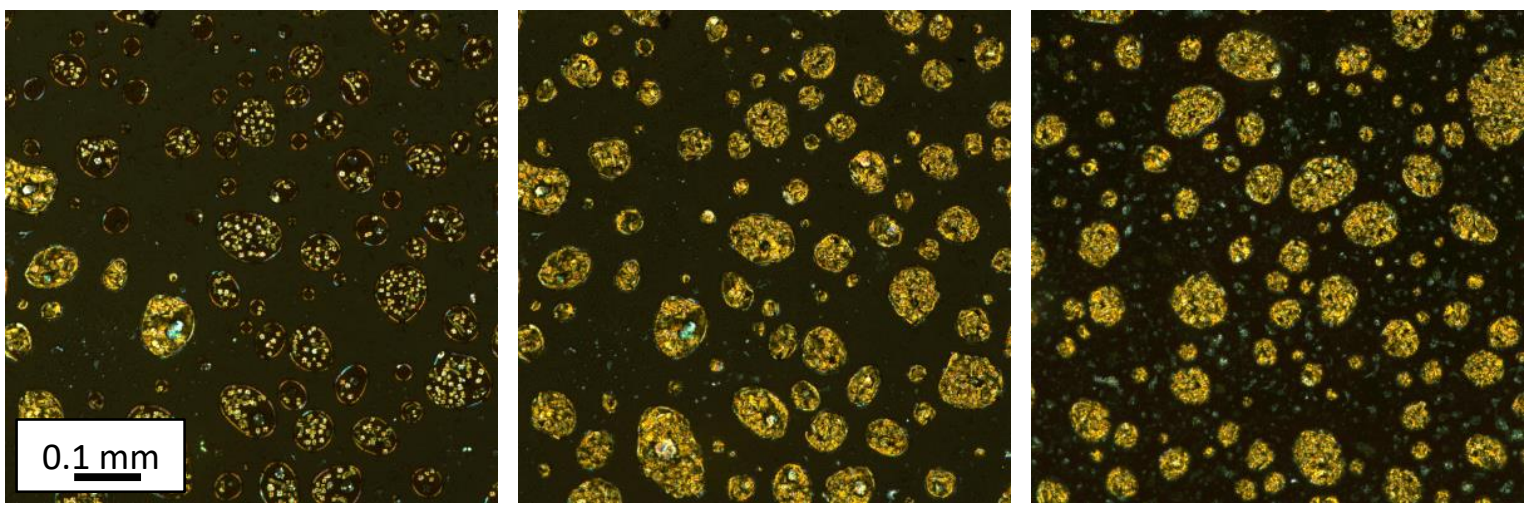

Figure S48: Polarized light microscopy images of $\mathbf{C}_{\mathbf{1}} \mathbf{N}_{\mathbf{9}}$ upon cooling at $388 \mathrm{~K}$ (left), at $383 \mathrm{~K}$ (middle) and 298K (right).
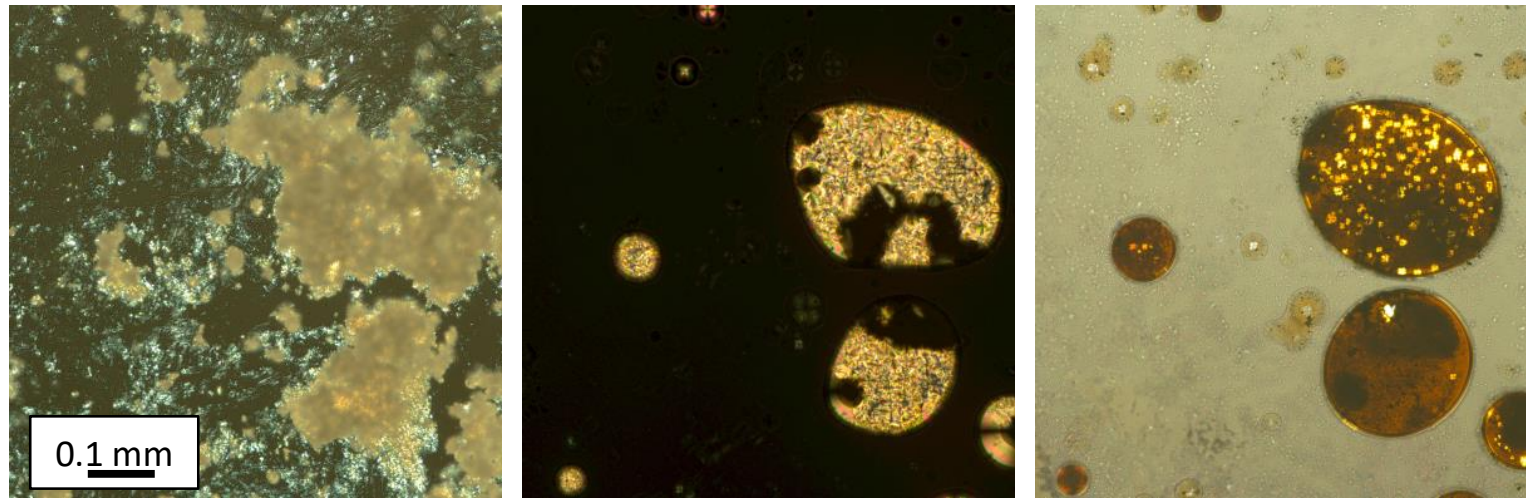

Figure S49: Polarized light microscopy images of $\mathbf{C}_{9} \mathbf{N}_{15}$ at $298 \mathrm{~K}$ (left), heated at $403 \mathrm{~K}$ (right) and cooled down to $392 \mathrm{~K}$ (right). Note that the image with the yellow back ground is without polarized light. 


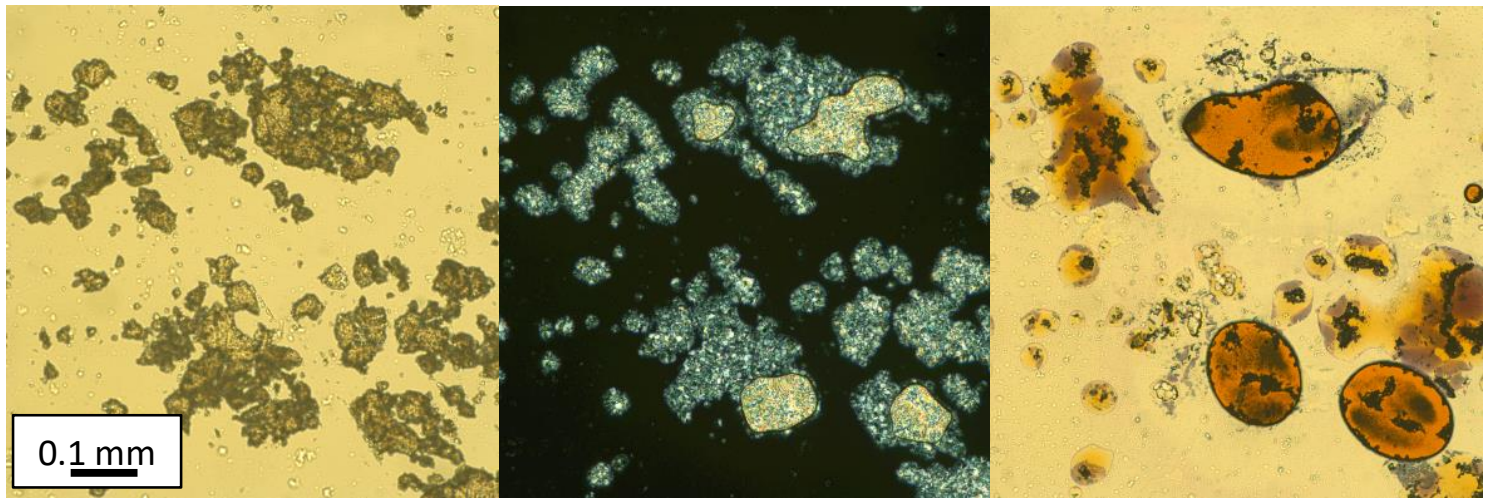

Figure S50: Polarized light microscopy images of $\mathbf{C}_{12} \mathbf{N}_{15}$ at $298 \mathrm{~K}$ (left), heated at $403 \mathrm{~K}$ (right) and heated at to $418 \mathrm{~K}$ (right). Note that the image with the yellow back ground is without polarized light.
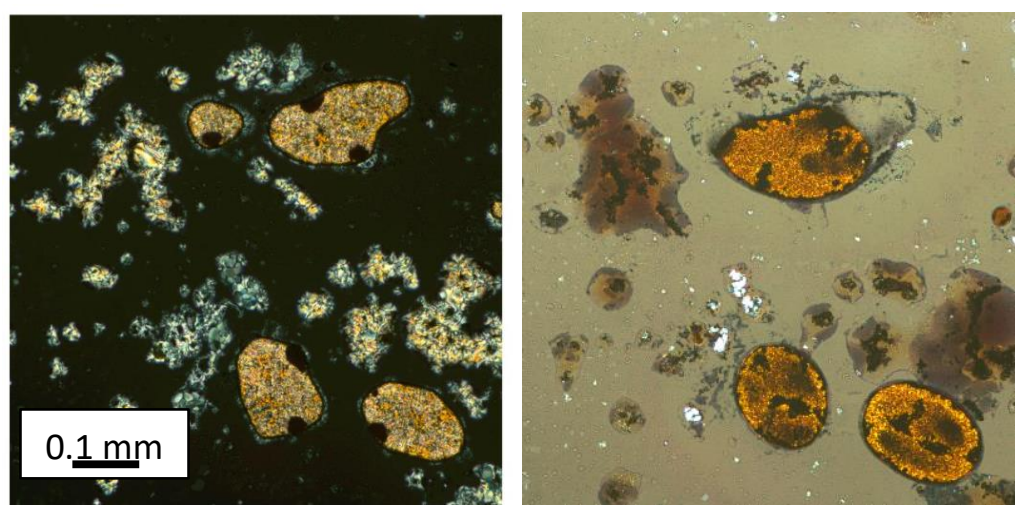

Figure S51: Polarized light microscopy images of $\mathbf{C}_{\mathbf{1 2}} \mathbf{N}_{\mathbf{1 5}}$ cooled down to $298 \mathrm{~K}$. Note that the image with the yellow back ground is without polarized light.

\section{DFT}

\section{Computational Details}

\section{$\mathrm{C}_{1} \mathrm{~N}_{9}$ in a $\mathrm{CH}_{2} \mathrm{Cl}_{2}$ solvent field}

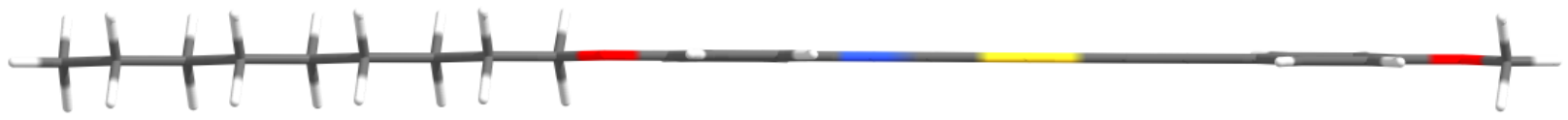

Figure S52: Structure (optimized geometry) of $\mathbf{C}_{1} \mathbf{N}_{9}$ in the ground state in a $\mathrm{CH}_{2} \mathrm{Cl}_{2}$ solvent field. 


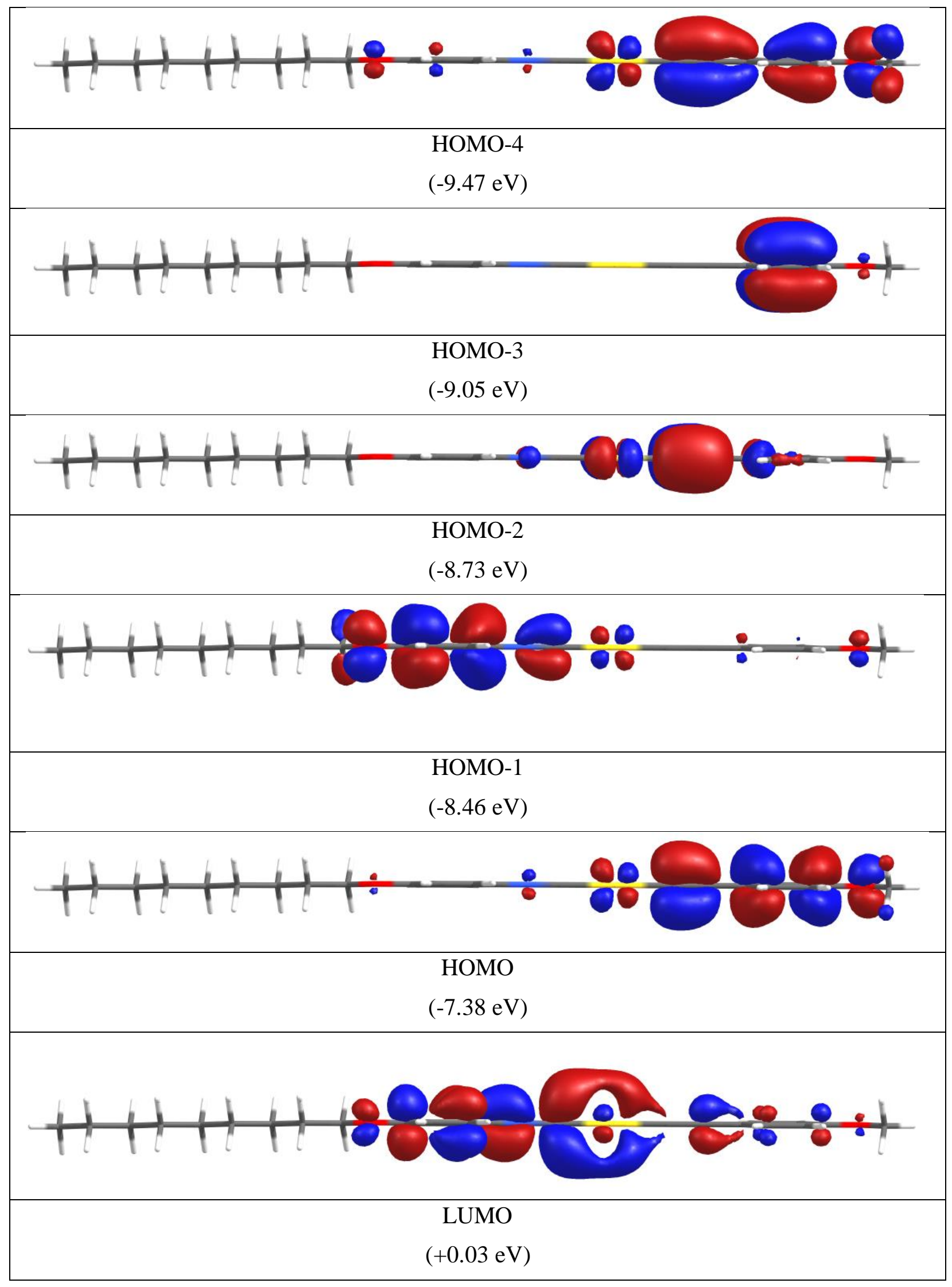




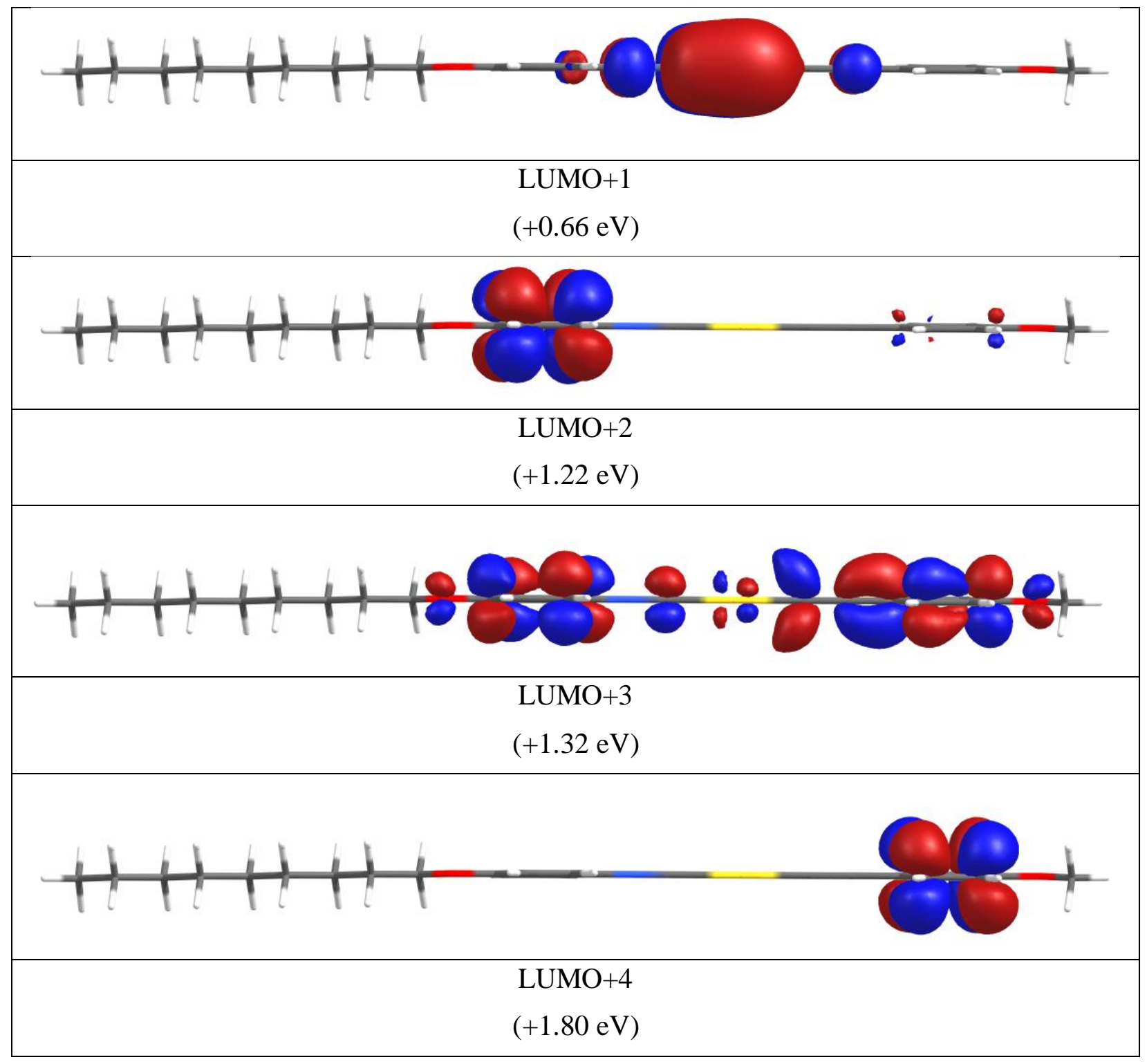

Figure S53: Representations of the frontier MOs of $\mathbf{C}_{\mathbf{1}} \mathbf{N}_{\mathbf{9}}$ in the ground state in a $\mathrm{CH}_{2} \mathrm{Cl}_{2}$ solvent field.

Table S1: Atomic contributions of the frontier MOs of $\mathbf{C}_{\mathbf{1}} \mathbf{N}_{9}$ in a $\mathrm{CH}_{2} \mathrm{Cl}_{2}$ solvent field. $(\mathrm{H}=\mathrm{HOMO}$; $\mathrm{L}=\mathrm{LUMO}$ ).

\begin{tabular}{lllllllllll}
\hline \multicolumn{1}{c}{ Fragment } & H-4 & H-3 & H-2 & H-1 & HOMO & LUMO & L+1 & L+2 & L+3 & L+4 \\
\hline Energy (eV) & -9.47 & -9.05 & -8.73 & -8.46 & -7.38 & 0.03 & 0.66 & 1.22 & 1.32 & 1.80 \\
\hline Au $(\%)$ & 11.10 & 0.20 & 19.55 & 3.28 & 6.63 & 12.89 & 29.25 & 0.94 & 9.42 & 0.53 \\
Ethynyl (\%) & 84.34 & 99.58 & 77.86 & 3.66 & 90.83 & 9.57 & 12.25 & 3.51 & 47.72 & 98.91 \\
Isocyanide (\%) & 4.56 & 0.22 & 2.59 & 93.06 & 2.54 & 77.53 & 58.51 & 95.55 & 42.86 & 0.57 \\
\hline
\end{tabular}




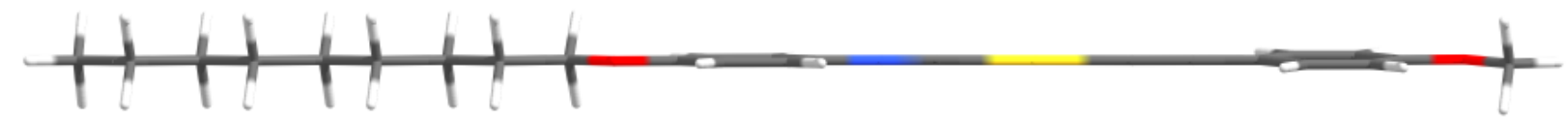

Figure S54: Optimized geometry of $\mathbf{C}_{\mathbf{1}} \mathbf{N}_{9}$ in the triplet state in a $\mathrm{CH}_{2} \mathrm{Cl}_{2}$ solvent field.

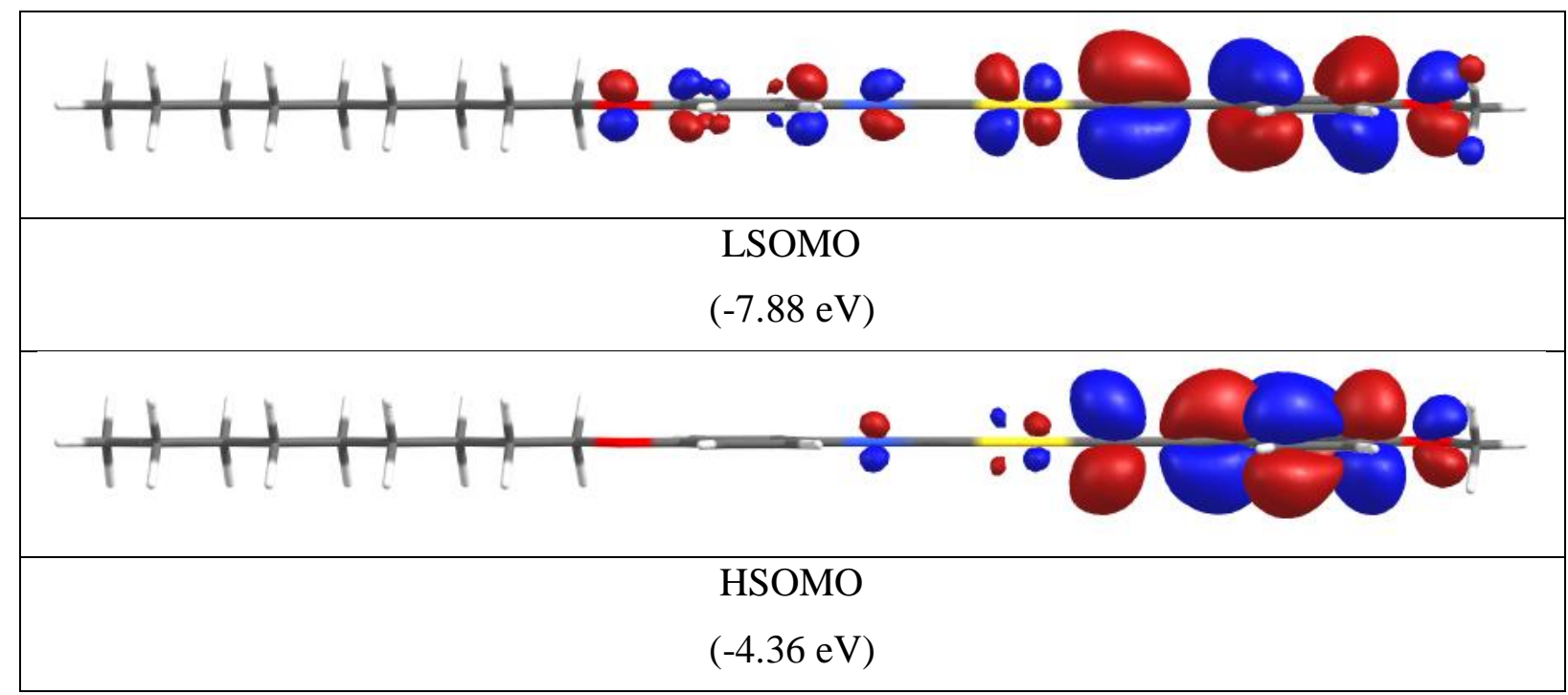

Figure S55: Representation of the frontier MOs of $\mathbf{C}_{\mathbf{1}} \mathbf{N}_{\mathbf{9}}$ in the triplet state in a $\mathrm{CH}_{2} \mathrm{Cl}_{2}$ solvent field.

Phosphorescence position : $E_{\text {triplet }}-E_{\text {singlet }}=3.07 \mathrm{eV}=404 \mathrm{~nm}$

Table S2: Atomic contributions of the frontier MOs of $\mathbf{C}_{\mathbf{1}} \mathbf{N}_{\mathbf{9}}$ in the triplet state in $\mathrm{CH}_{2} \mathrm{Cl}_{2}$ solvent field.

\begin{tabular}{lll}
\hline \multicolumn{1}{c}{ Fragment } & LSOMO & HSOMO \\
\hline Energy $(\mathrm{eV})$ & -7.88 & -4.36 \\
\hline $\mathrm{Au}(\%)$ & 10.24 & 3.52 \\
Ethynyl (\%) & 79.68 & 94.50 \\
Isocyanide (\%) & 10.08 & 1.98 \\
\hline
\end{tabular}




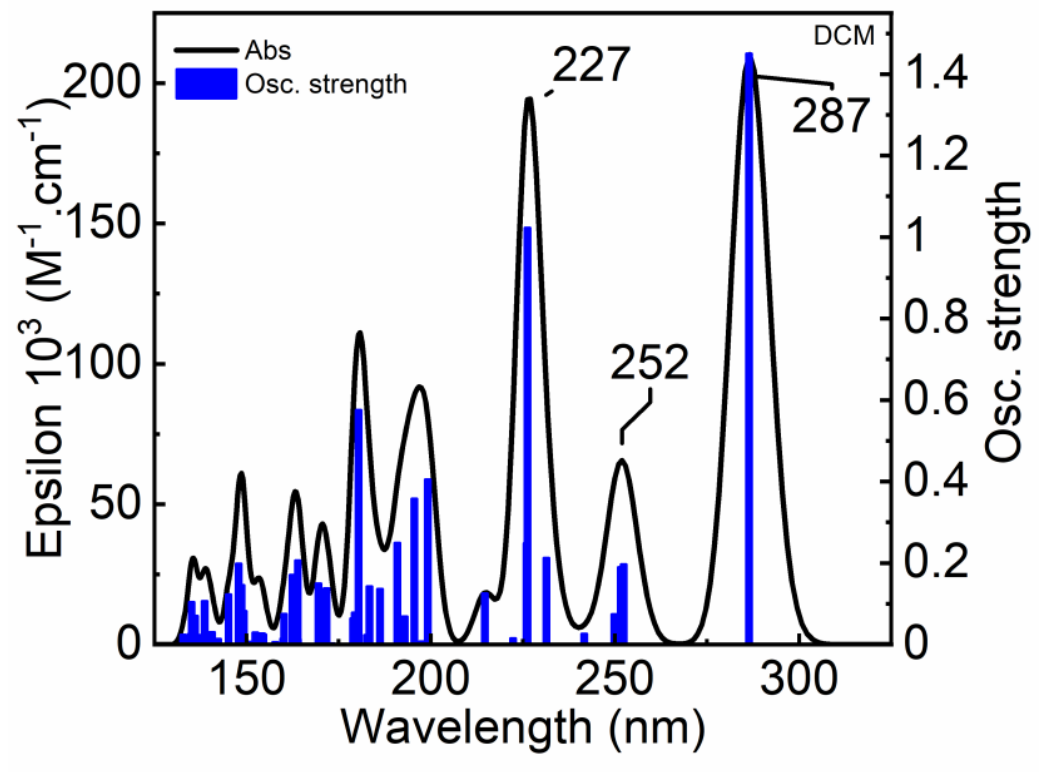

Figure S56 : Bar graph of the calculated positions of the spin-allowed electronic transition (blue) of $\mathrm{C}_{1} \mathrm{~N}_{9}$ in a $\mathrm{CH}_{2} \mathrm{Cl}_{2}$ solvent field $v s$ their oscillator strength (the simulated spectrum (black) is generated by assigning an arbitrary thickness of $1500 \mathrm{~cm}^{-1}$ for each bar). 
Table S3: Calculated positions, oscillator strengths and major contributions of the 100 first spinallowed electronic transitions of $\mathbf{C}_{\mathbf{1}} \mathbf{N}_{9}$ in a $\mathrm{CH}_{2} \mathrm{Cl}_{2}$ solvent field.

\begin{tabular}{|c|c|c|c|}
\hline $\begin{array}{l}\text { Transition } \\
\quad \text { No. }\end{array}$ & $\begin{array}{c}\lambda \\
(\mathbf{n m})\end{array}$ & $\begin{array}{l}\text { Osc. } \\
\text { Str. }\end{array}$ & $\begin{array}{c}\text { Major contribs } \\
(\% ;- \text { means no major contribution) }\end{array}$ \\
\hline 1 & 286.3952 & 1.4505 & $\mathrm{HOMO} \rightarrow \mathrm{LUMO}(59 \%), \mathrm{HOMO} \rightarrow \mathrm{L}+3(22 \%)$ \\
\hline 2 & 266.0815 & 0 & $\mathrm{H}-4 \rightarrow \mathrm{L}+1(11 \%), \mathrm{HOMO} \rightarrow \mathrm{L}+1(75 \%)$ \\
\hline 3 & 252.3731 & 0.1971 & $\mathrm{H}-2 \rightarrow \mathrm{LUMO}(30 \%), \mathrm{H}-2 \rightarrow \mathrm{L}+3(13 \%), \mathrm{H}-1 \rightarrow \mathrm{LUMO}(38 \%)$ \\
\hline 4 & 251.5947 & 0.19 & $\mathrm{H}-2 \rightarrow \mathrm{LUMO}(34 \%), \mathrm{H}-2 \rightarrow \mathrm{L}+3(12 \%), \mathrm{H}-1 \rightarrow \mathrm{LUMO}(32 \%)$ \\
\hline 5 & 249.8455 & 0.0748 & $\mathrm{HOMO} \rightarrow \mathrm{L}+4(74 \%)$ \\
\hline 6 & 241.6452 & 0.0272 & $\mathrm{H}-6 \rightarrow \mathrm{LUMO}(20 \%), \mathrm{H}-1 \rightarrow \mathrm{L}+2(60 \%)$ \\
\hline 7 & 231.3467 & 0.2131 & $\mathrm{H}-5 \rightarrow \mathrm{LUMO}(87 \%)$ \\
\hline 8 & 226.247 & 1.0237 & $\mathrm{H}-2 \rightarrow \mathrm{L}+1(47 \%), \mathrm{HOMO} \rightarrow \mathrm{L}+3(14 \%), \mathrm{HOMO} \rightarrow \mathrm{L}+5(16 \%)$ \\
\hline 9 & 225.9995 & 0.2495 & $\mathrm{H}-5 \rightarrow \mathrm{L}+1(97 \%)$ \\
\hline 10 & 222.3478 & 0.0156 & $\mathrm{H}-1 \rightarrow \mathrm{L}+1(69 \%)$ \\
\hline 11 & 214.6414 & 0.1263 & $\begin{array}{l}\mathrm{H}-2 \rightarrow \mathrm{L}+1 \quad(33 \%), \mathrm{HOMO} \rightarrow \mathrm{LUMO} \quad(23 \%), \mathrm{HOMO} \rightarrow \mathrm{L}+3 \quad(15 \%), \\
\mathrm{HOMO} \rightarrow \mathrm{L}+5(12 \%)\end{array}$ \\
\hline 12 & 202.6401 & 0.0005 & $\mathrm{H}-2 \rightarrow \mathrm{LUMO}(16 \%), \mathrm{H}-2 \rightarrow \mathrm{L}+3(33 \%), \mathrm{H}-2 \rightarrow \mathrm{L}+5(23 \%)$ \\
\hline 13 & 199.1636 & 0.4055 & $\mathrm{H}-6 \rightarrow \mathrm{LUMO}(62 \%), \mathrm{H}-1 \rightarrow \mathrm{L}+2(25 \%)$ \\
\hline 14 & 197.6239 & 0.008 & $\mathrm{H}-9 \rightarrow \mathrm{L}+1(14 \%), \mathrm{H}-8 \rightarrow \mathrm{LUMO}(73 \%)$ \\
\hline 15 & 197.6145 & 0.0083 & $\mathrm{H}-9 \rightarrow \mathrm{LUMO}(72 \%), \mathrm{H}-8 \rightarrow \mathrm{L}+1(14 \%)$ \\
\hline 16 & 195.5049 & 0.3586 & $\begin{array}{l}\mathrm{H}-3 \rightarrow \mathrm{LUMO} \quad(25 \%), \quad \mathrm{H}-3 \rightarrow \mathrm{L}+3 \quad(33 \%), \quad \mathrm{H}-3 \rightarrow \mathrm{L}+5 \quad(10 \%), \\
\mathrm{HOMO} \rightarrow \mathrm{L}+4 \quad(15 \%)\end{array}$ \\
\hline 17 & 192.9401 & 0.0592 & $\mathrm{H}-9 \rightarrow \mathrm{L}+1(35 \%), \mathrm{H}-8 \rightarrow \mathrm{L}+1(48 \%)$ \\
\hline 18 & 192.9251 & 0.0691 & $\mathrm{H}-9 \rightarrow \mathrm{L}+1(48 \%), \mathrm{H}-8 \rightarrow \mathrm{L}+1(35 \%)$ \\
\hline 19 & 190.8993 & 0.2499 & $\begin{array}{l}\mathrm{H}-4 \rightarrow \mathrm{LUMO} \quad(11 \%), \quad \mathrm{H}-4 \rightarrow \mathrm{L}+3 \quad(17 \%), \quad \mathrm{H}-3 \rightarrow \mathrm{L}+4 \quad(16 \%), \\
\mathrm{HOMO} \rightarrow \mathrm{L}+5 \quad(11 \%)\end{array}$ \\
\hline 20 & 186.2003 & 0.1367 & $\mathrm{H}-6 \rightarrow \mathrm{L}+2(38 \%)$ \\
\hline 21 & 183.3314 & 0.143 & $\mathrm{H}-3 \rightarrow \mathrm{L}+4(16 \%), \mathrm{HOMO} \rightarrow \mathrm{L}+3(10 \%), \mathrm{HOMO} \rightarrow \mathrm{L}+5(43 \%)$ \\
\hline 22 & 182.9472 & 0.0047 & $\mathrm{H}-2 \rightarrow \mathrm{L}+4(81 \%), \mathrm{HOMO} \rightarrow \mathrm{L}+7(10 \%)$ \\
\hline 23 & 182.5862 & 0.0236 & $\mathrm{H}-2 \rightarrow \mathrm{L}+4(13 \%), \mathrm{HOMO} \rightarrow \mathrm{L}+7(65 \%), \mathrm{HOMO} \rightarrow \mathrm{L}+10(11 \%)$ \\
\hline 24 & 180.3656 & 0.5762 & $\mathrm{H}-6 \rightarrow \mathrm{L}+2(10 \%), \mathrm{H}-4 \rightarrow \mathrm{LUMO}(18 \%), \mathrm{H}-3 \rightarrow \mathrm{L}+4$ (47\%) \\
\hline 25 & 179.317 & 0.0785 & $\mathrm{H}-6 \rightarrow \mathrm{L}+2(16 \%), \mathrm{HOMO} \rightarrow \mathrm{L}+9(19 \%)$ \\
\hline 26 & 178.9185 & 0.0646 & $\begin{array}{l}\mathrm{H}-6 \rightarrow \mathrm{L}+2(16 \%), \mathrm{HOMO} \rightarrow \mathrm{L}+9(20 \%) \\
\mathrm{H}-4 \rightarrow \mathrm{L}+1 \quad(26 \%), \quad \mathrm{HOMO} \rightarrow \mathrm{L}+1 \quad(14 \%), \quad \mathrm{HOMO} \rightarrow \mathrm{L}+6 \quad(11 \%),\end{array}$ \\
\hline 27 & 175.7706 & 0 & $\mathrm{HOMO} \rightarrow \mathrm{L}+9(14 \%)$ \\
\hline 28 & 175.5317 & 0.0021 & H-19 $\rightarrow$ LUMO (13\%), H-17 $\rightarrow$ LUMO (30\%), H-2 $\rightarrow$ L+5 (27\%) \\
\hline 29 & 173.2046 & 0.0033 & $\mathrm{HOMO} \rightarrow \mathrm{L}+2(82 \%)$ \\
\hline 30 & 172.0891 & 0.0013 & $\mathrm{H}-4 \rightarrow \mathrm{L}+1(12 \%), \mathrm{HOMO} \rightarrow \mathrm{L}+6(58 \%)$ \\
\hline 31 & 171.9746 & 0.0002 & $\mathrm{H}-6 \rightarrow \mathrm{L}+1(85 \%)$ \\
\hline 32 & 171.665 & 0.1383 & $H-5 \rightarrow L+3(65 \%)$ \\
\hline 33 & 170.0032 & 0.0523 & $\mathrm{H}-4 \rightarrow \mathrm{L}+4(78 \%)$ \\
\hline
\end{tabular}




\begin{tabular}{|c|c|c|c|}
\hline 34 & 169.4989 & 0.1502 & $\mathrm{H}-1 \rightarrow \mathrm{L}+3(24 \%)$ \\
\hline 35 & 166.7003 & 0.0007 & $\mathrm{H}-3 \rightarrow \mathrm{L}+1(87 \%)$ \\
\hline 36 & 165.5429 & 0.0002 & $\begin{array}{l}\mathrm{H}-17 \rightarrow \mathrm{LUMO}(11 \%), \mathrm{H}-2 \rightarrow \mathrm{LUMO}(11 \%), \mathrm{H}-2 \rightarrow \mathrm{L}+3 \quad(22 \%), \mathrm{H}- \\
2 \rightarrow \mathrm{L}+5(35 \%)\end{array}$ \\
\hline 37 & 163.9319 & 0.0139 & $\mathrm{H}-3 \rightarrow \mathrm{LUMO}(21 \%), \mathrm{H}-2 \rightarrow \mathrm{L}+7(40 \%), \mathrm{H}-2 \rightarrow \mathrm{L}+10(10 \%)$ \\
\hline 38 & 163.8712 & 0.2067 & $\mathrm{H}-3 \rightarrow \mathrm{LUMO}(26 \%), \mathrm{H}-3 \rightarrow \mathrm{L}+5(11 \%), \mathrm{H}-2 \rightarrow \mathrm{L}+7$ (31\%) \\
\hline 39 & 163.683 & 0.0022 & H-22 $\rightarrow$ LUMO (18\%), H-19 $\rightarrow$ LUMO (33\%) \\
\hline 40 & 162.4286 & 0.1716 & $\mathrm{H}-19 \rightarrow \mathrm{L}+1(18 \%), \mathrm{H}-17 \rightarrow \mathrm{L}+1(16 \%), \mathrm{H}-2 \rightarrow \mathrm{L}+6(13 \%)$ \\
\hline 41 & 160.1314 & 0.0754 & $\mathrm{H}-5 \rightarrow \mathrm{L}+6(73 \%)$ \\
\hline 42 & 159.898 & 0.0151 & $\mathrm{H}-13 \rightarrow \mathrm{LUMO}(22 \%)$ \\
\hline 43 & 158.1178 & 0.0009 & H-14 $\rightarrow$ LUMO (16\%), H-14 $\rightarrow \mathrm{L}+3(37 \%), \mathrm{H}-14 \rightarrow \mathrm{L}+5(19 \%)$ \\
\hline 44 & 157.7537 & 0.0061 & $\begin{array}{l}\mathrm{H}-1 \rightarrow \mathrm{L}+7(18 \%), \mathrm{HOMO} \rightarrow \mathrm{L}+10 \quad(36 \%) \\
\mathrm{H}-24 \rightarrow \mathrm{L}+1 \quad(16 \%), \quad \mathrm{H}-20 \rightarrow \mathrm{L}+1 \quad(18 \%), \quad \mathrm{H}-13 \rightarrow \mathrm{L}+1 \quad(12 \%), \quad \mathrm{H}-\end{array}$ \\
\hline 45 & 157.4532 & 0.0001 & $4 \rightarrow \mathrm{L}+1(20 \%), \mathrm{HOMO} \rightarrow \mathrm{L}+9(10 \%)$ \\
\hline 46 & 157.3792 & 0.0017 & $\mathrm{H}-22 \rightarrow \mathrm{L}+2(15 \%), \mathrm{H}-17 \rightarrow \mathrm{L}+2(35 \%), \mathrm{H}-2 \rightarrow \mathrm{L}+2(20 \%)$ \\
\hline 47 & 155.146 & 0.0011 & $\mathrm{H}-24 \rightarrow \mathrm{LUMO}(12 \%), \mathrm{H}-4 \rightarrow \mathrm{LUMO}(12 \%), \mathrm{H}-2 \rightarrow \mathrm{L}+6(27 \%)$ \\
\hline 48 & 154.5098 & 0.0254 & $\mathrm{H}-4 \rightarrow \mathrm{LUMO}(10 \%), \mathrm{H}-2 \rightarrow \mathrm{L}+6(41 \%)$ \\
\hline 49 & 154.1583 & 0.0276 & $\begin{array}{l}\mathrm{H}-14 \rightarrow \mathrm{L}+4(51 \%), \mathrm{H}-5 \rightarrow \mathrm{L}+5(10 \%) \\
\mathrm{H}-23 \rightarrow \mathrm{LUMO}(13 \%), \mathrm{H}-14 \rightarrow \mathrm{L}+4 \quad(26 \%), \mathrm{H}-5 \rightarrow \mathrm{L}+5 \quad(18 \%), \mathrm{H}-\end{array}$ \\
\hline 50 & 154.0931 & 0.0155 & $1 \rightarrow \mathrm{L}+7(14 \%)$ \\
\hline 51 & 153.4523 & 0.0097 & $\mathrm{H}-1 \rightarrow \mathrm{L}+1(10 \%), \mathrm{H}-1 \rightarrow \mathrm{L}+6(36 \%)$ \\
\hline 52 & 153.2588 & 0.0225 & $\mathrm{H}-2 \rightarrow \mathrm{L}+9(11 \%), \mathrm{HOMO} \rightarrow \mathrm{L}+8(24 \%), \mathrm{HOMO} \rightarrow \mathrm{L}+13(14 \%)$ \\
\hline 53 & 152.766 & 0.0249 & $\mathrm{H}-1 \rightarrow \mathrm{L}+7(22 \%), \mathrm{HOMO} \rightarrow \mathrm{L}+10(20 \%)$ \\
\hline 54 & 152.4841 & 0.0251 & $\mathrm{H}-6 \rightarrow \mathrm{L}+3(13 \%), \mathrm{H}-2 \rightarrow \mathrm{L}+2(26 \%)$ \\
\hline 55 & 152.3474 & 0.0303 & $\begin{array}{l}\mathrm{H}-6 \rightarrow \mathrm{L}+3(14 \%), \mathrm{H}-2 \rightarrow \mathrm{L}+2(23 \%) \\
\mathrm{H}-32 \rightarrow \text { LUMO }(10 \%), \mathrm{H}-28 \rightarrow \text { LUMO }(13 \%), \mathrm{H}-26 \rightarrow \text { LUMO }(10 \%),\end{array}$ \\
\hline 56 & 151.8975 & 0.0006 & $\mathrm{H}-2 \rightarrow \mathrm{L}+2(11 \%), \mathrm{H}-1 \rightarrow \mathrm{L}+6(10 \%)$ \\
\hline 57 & 150.9709 & 0.0076 & $\mathrm{H}-23 \rightarrow \mathrm{LUMO}(23 \%), \mathrm{H}-5 \rightarrow \mathrm{L}+5(28 \%), \mathrm{HOMO} \rightarrow \mathrm{L}+15(14 \%)$ \\
\hline 58 & 150.4086 & 0.0012 & $\mathrm{HOMO} \rightarrow \mathrm{L}+15(50 \%)$ \\
\hline 59 & 149.2714 & 0.0827 & $\mathrm{H}-23 \rightarrow \mathrm{L}+1(55 \%), \mathrm{H}-5 \rightarrow \mathrm{L}+6(10 \%)$ \\
\hline 60 & 148.92 & 0.002 & $\mathrm{H}-9 \rightarrow \mathrm{L}+3(36 \%), \mathrm{H}-8 \rightarrow \mathrm{L}+3(29 \%)$ \\
\hline 61 & 148.8842 & 0.0125 & $\mathrm{H}-9 \rightarrow \mathrm{L}+3(29 \%), \mathrm{H}-8 \rightarrow \mathrm{L}+3(36 \%)$ \\
\hline 62 & 148.6076 & 0.1466 & $\mathrm{H}-13 \rightarrow \mathrm{L}+2(39 \%), \mathrm{H}-6 \rightarrow \mathrm{L}+3(11 \%)$ \\
\hline 63 & 147.8315 & 0.1991 & $\mathrm{H}-2 \rightarrow \mathrm{L}+9(26 \%), \mathrm{HOMO} \rightarrow \mathrm{L}+8(18 \%)$ \\
\hline 64 & 145.9623 & 0.0002 & $\mathrm{H}-5 \rightarrow \mathrm{L}+2(90 \%)$ \\
\hline 65 & 145.1915 & 0.0031 & $\mathrm{H}-5 \rightarrow \mathrm{L}+7(54 \%), \mathrm{H}-1 \rightarrow \mathrm{L}+8(12 \%)$ \\
\hline 66 & 145.1099 & 0.0054 & $\mathrm{H}-2 \rightarrow \mathrm{L}+10(51 \%)$ \\
\hline 67 & 145.0946 & 0.1237 & $\mathrm{H}-5 \rightarrow \mathrm{L}+7(34 \%), \mathrm{H}-1 \rightarrow \mathrm{L}+8(17 \%)$ \\
\hline 68 & 144.1415 & 0.0001 & H-32 $\rightarrow$ LUMO (11\%), H-7 $\rightarrow$ LUMO (45\%) \\
\hline 69 & 142.2578 & 0.0142 & $\mathrm{H}-18 \rightarrow \mathrm{L}+3(16 \%), \mathrm{H}-5 \rightarrow \mathrm{L}+10(13 \%)$ \\
\hline 70 & 141.9971 & 0.0017 & $\mathrm{H}-1 \rightarrow \mathrm{L}+3(12 \%), \mathrm{H}-1 \rightarrow \mathrm{L}+5(46 \%)$ \\
\hline 71 & 141.0232 & 0.0001 & $\mathrm{H}-3 \rightarrow \mathrm{L}+7(45 \%), \mathrm{H}-3 \rightarrow \mathrm{L}+10(10 \%), \mathrm{H}-3 \rightarrow \mathrm{L}+15(16 \%)$ \\
\hline
\end{tabular}




\begin{tabular}{|c|c|c|c|}
\hline 72 & 140.9574 & 0.0023 & $\mathrm{H}-30 \rightarrow \mathrm{L}+4(11 \%), \mathrm{H}-23 \rightarrow \mathrm{L}+4(14 \%), \mathrm{H}-5 \rightarrow \mathrm{L}+4(39 \%)$ \\
\hline 73 & 140.7143 & 0.0014 & $\mathrm{H}-1 \rightarrow \mathrm{L}+7(17 \%), \mathrm{H}-1 \rightarrow \mathrm{L}+12(28 \%)$ \\
\hline 74 & 140.5962 & 0.0308 & \\
\hline 75 & 140.3352 & 0.0003 & $\mathrm{H}-5 \rightarrow \mathrm{L}+4(12 \%), \mathrm{H}-2 \rightarrow \mathrm{L}+8(21 \%), \mathrm{H}-2 \rightarrow \mathrm{L}+13(23 \%)$ \\
\hline 76 & 140.2352 & 0.0168 & $\mathrm{H}-9 \rightarrow \mathrm{L}+6(39 \%), \mathrm{H}-8 \rightarrow \mathrm{L}+6(46 \%)$ \\
\hline 77 & 140.2193 & 0.0158 & $\begin{array}{l}\mathrm{H}-9 \rightarrow \mathrm{L}+6(47 \%), \mathrm{H}-8 \rightarrow \mathrm{L}+6(39 \%) \\
\mathrm{H}-27 \rightarrow \mathrm{L}+1 \quad(11 \%), \quad \mathrm{H}-24 \rightarrow \mathrm{L}+1 \quad(13 \%), \quad \mathrm{H}-13 \rightarrow \mathrm{L}+1 \quad(14 \%), \quad \mathrm{H}-\end{array}$ \\
\hline 78 & 139.8335 & 0.0008 & $1 \rightarrow \mathrm{L}+6(15 \%)$ \\
\hline 79 & 139.709 & 0.005 & $\mathrm{H}-3 \rightarrow \mathrm{L}+3(23 \%), \mathrm{H}-3 \rightarrow \mathrm{L}+5(35 \%)$ \\
\hline 80 & 139.2539 & 0.0112 & $\mathrm{H}-4 \rightarrow \mathrm{L}+19(11 \%), \mathrm{HOMO} \rightarrow \mathrm{L}+19(53 \%)$ \\
\hline 81 & 138.5769 & 0.1068 & $\mathrm{H}-18 \rightarrow \mathrm{L}+4(29 \%), \mathrm{H}-1 \rightarrow \mathrm{L}+4(23 \%)$ \\
\hline 82 & 138.4809 & 0.0117 & $\mathrm{H}-1 \rightarrow \mathrm{L}+8(19 \%), \mathrm{HOMO} \rightarrow \mathrm{L}+8(17 \%)$ \\
\hline 83 & 138.2185 & 0.0026 & $\mathrm{H}-28 \rightarrow \mathrm{L}+2(15 \%), \mathrm{H}-26 \rightarrow \mathrm{L}+2(11 \%), \mathrm{H}-19 \rightarrow \mathrm{L}+2(22 \%)$ \\
\hline 84 & 137.911 & 0.0008 & $\mathrm{H}-23 \rightarrow \mathrm{L}+3(13 \%)$ \\
\hline 85 & 137.8159 & 0.0239 & $\mathrm{H}-4 \rightarrow \mathrm{L}+5(24 \%), \mathrm{H}-1 \rightarrow \mathrm{L}+4(15 \%)$ \\
\hline 86 & 136.9966 & 0.0009 & $\mathrm{H}-6 \rightarrow \mathrm{L}+7(41 \%), \mathrm{H}-6 \rightarrow \mathrm{L}+10(18 \%), \mathrm{H}-6 \rightarrow \mathrm{L}+12(16 \%)$ \\
\hline 87 & 136.547 & 0.0024 & $\mathrm{H}-3 \rightarrow \mathrm{L}+2(77 \%), \mathrm{H}-3 \rightarrow \mathrm{L}+3(14 \%)$ \\
\hline 88 & 136.0182 & 0.0708 & $\mathrm{H}-18 \rightarrow \mathrm{L}+4(26 \%), \mathrm{H}-1 \rightarrow \mathrm{L}+4(44 \%)$ \\
\hline 89 & 135.7472 & 0 & $\mathrm{H}-7 \rightarrow \mathrm{LUMO}(28 \%)$ \\
\hline 90 & 135.3574 & 0.0032 & $\begin{array}{l}\mathrm{H}-30 \rightarrow \mathrm{L}+4 \quad(22 \%), \quad \mathrm{H}-25 \rightarrow \mathrm{L}+4 \quad(15 \%), \quad \mathrm{H}-23 \rightarrow \mathrm{L}+4 \quad(18 \%), \mathrm{H}- \\
5 \rightarrow \mathrm{L}+4(28 \%)\end{array}$ \\
\hline 91 & 135.0802 & 0.1048 & H-16 $\rightarrow$ LUMO (18\%), H-11 $\rightarrow$ LUMO (17\%) \\
\hline 92 & 134.9831 & 0.0011 & $\mathrm{H}-5 \rightarrow \mathrm{L}+9(87 \%)$ \\
\hline 93 & 134.7718 & 0.0261 & $\mathrm{H}-4 \rightarrow \mathrm{L}+7(52 \%)$ \\
\hline 94 & 134.5846 & 0.0017 & $\mathrm{H}-9 \rightarrow \mathrm{L}+10(34 \%), \mathrm{H}-8 \rightarrow \mathrm{L}+10(26 \%)$ \\
\hline 95 & 134.3964 & 0.0012 & $\mathrm{H}-9 \rightarrow \mathrm{L}+10(27 \%), \mathrm{H}-8 \rightarrow \mathrm{L}+10(35 \%)$ \\
\hline 96 & 134.2232 & 0.0155 & $\mathrm{H}-4 \rightarrow \mathrm{L}+2(52 \%)$ \\
\hline 97 & 134.1796 & 0.0016 & $\mathrm{H}-25 \rightarrow \mathrm{L}+3(17 \%)$ \\
\hline 98 & 133.0565 & 0.0006 & $\mathrm{H}-19 \rightarrow \mathrm{L}+3(11 \%), \mathrm{H}-17 \rightarrow \mathrm{L}+3(10 \%), \mathrm{H}-4 \rightarrow \mathrm{L}+6(14 \%)$ \\
\hline 99 & 132.9965 & 0.0063 & $\mathrm{H}-1 \rightarrow \mathrm{L}+18(12 \%)$ \\
\hline 100 & 132.7317 & 0.0249 & $\mathrm{H}-1 \rightarrow \mathrm{L}+16(12 \%), \mathrm{H}-1 \rightarrow \mathrm{L}+18(19 \%)$ \\
\hline
\end{tabular}




\section{Photophysics}

Table S4: Absorption maxima of the gold complexes

\begin{tabular}{cccc}
\hline Sample & $\begin{array}{c}\lambda_{\mathrm{Abs}}\left(\mathrm{CH}_{2} \mathrm{Cl}_{2}\right) \\
298 \mathrm{~K}(\mathrm{~nm})\end{array}$ & $\begin{array}{c}\lambda_{\text {Abs }}(2-\mathrm{MeTHF}) \\
77 \mathrm{~K}(\mathrm{~nm})\end{array}$ & $\begin{array}{c}\lambda_{\text {Abs }}(\text { solid state }) \\
298 \mathrm{~K}(\mathrm{~nm})\end{array}$ \\
\hline $\mathbf{C}_{\mathbf{1}} \mathbf{N}_{\mathbf{9}}$ & 285 & 294 & 286 \\
$\mathbf{C}_{\mathbf{6}} \mathbf{N}_{\mathbf{1 5}}$ & 281 & 290 & 298 \\
$\mathbf{C}_{\mathbf{9}} \mathbf{N}_{\mathbf{1 5}}$ & 286 & 290 & 297 \\
$\mathbf{C}_{\mathbf{1 2}} \mathbf{N}_{\mathbf{1 5}}$ & 286 & 286 & 297 \\
$\mathbf{C}_{\mathbf{1 5}} \mathbf{N}_{\mathbf{9}}$ & 286 & 288 & 298 \\
\hline
\end{tabular}

\section{Solution 298K}
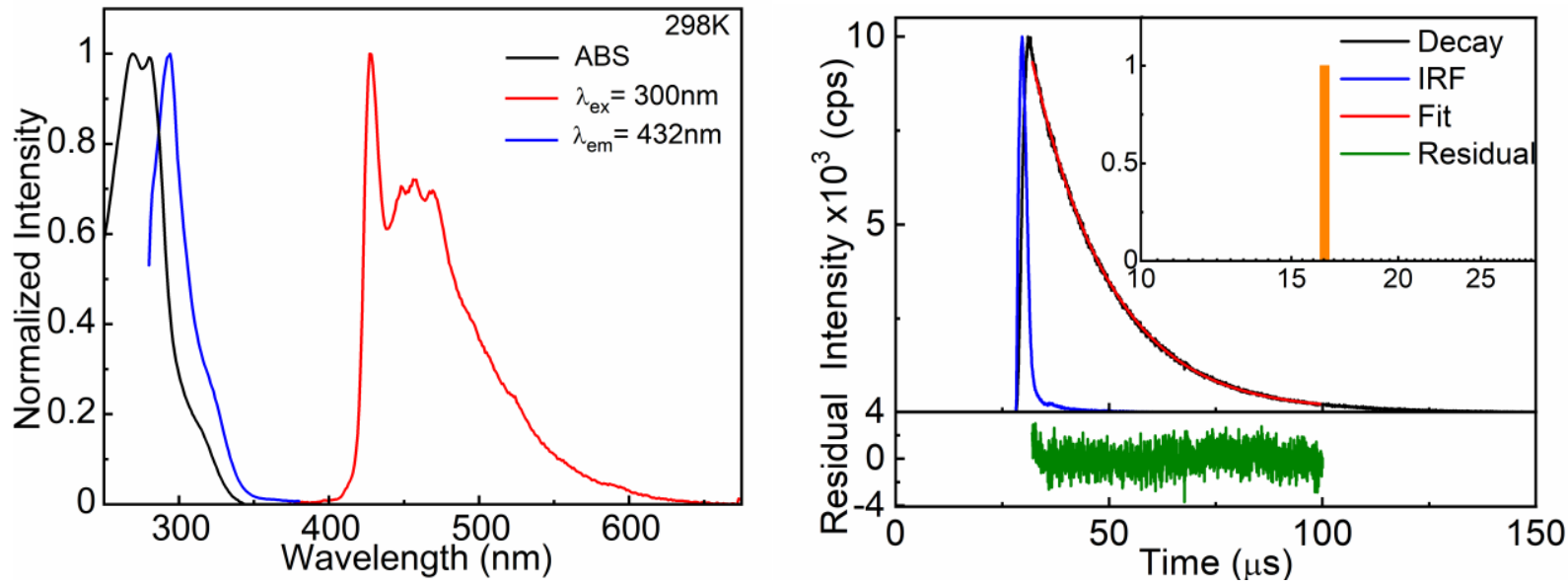

Figure S57: $\mathbf{C}_{\mathbf{1}} \mathbf{N}_{9}$ in $\mathrm{CH}_{2} \mathrm{Cl}_{2}$ at 298K. Left, excitation (blue), absorption (black) and emission (red) spectra. Right, emission decay (black), IRF (blue), residuals (green) and best fit (red). Multiexponential analysis yields $\tau \mathrm{e}=16.4 \mu \mathrm{s}(100 \%), \chi 2=1.040$.
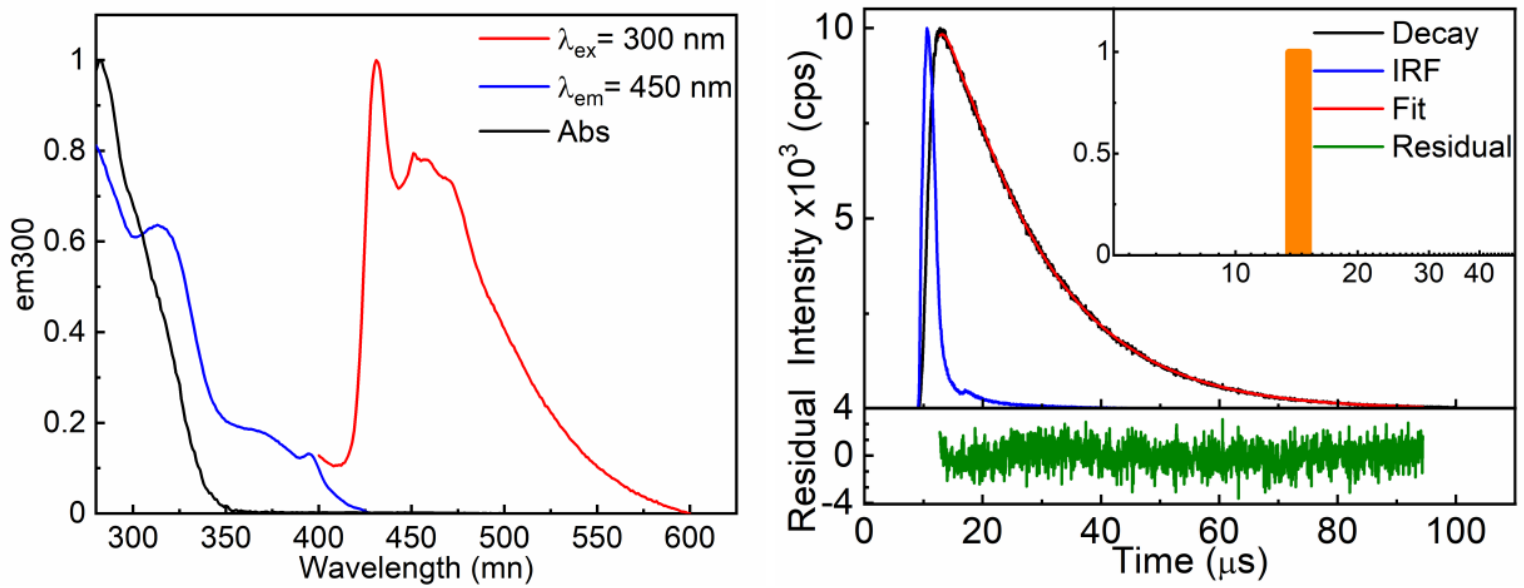
Figure S58: $\mathbf{C}_{6} \mathbf{N}_{15}$ in $\mathrm{CH}_{2} \mathrm{Cl}_{2}$ at 298K. Left, excitation (blue), absorption (black) and emission (red) spectra. Right, emission decay (black), IRF (blue), residuals (green) and best fit (red). Multiexponential analysis yields $\tau_{\mathrm{e}}=14.3 \mu \mathrm{s}(100 \%), \chi^{2}=1.00$.
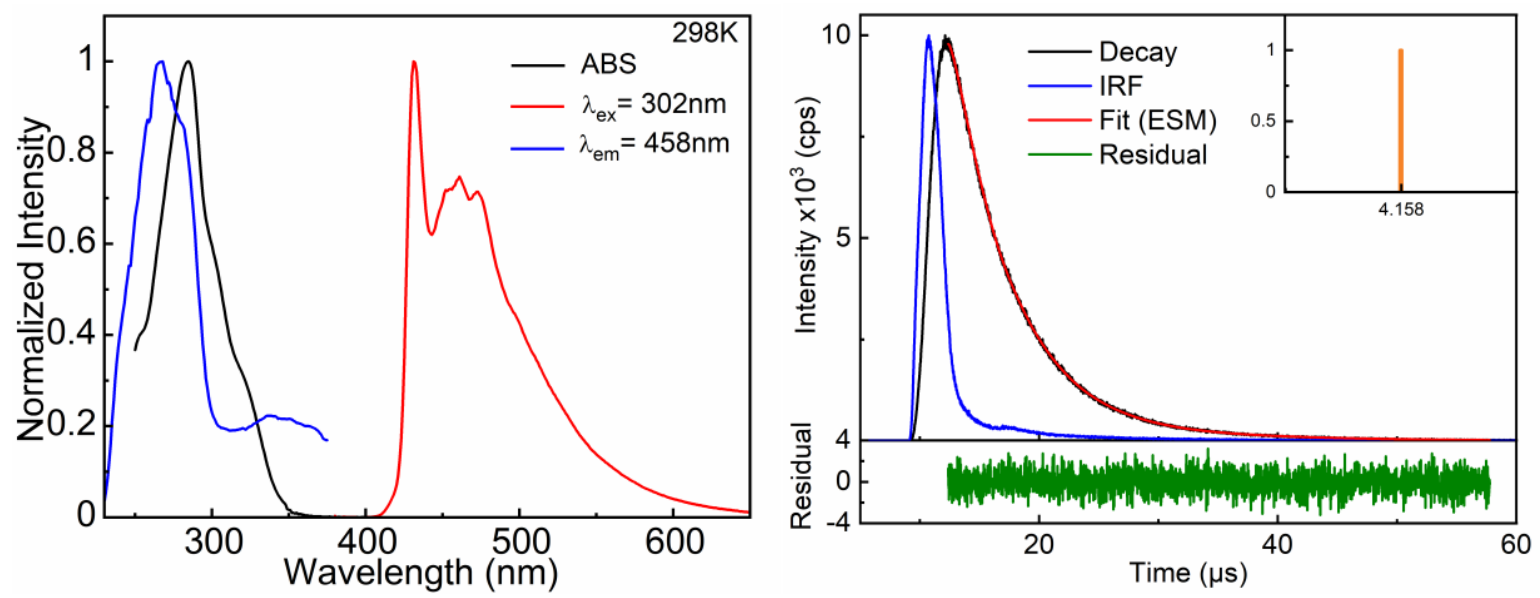

Figure S59: $\mathbf{C}_{9} \mathbf{N}_{15}$ in $\mathrm{CH}_{2} \mathrm{Cl}_{2}$ at 298K. Left, excitation (blue), absorption (black) and emission (red) spectra. Right, emission decay (black), IRF (blue), residuals (green) and best fit (red). Exponential smoothing model $(\mathrm{ESM})$ yields $\tau_{\mathrm{e}}=4.2 \mu \mathrm{s}(100 \%), \chi^{2}=1.10$.
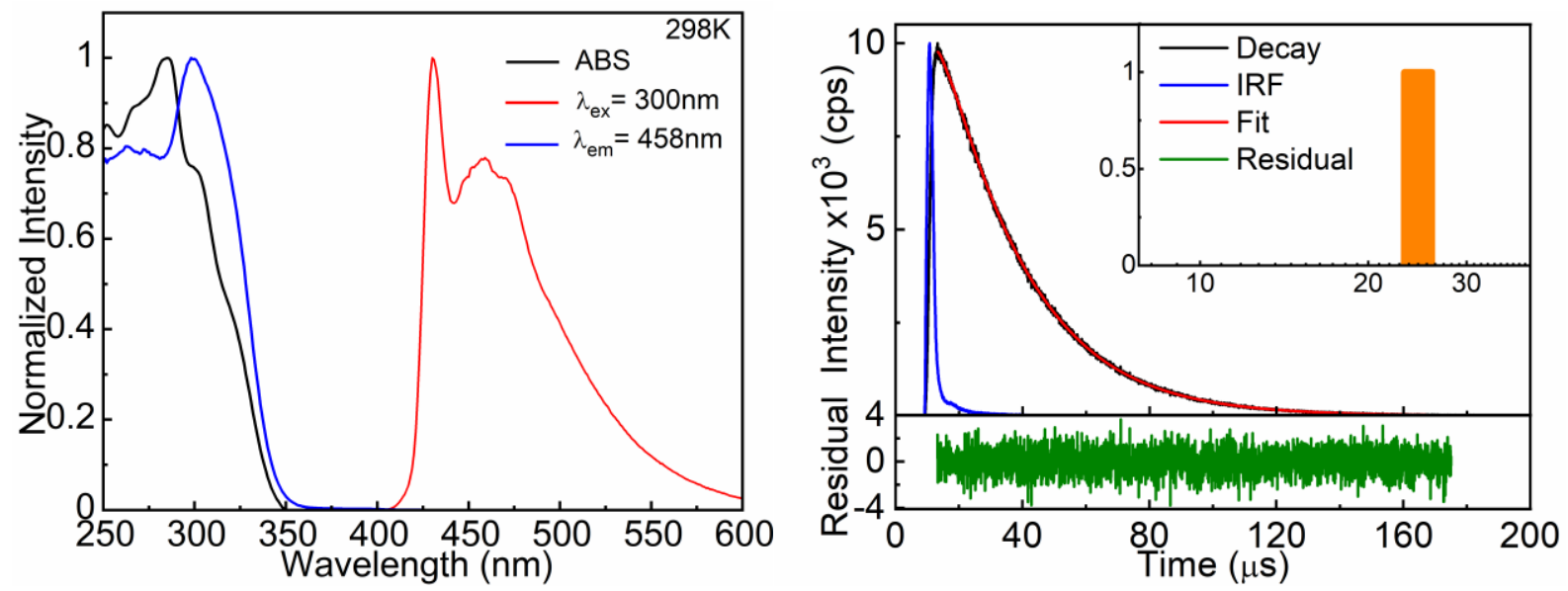

Figure S60: $\mathbf{C}_{12} \mathbf{N}_{15}$ in $\mathrm{CH}_{2} \mathrm{Cl}_{2}$ at $298 \mathrm{~K}$. Left, excitation (blue), absorption (black) and emission (red) spectra. Right, emission decay (black), IRF (blue), residuals (green) and best fit (red). Exponential smoothing model $(\mathrm{ESM})$ yields $\tau_{\mathrm{e}}=24.6 \mu \mathrm{s}(100 \%), \chi^{2}=1.00$. 

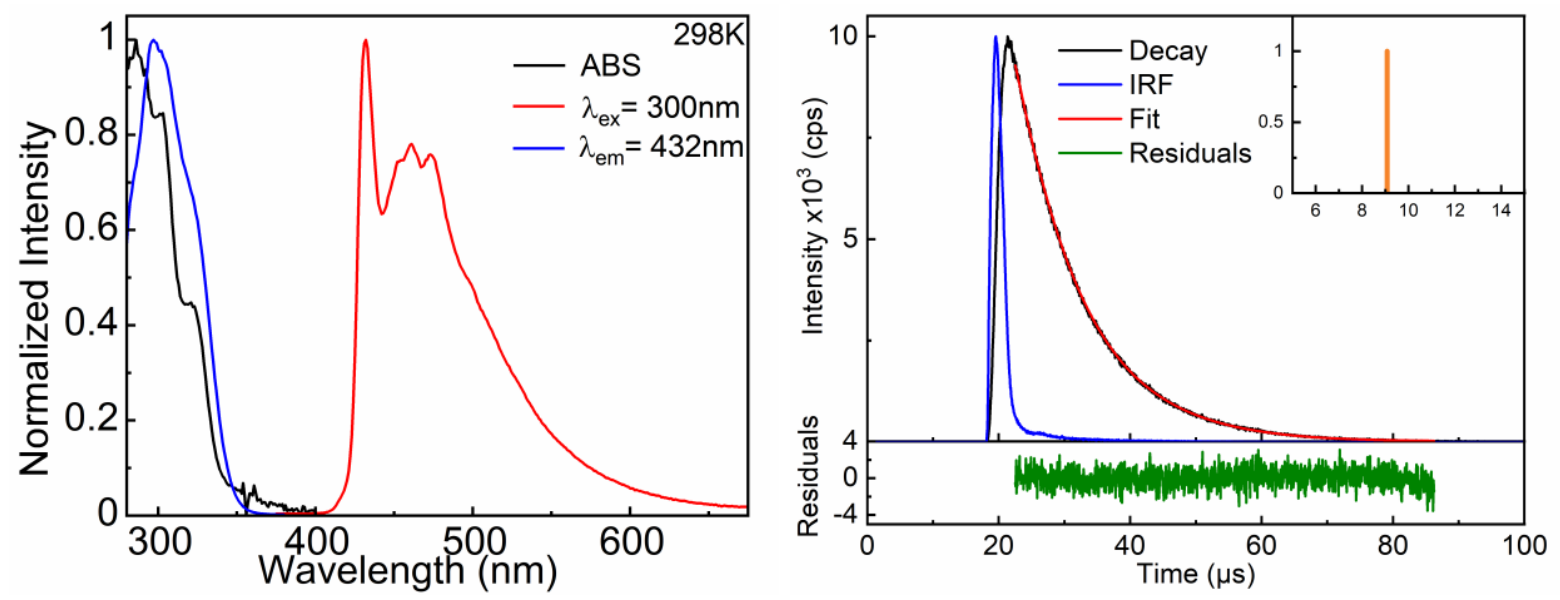

Figure S61: $\mathbf{C}_{15} \mathbf{N}_{9}$ in $\mathrm{CH}_{2} \mathrm{Cl}_{2}$ at 298K. Left, excitation (blue), absorption (black) and emission (red) spectra. Right, emission decay (black), IRF (blue), residuals (green) and best fit (red). Exponential smoothing model $(\mathrm{ESM})$ yields $\tau_{\mathrm{e}}=9.1 \mu \mathrm{s}(100 \%), \chi^{2}=1.02$.

\section{Solution 77K}
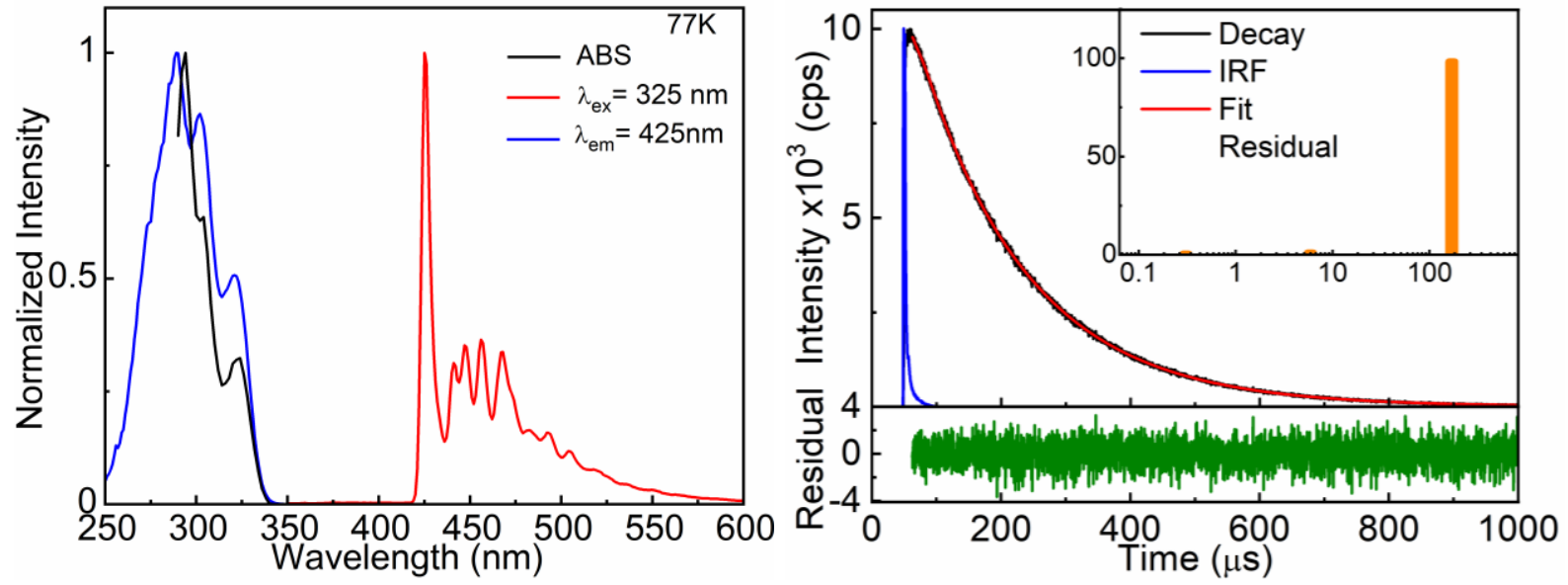

Figure S62: $\mathbf{C}_{\mathbf{1}} \mathbf{N}_{\mathbf{9}}$ in 2-MeTHF at $77 \mathrm{~K}$. Left, excitation (blue), absorption (black) and emission (red) spectra. Right, emission decay (black), IRF (blue), residuals (green) and best fit (red). Multiexponential analysis yields $\tau_{\mathrm{e}}=0.3 \mu \mathrm{s}(0.6 \%), 5.9 \mu \mathrm{s}(1.1 \%)$ and $170 \mu \mathrm{s}(98.3 \%), \chi^{2}=1.06$. 

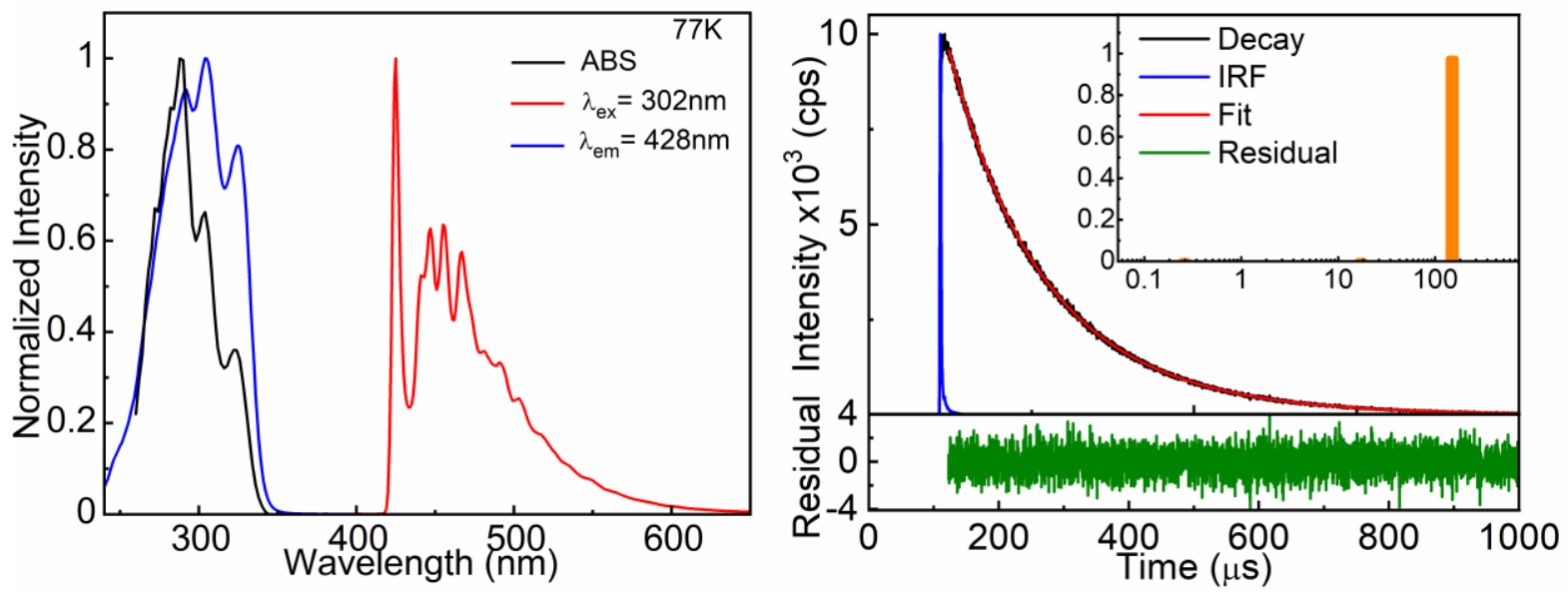

Figure S63: $\mathbf{C}_{\mathbf{6}} \mathbf{N}_{\mathbf{1 5}}$ in 2-MeTHF at 77K. Left, excitation (blue), absorption (black) and emission (red) spectra. Right, emission decay (black), IRF (blue), residuals (green) and best fit (red). Multiexponential analysis yields $\tau_{\mathrm{e}}=0.3 \mu \mathrm{s}(1.1 \%), 17.2 \mu \mathrm{s}(1.3 \%)$ and $150 \mu \mathrm{s}(97.6 \%), \chi^{2}=1.10$.
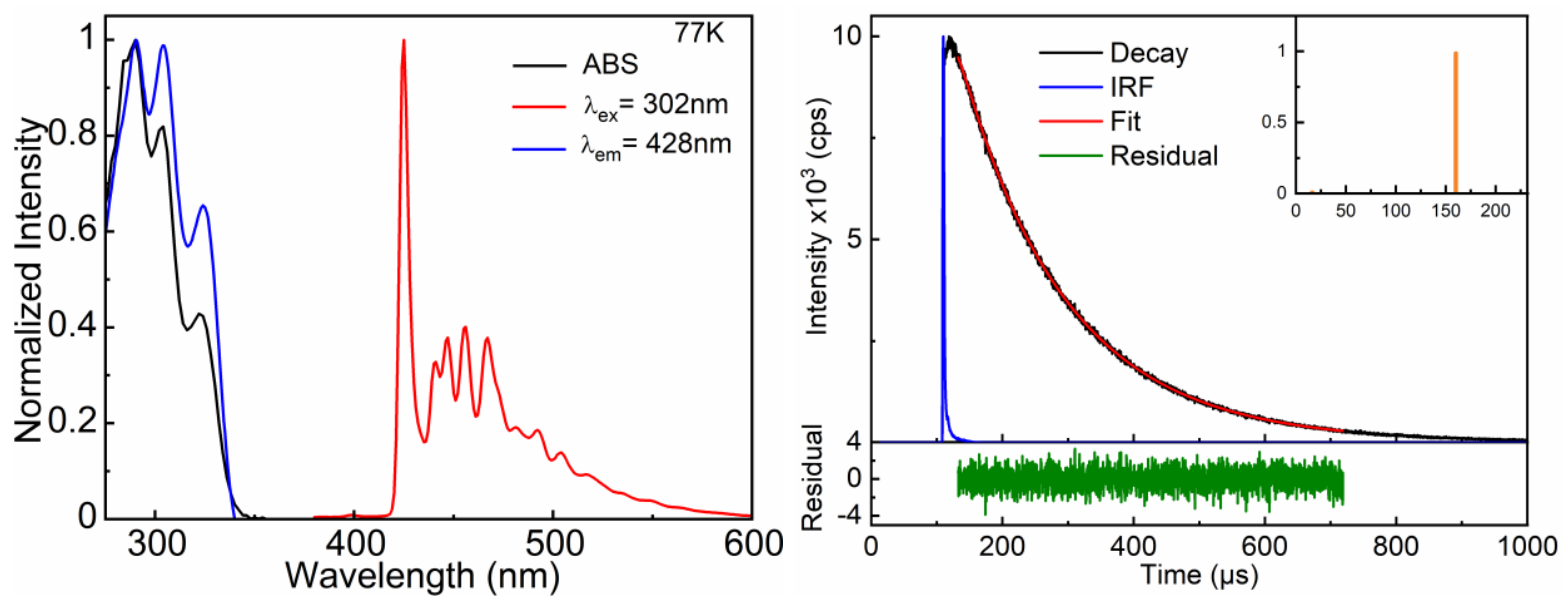

Figure S64: $\mathbf{C}_{9} \mathbf{N}_{15}$ in 2-MeTHF at 77K. Left, excitation (blue), absorption (black) and emission (red) spectra. Right, emission decay (black), IRF (blue), residuals (green) and best fit (red). Multiexponential analysis yields $\tau_{\mathrm{e}}=0.3 \mu \mathrm{s}(2.0 \%), 6.1 \mu \mathrm{s}(0.6 \%)$ and $160 \mu \mathrm{s}(97.4 \%), \chi^{2}=1.09$. 

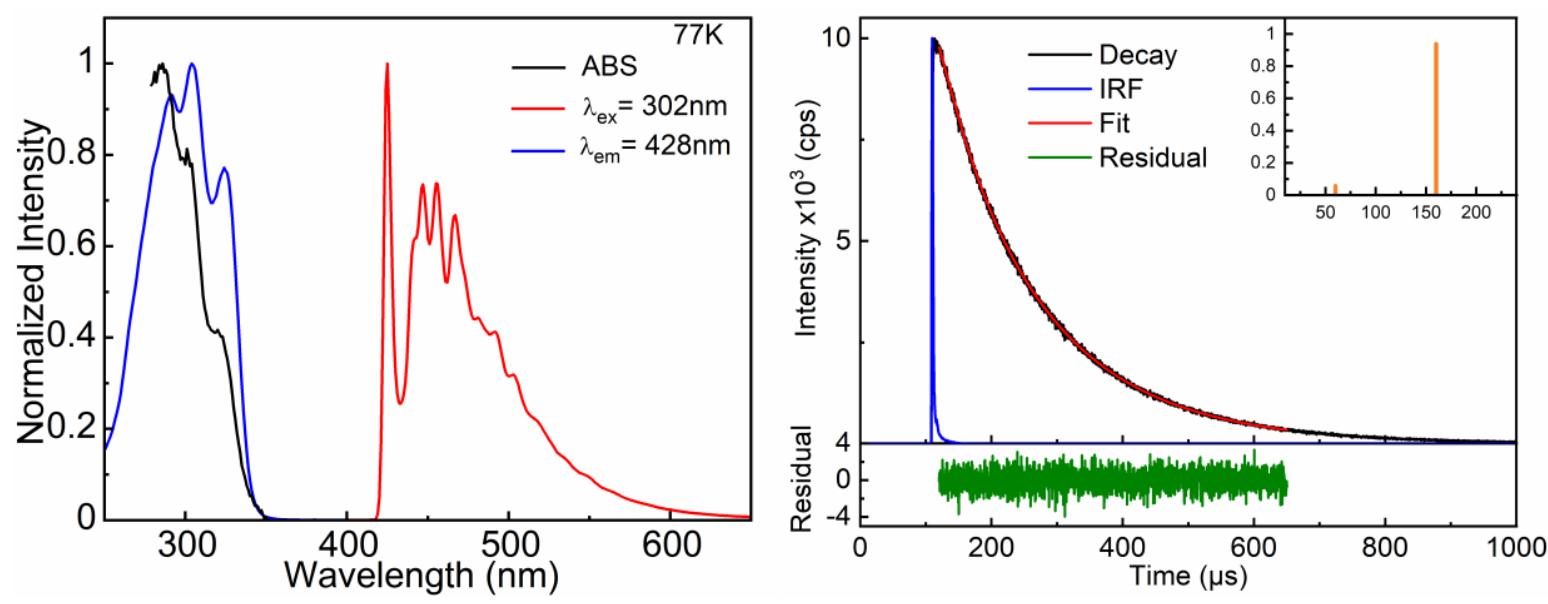

Figure S65: $\mathbf{C}_{12} \mathbf{N}_{15}$ in 2-MeTHF at 77K. Left, excitation (blue), absorption (black) and emission (red) spectra. Right, emission decay (black), IRF (blue), residuals (green) and best fit (red). Multiexponential analysis yields $\tau_{\mathrm{e}}=0.3 \mu \mathrm{s}(2.1 \%), 14.1 \mu \mathrm{s}(0.6 \%), 67.4 \mu \mathrm{s}(5.2 \%)$ and $160 \mu \mathrm{s}(92.1 \%)$, $\chi^{2}=1.10$.
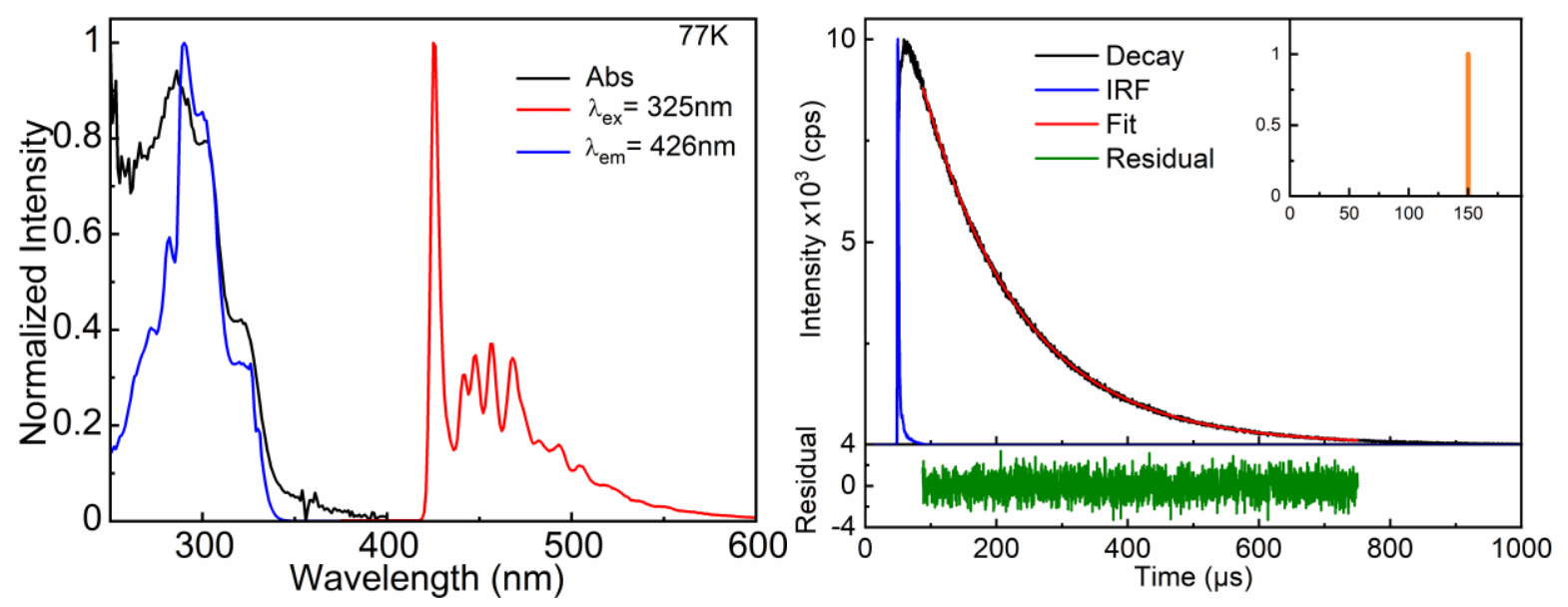

Figure S66: $\mathbf{C}_{15} \mathbf{N}_{9}$ in 2-MeTHF at $77 \mathrm{~K}$. Left, excitation (blue), absorption (black) and emission (red) spectra. Right, emission decay (black), IRF (blue), residuals (green) and best fit (red). Multiexponential analysis yields $\tau_{\mathrm{e}}=150 \mu \mathrm{s}(100 \%), \chi^{2}=1.00$. 


\section{Solid state 298K}

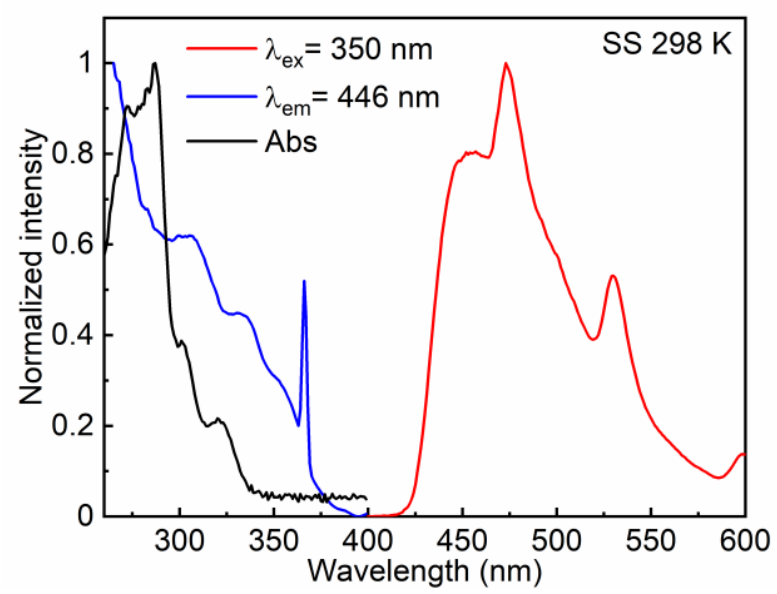

Figure S67: $\mathbf{C}_{\mathbf{1}} \mathbf{N}_{\mathbf{9}}$ in the solid state at 298K. Excitation (blue), absorption (black) and emission (red) spectra. The sharper peaks at 370 (blue), 475 (red) and 530 (red) nm are instrumental artifacts.

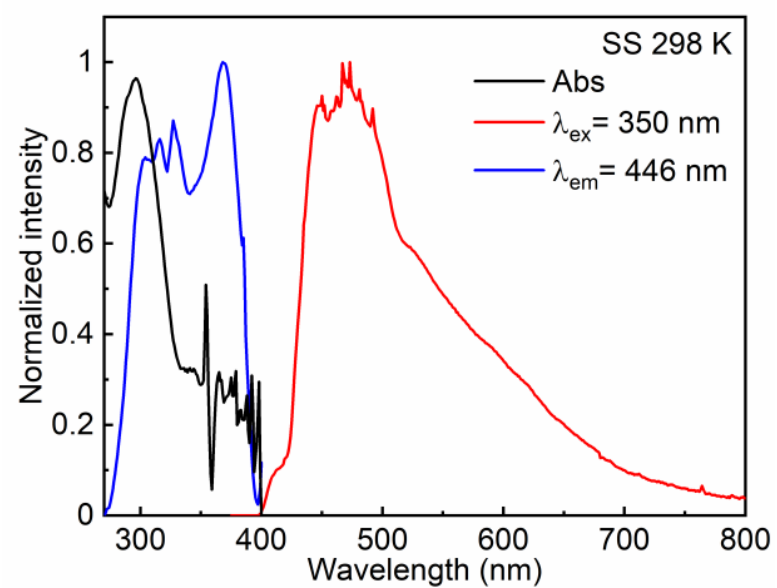

Figure S68: $\mathbf{C}_{6} \mathbf{N}_{15}$ in the solid state at $298 \mathrm{~K}$. Excitation (blue), absorption (black) and emission (red) spectra. 


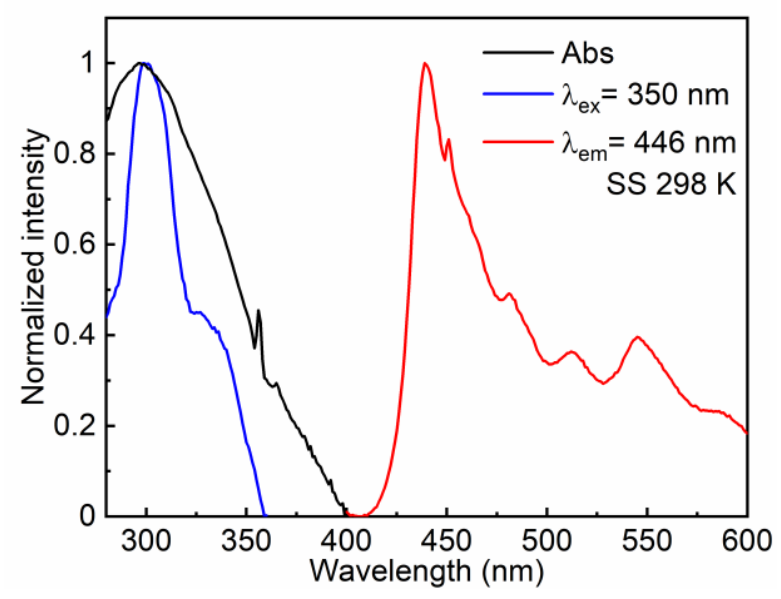

Figure S69: $\mathbf{C}_{9} \mathbf{N}_{15}$ in the solid state at $298 \mathrm{~K}$. Excitation (blue), absorption (black) and emission (red) spectra.

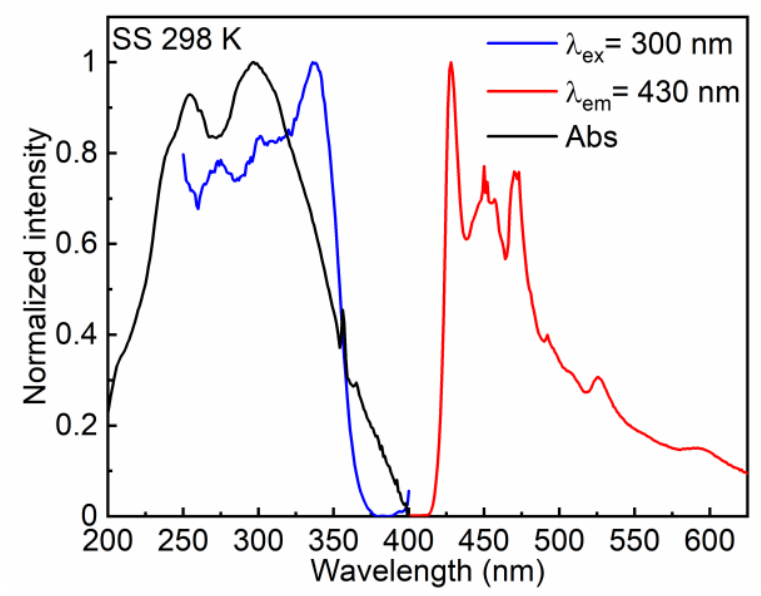

Figure S70: $\mathbf{C}_{12} \mathbf{N}_{15}$ in the solid state at $298 \mathrm{~K}$. Excitation (blue), absorption (black) and emission (red) spectra. 


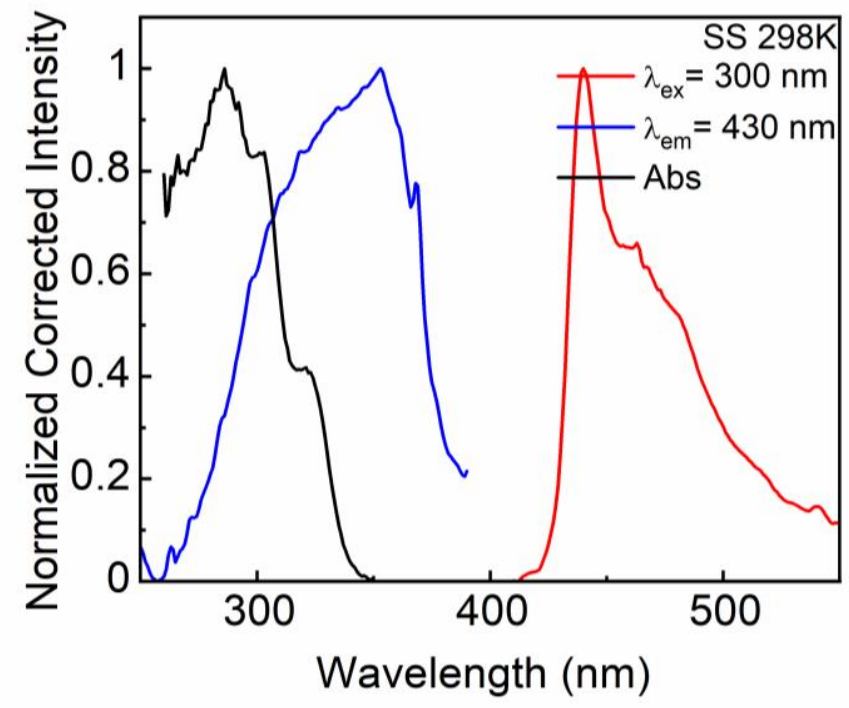

Figure S71: $\mathbf{C}_{15} \mathbf{N}_{\mathbf{9}}$ in the solid state at 298K. Excitation (blue), absorption (black) and emission (red) spectra.

\section{Solid state $77 \mathrm{~K}$}
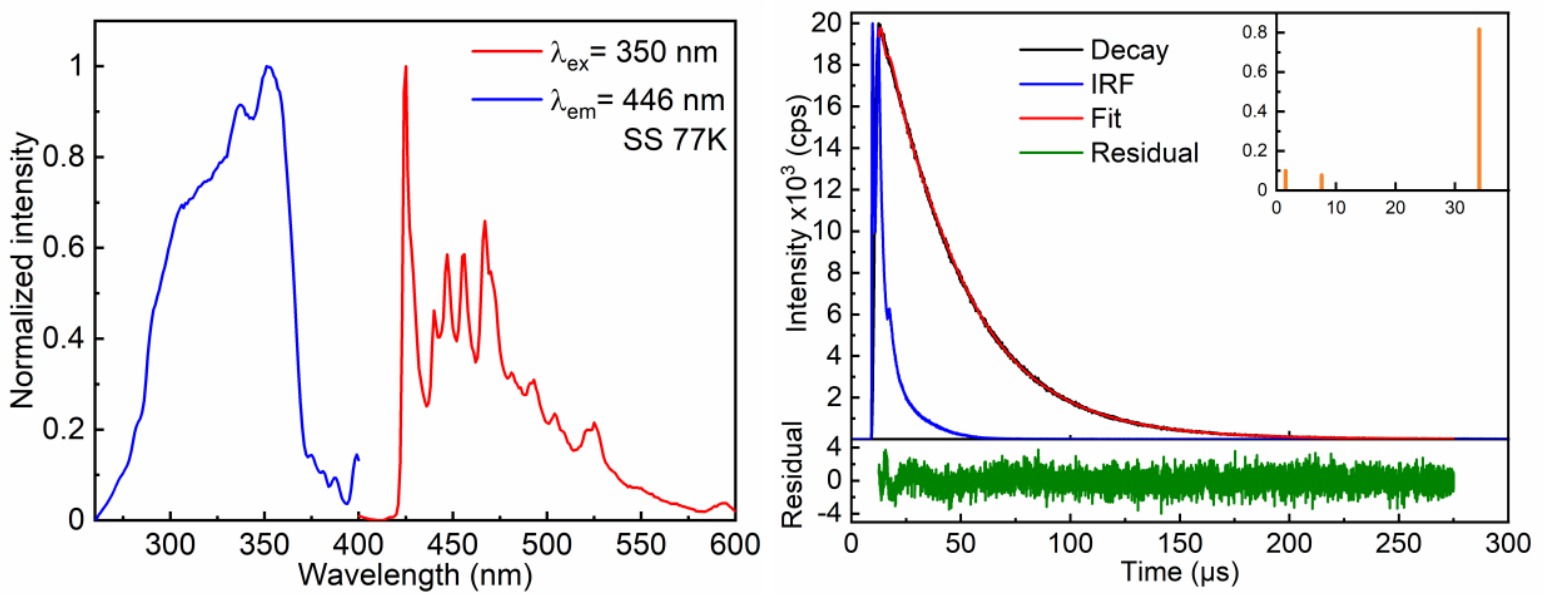

Figure S72: $\mathbf{C}_{\mathbf{1}} \mathbf{N}_{\mathbf{9}}$ in the solid state at $77 \mathrm{~K}$. Left, excitation (blue) and emission (red) spectra. Right, emission decay (black), IRF (blue), residuals (green) and best fit (red). Multi-exponential analysis yields $\tau_{\mathrm{P}}=1.52 \mu \mathrm{s}(10.18 \%), 7.56 \mu \mathrm{s}(7.99 \%), 34.07 \mu \mathrm{s}(81.83 \%), \chi^{2}=1.07$. Inset, Multiexponential analysis. $\lambda_{\mathrm{ex}}=300 \mathrm{~nm}, \lambda_{\mathrm{em}}=425 \mathrm{~nm}$. 

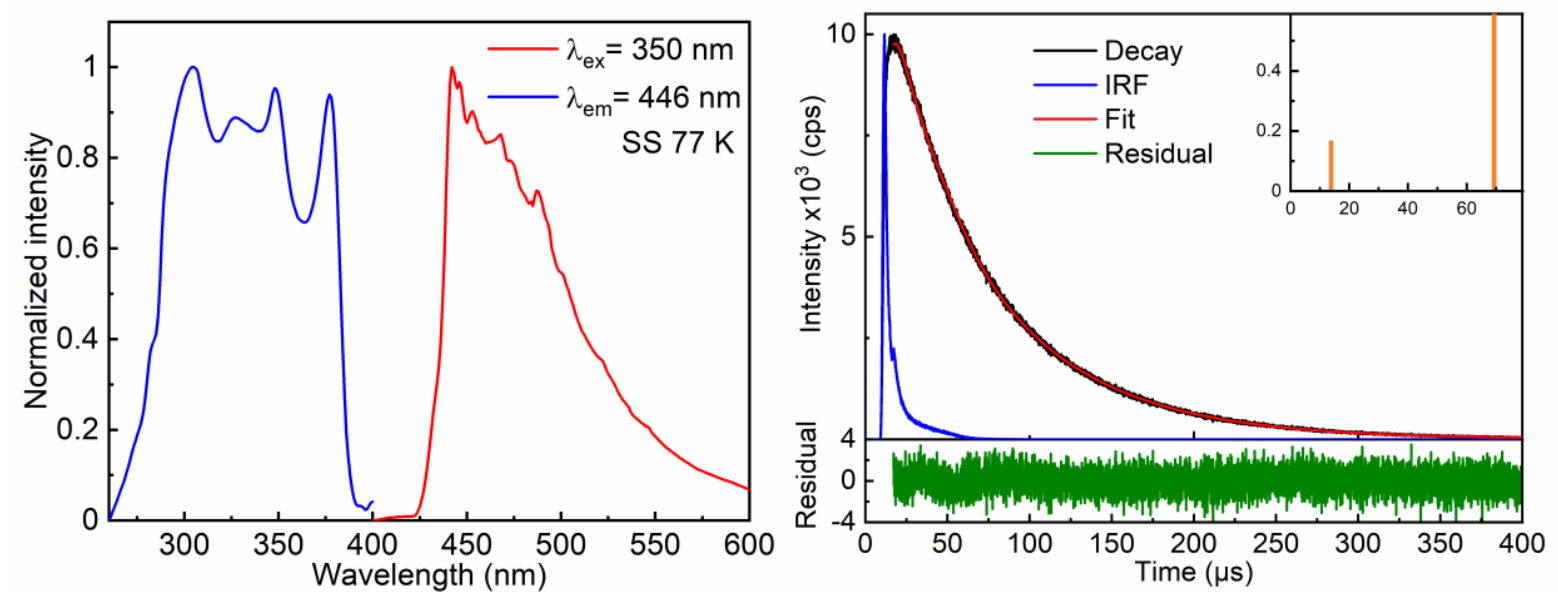

Figure S73: $\mathbf{C}_{6} \mathbf{N}_{15}$ in the solid state at $77 \mathrm{~K}$. Left, excitation (blue) and emission (red) spectra. Right, emission decay (black), IRF (blue), residuals (green) and best fit (red). Multi-exponential analysis yields $\tau_{\mathrm{P}}=13.78 \mu \mathrm{s}(16.42 \%), 69.34 \mu \mathrm{s}(83.58 \%), \chi^{2}=1.06$. Inset, Multi-exponential analysis. $\lambda_{\mathrm{ex}}=350 \mathrm{~nm}, \lambda_{\mathrm{em}}=442 \mathrm{~nm}$.
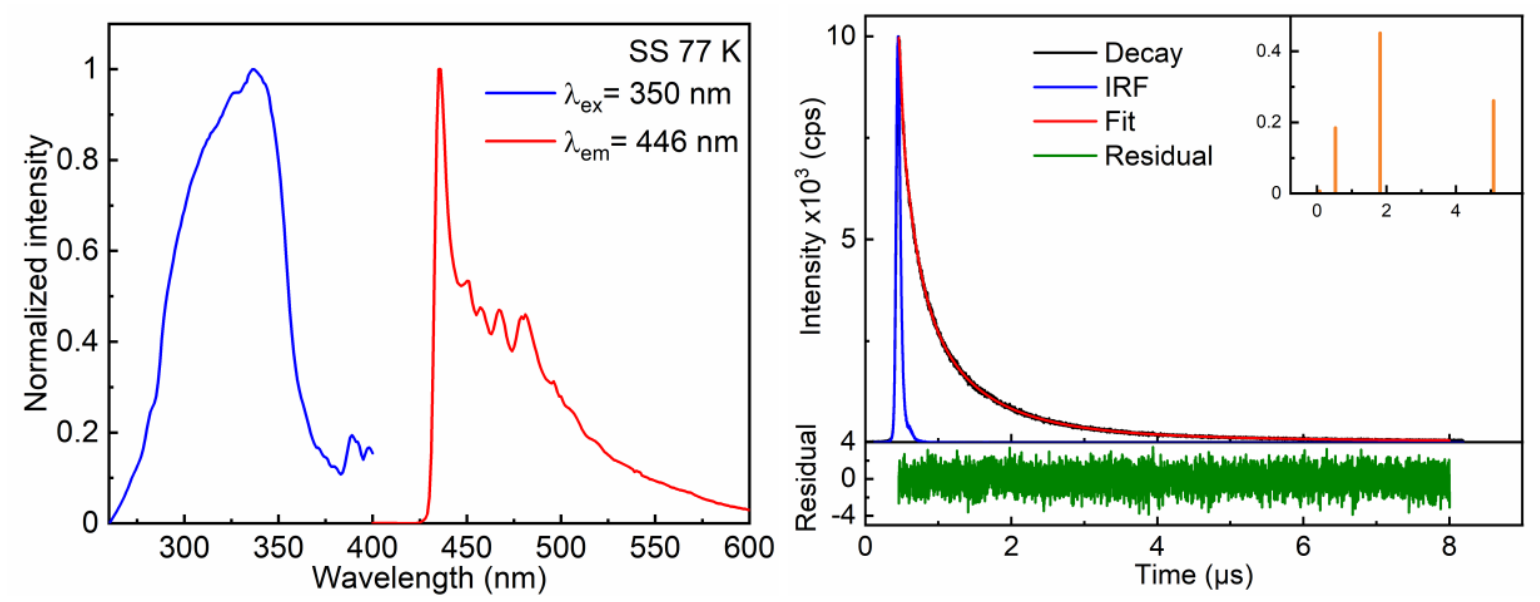

Figure S74: $\mathbf{C}_{9} \mathbf{N}_{15}$ in the solid state at $77 \mathrm{~K}$. Left, excitation (blue) and emission (red) spectra. Right, emission decay (black), IRF (blue), residuals (green) and best fit (red). Multi-exponential analysis yields $\tau_{\mathrm{p}}=5.08 \mathrm{~ns}(26.13 \%), 1.81 \mathrm{~ns}(48.23 \%), 0.52 \mathrm{~ns}(18.51 \%), 0.07 \mathrm{~ns}(7.14 \%), \chi^{2}=$ 1.03. Inset, Multi-exponential analysis. $\lambda_{\mathrm{ex}}=300 \mathrm{~nm}, \lambda_{\mathrm{em}}=425 \mathrm{~nm}$. 

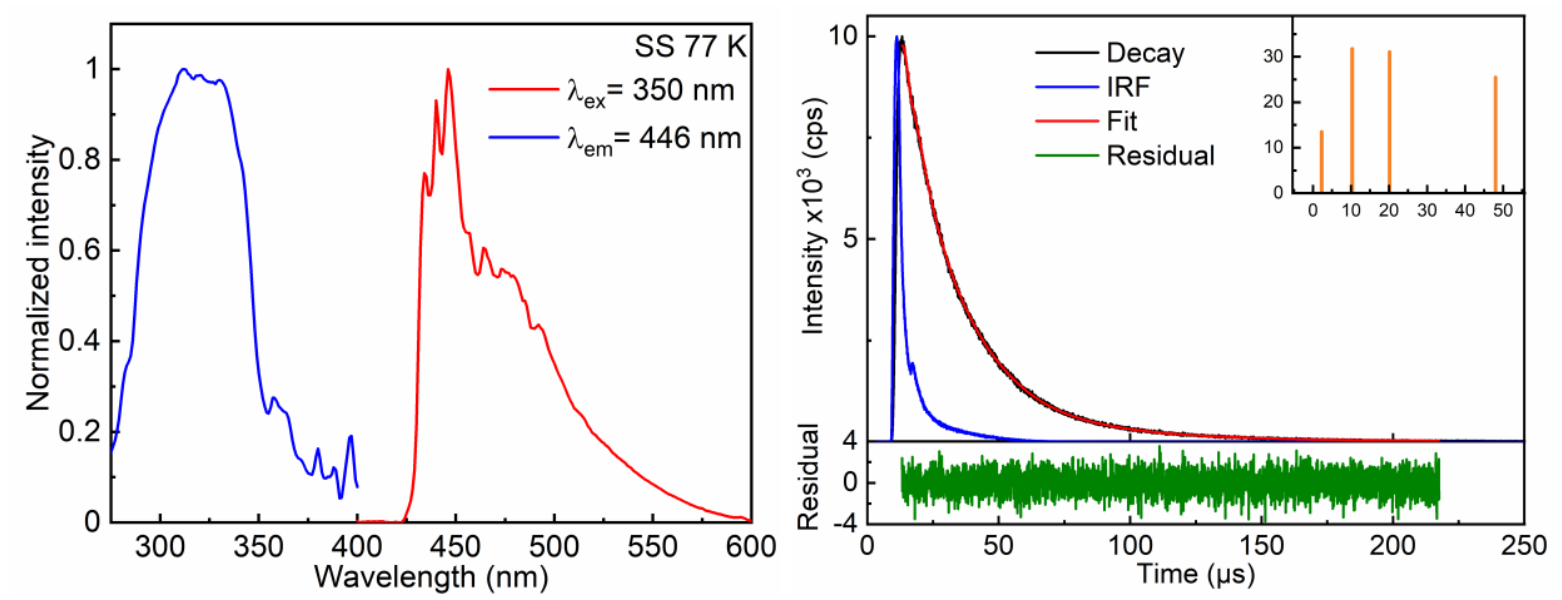

Figure S75: $\mathbf{C}_{12} \mathbf{N}_{15}$ in the solid state at $77 \mathrm{~K}$. Left, excitation (blue) and emission (red) spectra. Right, emission decay (black), IRF (blue), residuals (green) and best fit (red). Multi-exponential analysis yields $\tau_{\mathrm{P}}=2.23 \mu \mathrm{s}$ (13.53\%), $10.27 \mu \mathrm{s}(31.80 \%), 20.10 \mu \mathrm{s}$ (31.13\%), $48.00 \mu \mathrm{s}$ (23.54\%), $\chi^{2}=1.00$. Inset, Multi-exponential analysis. $\lambda_{\mathrm{ex}}=350 \mathrm{~nm}, \lambda_{\mathrm{em}}=434 \mathrm{~nm}$.
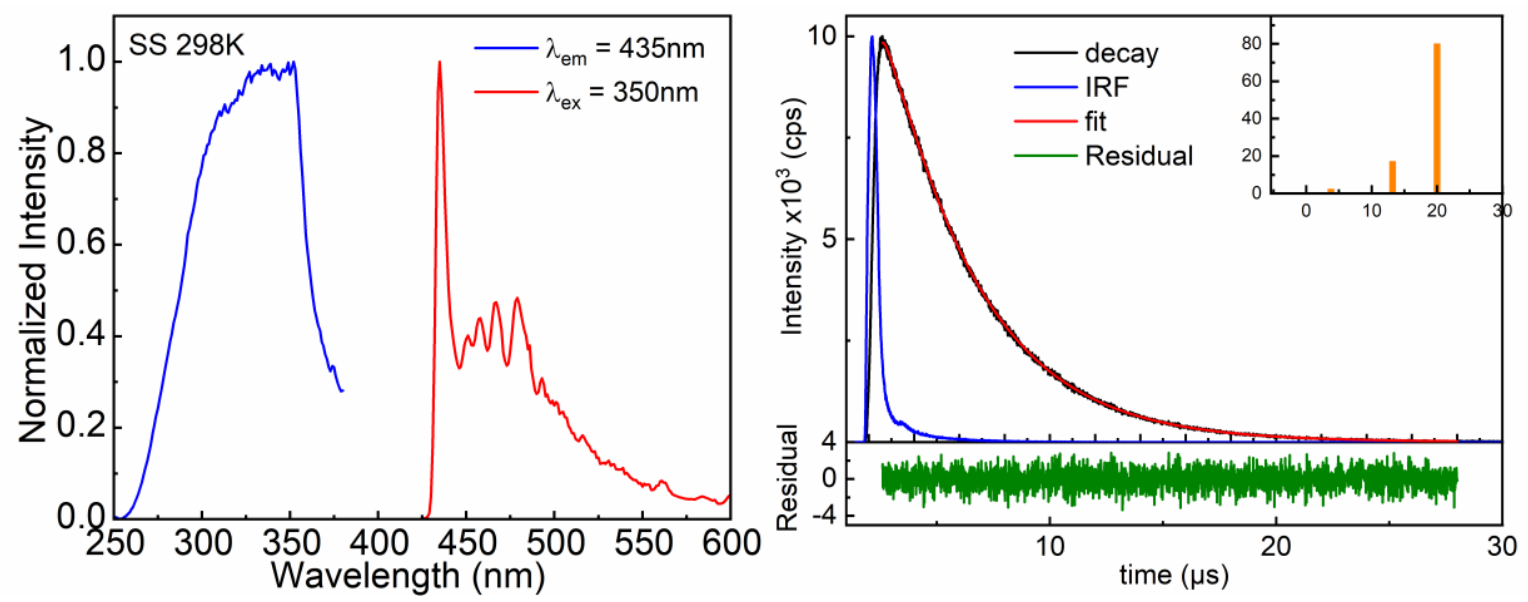

Figure S76: $\mathbf{C}_{15} \mathbf{N}_{9}$ in the solid state at $77 \mathrm{~K}$. Excitation (blue), absorption (black) and emission (red) spectra. Multi-exponential analysis yields $\tau_{\mathrm{p}}=19.98 \mu \mathrm{s}(80.15 \%), 13.19 \mu \mathrm{s}(17.32 \%), 3.76 \mu \mathrm{s}$ $(2.52 \%), \chi^{2}=1.01$. Inset, Multi-exponential analysis. $\lambda_{\mathrm{ex}}=300 \mathrm{~nm}, \lambda_{\mathrm{em}}=425 \mathrm{~nm}$. 


\section{Transient Absorption Spectroscopy}
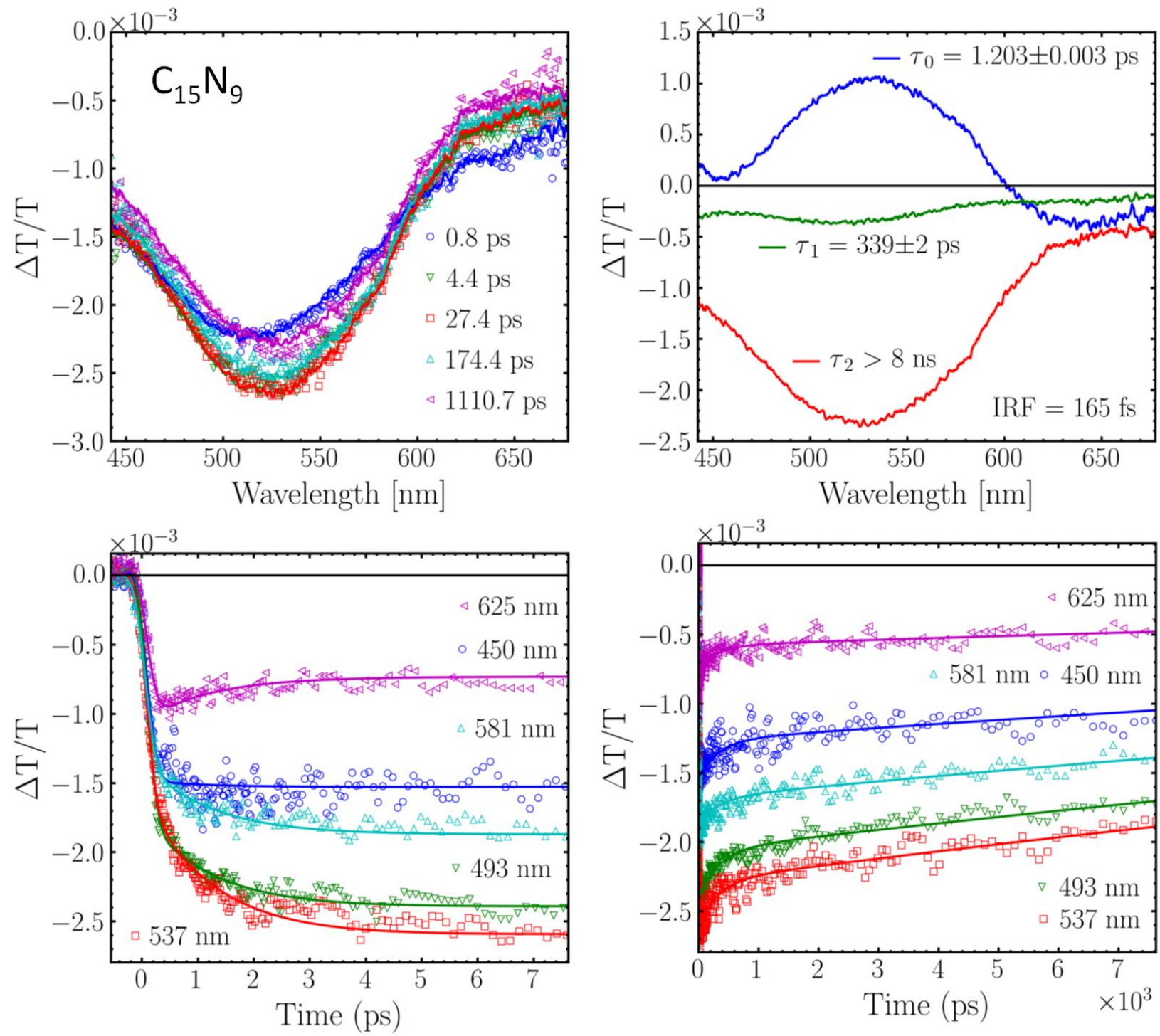

Figure S77: a) Time evolution of the fs-TAS of $\mathbf{C}_{15} \mathbf{N}_{9}$ in $\mathrm{CH}_{2} \mathrm{Cl}_{2}\left(295 \mathrm{~K}\right.$; $\lambda_{\text {exc }}=266 \mathrm{~nm}$; pulse power $=0.2 \mathrm{~mJ} / \mathrm{cm}^{2}$ ). Note that in this scale the positive and negative responses represent the bleached and transient signals, respectively. Also note the presence of an isosbestic point at 585 $\mathrm{nm}$. b) Corresponding decay associated spectra and the transient lifetimes (note that the lifetime indicated inside the frame are those directly issued from best fits. The uncertainties based on multiple measurements is $\pm 10 \%$. c) and d) Decay traces monitored at different wavelengths. 

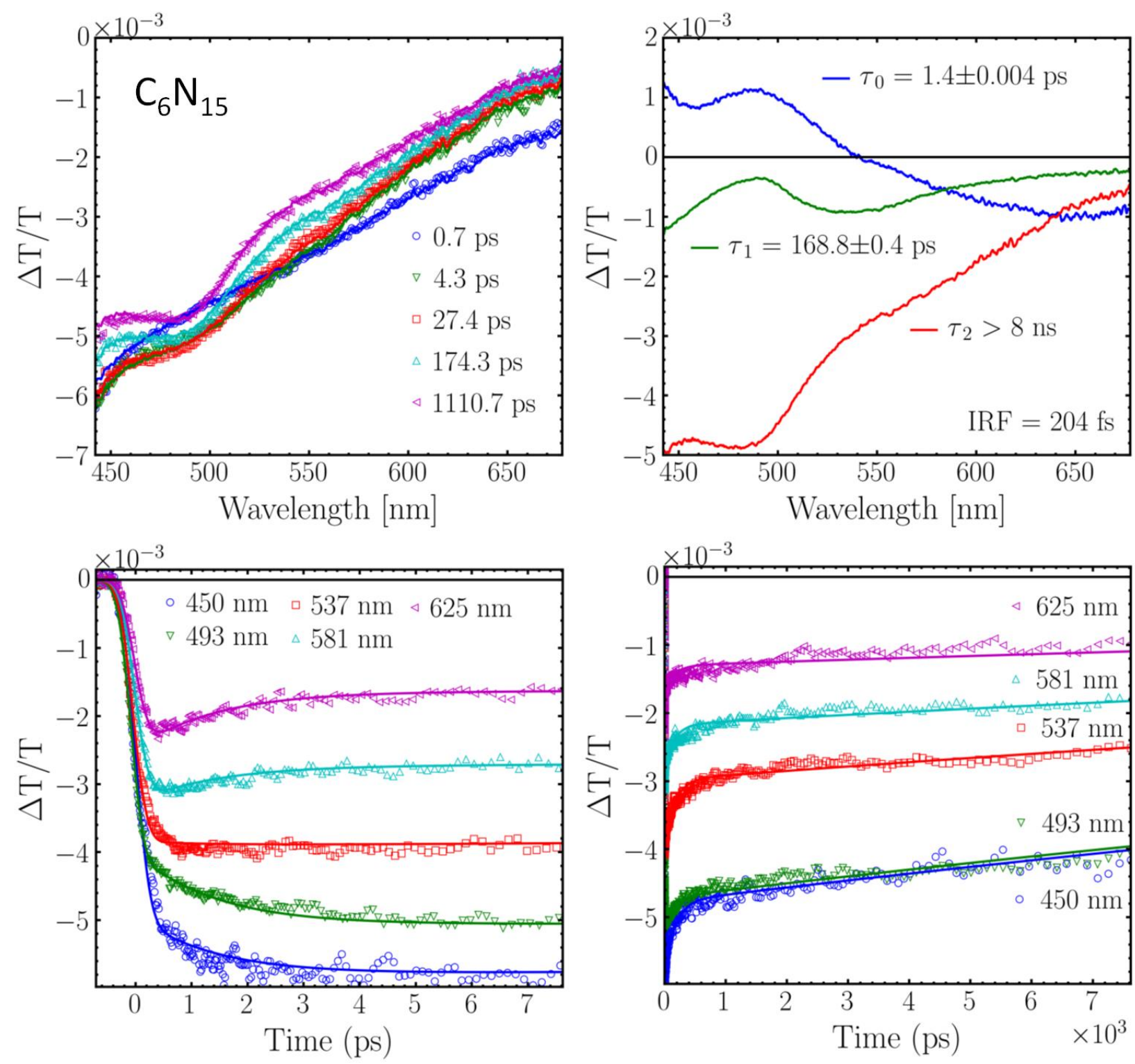

Figure S78: a) Time evolution of the fs-TAS of $\mathbf{C}_{6} \mathbf{N}_{\mathbf{1 5}}$ in $\mathrm{CH}_{2} \mathrm{Cl}_{2}\left(295 \mathrm{~K}\right.$; $\lambda_{\text {exc }}=266 \mathrm{~nm}$; pulse power $=0.2 \mathrm{~mJ} / \mathrm{cm}^{2}$ ). Note that in this scale the positive and negative responses represent the bleached and transient signals, respectively. Also note the presence of an isosbestic point at 585 $\mathrm{nm}$. b) Corresponding decay associated spectra and the transient lifetimes (note that the lifetime indicated inside the frame are those directly issued from best fits. The uncertainties based on multiple measurements is $\pm 10 \%$. c) and d) Decay traces monitored at different wavelengths. 

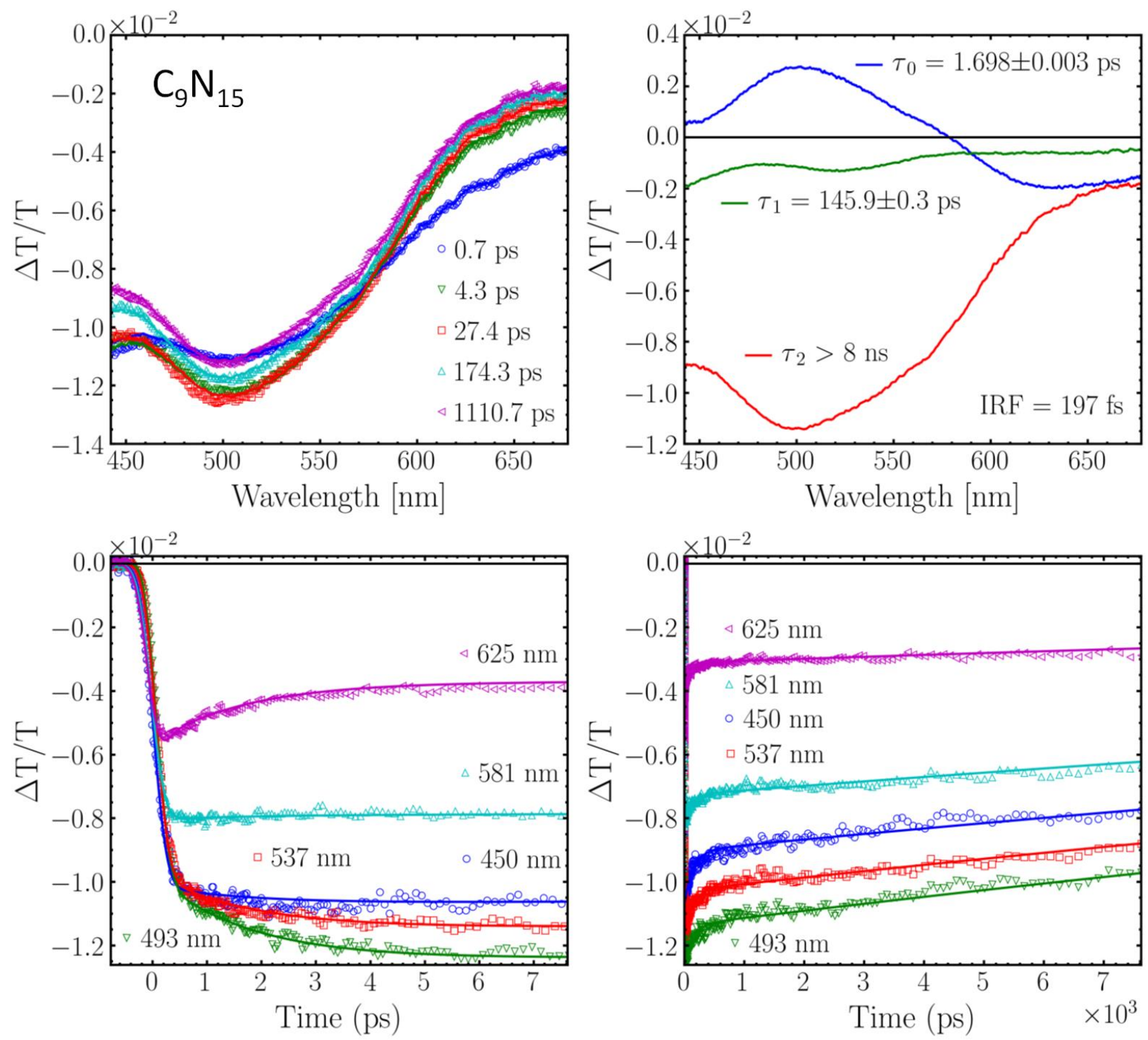

Figure S79: a) Time evolution of the fs-TAS of $\mathbf{C}_{9} \mathbf{N}_{15}$ in $\mathrm{CH}_{2} \mathrm{Cl}_{2}\left(295 \mathrm{~K}\right.$; $\lambda_{\text {exc }}=266 \mathrm{~nm}$; pulse power $=0.2 \mathrm{~mJ} / \mathrm{cm}^{2}$ ). Note that in this scale the positive and negative responses represent the bleached and transient signals, respectively. Also note the presence of an isosbestic point at 585 $\mathrm{nm}$. b) Corresponding decay associated spectra and the transient lifetimes (note that the lifetime indicated inside the frame are those directly issued from best fits. The uncertainties based on multiple measurements is $\pm 10 \%$. c) and d) Decay traces monitored at different wavelengths. 

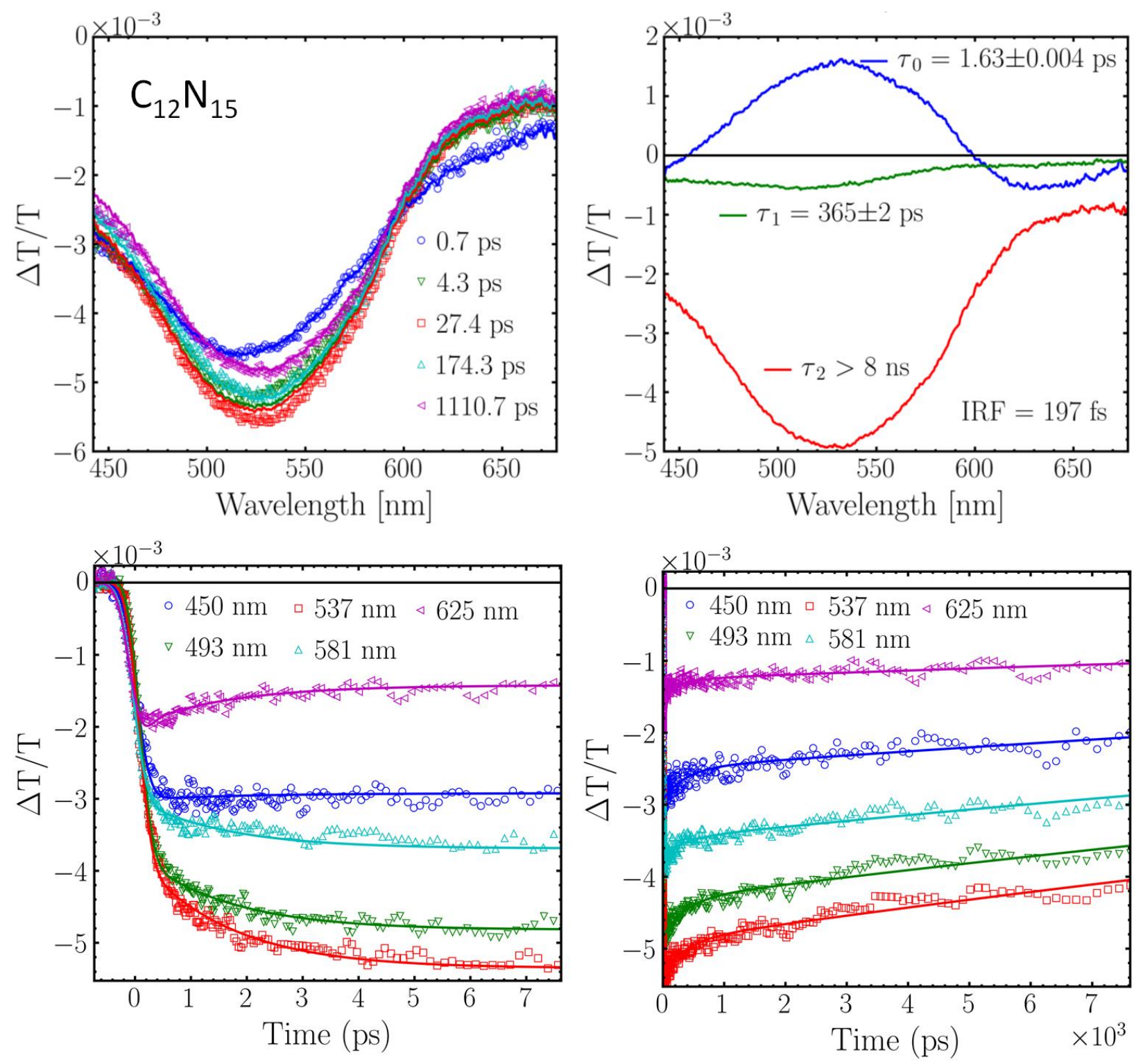

Figure S80: a) Time evolution of the fs-TAS of $\mathbf{C}_{\mathbf{1 2}} \mathbf{N}_{\mathbf{1 5}}$ in $\mathrm{CH}_{2} \mathrm{Cl}_{2}\left(295 \mathrm{~K}\right.$; $\lambda_{\text {exc }}=266 \mathrm{~nm}$; pulse power $=0.2 \mathrm{~mJ} / \mathrm{cm}^{2}$ ). Note that in this scale the positive and negative responses represent the bleached and transient signals, respectively. Also note the presence of an isosbestic point at 585 nm. b) Corresponding decay associated spectra and the transient lifetimes (note that the lifetime indicated inside the frame are those directly issued from best fits. The uncertainties based on multiple measurements is $\pm 10 \%$. c) and d) Decay traces monitored at different wavelengths. 

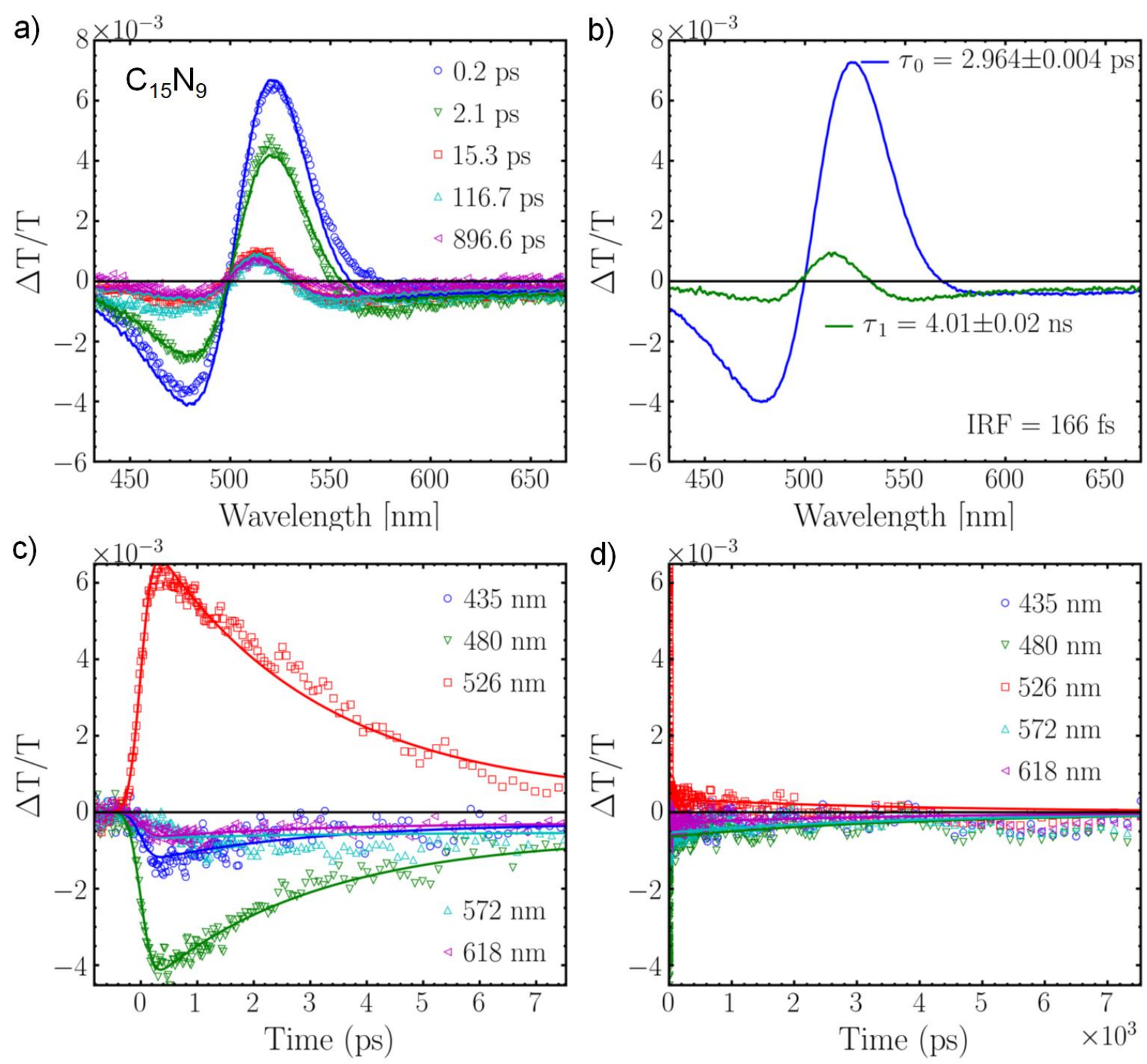

Figure S81: a) Time evolution of the fs-TAS of Au NPs generated upon the photodecomposition of $\mathbf{C}_{15} \mathbf{N}_{9}$ in $\mathrm{CH}_{2} \mathrm{Cl}_{2}\left(295 \mathrm{~K} ; \lambda_{\text {exc }}=266 \mathrm{~nm}\right.$; pulse power $\left.=0.2 \mathrm{~mJ} / \mathrm{cm}^{2}\right)$. Note that in this scale the positive and negative responses represent the bleached and transient signals, respectively. b) Corresponding decay associated spectra and the transient lifetimes (note that the lifetime indicated inside the frame are those directly issued from best fits. The uncertainties based on multiple measurements is $\pm 10 \%$. c) and d) Decay traces monitored at different wavelengths. The fs-TAS data for the other four complexes are placed in the SI. 

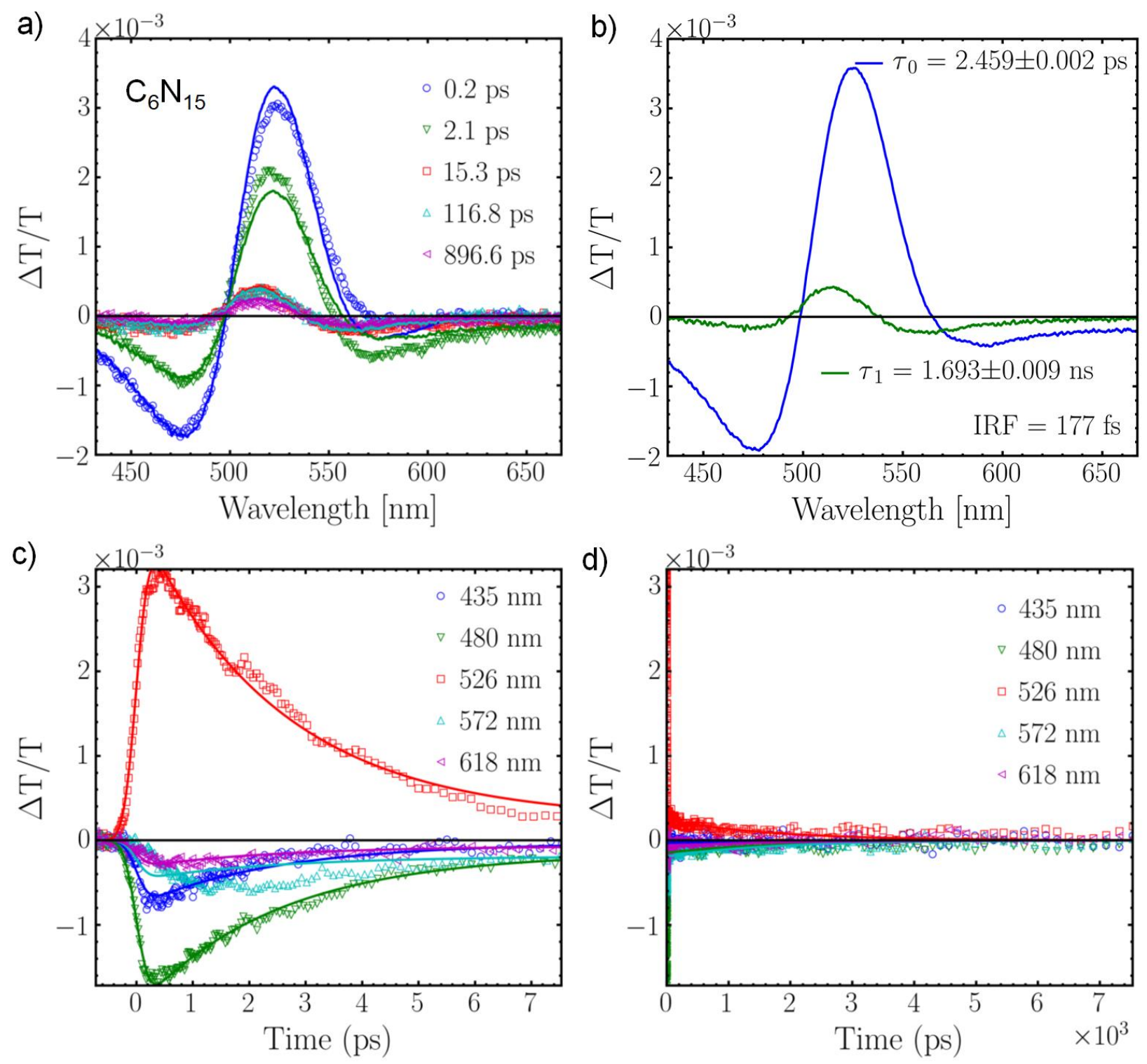

Figure S82: a) Time evolution of the fs-TAS of Au NPs generated upon the photodecomposition of $\mathbf{C}_{6} \mathbf{N}_{15}$ in $\mathrm{CH}_{2} \mathrm{Cl}_{2}\left(295 \mathrm{~K} ; \lambda_{\text {exc }}=266 \mathrm{~nm}\right.$; pulse power $\left.=0.2 \mathrm{~mJ} / \mathrm{cm}^{2}\right)$. Note that in this scale the positive and negative responses represent the bleached and transient signals, respectively. b) Corresponding decay associated spectra and the transient lifetimes (note that the lifetime indicated inside the frame are those directly issued from best fits. The uncertainties based on multiple measurements is $\pm 10 \%$. c) and d) Decay traces monitored at different wavelengths. The fs-TAS data for the other four complexes are placed in the SI. 

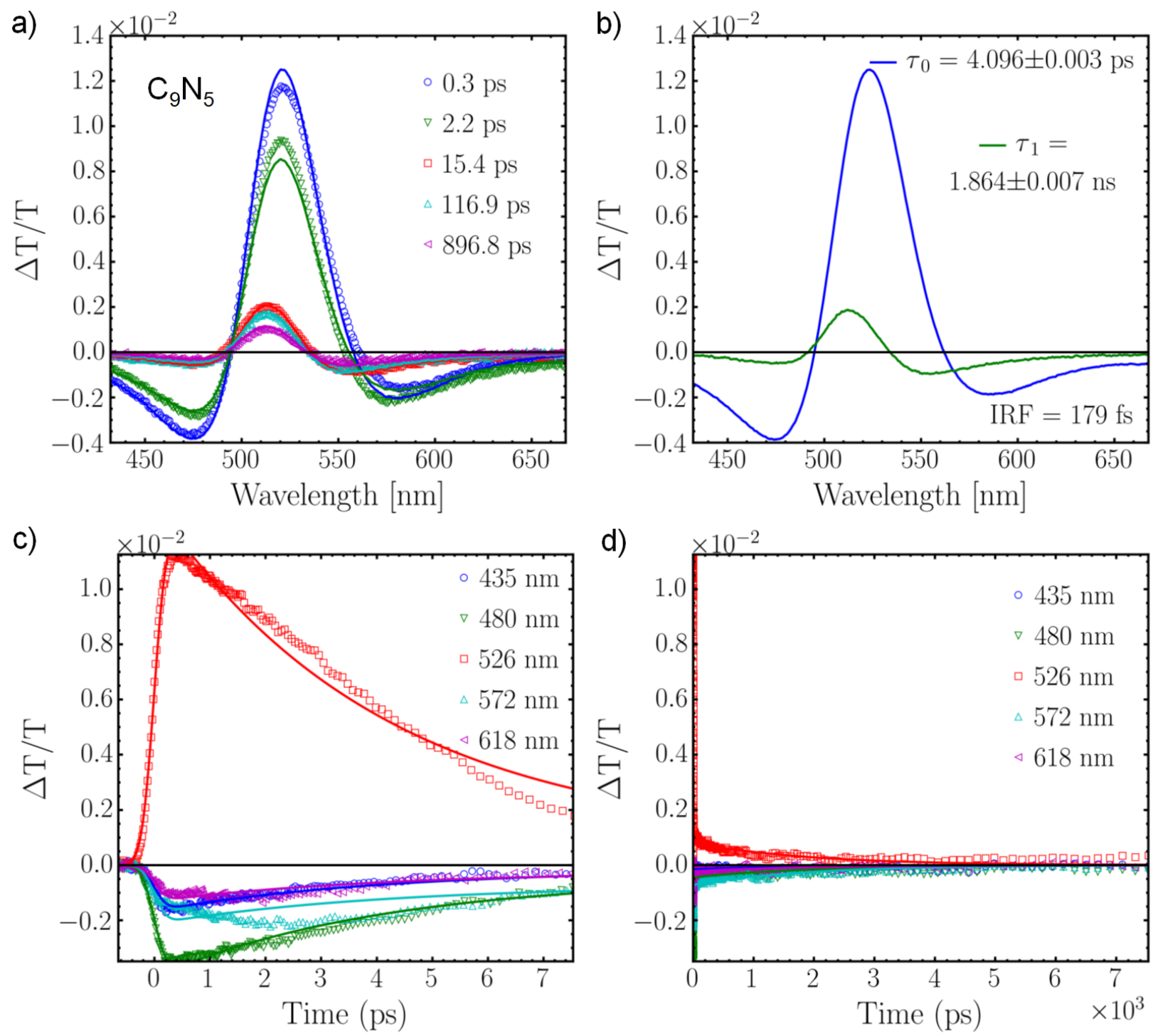

Figure S83: a) Time evolution of the fs-TAS of Au NPs generated upon the photodecomposition of $\mathbf{C}_{9} \mathrm{~N}_{15}$ in $\mathrm{CH}_{2} \mathrm{Cl}_{2}\left(295 \mathrm{~K} ; \lambda_{\text {exc }}=266 \mathrm{~nm}\right.$; pulse power $\left.=0.2 \mathrm{~mJ} / \mathrm{cm}^{2}\right)$. Note that in this scale the positive and negative responses represent the bleached and transient signals, respectively. b) Corresponding decay associated spectra and the transient lifetimes (note that the lifetime indicated inside the frame are those directly issued from best fits. The uncertainties based on multiple measurements is $\pm 10 \%$. c) and d) Decay traces monitored at different wavelengths. The fs-TAS data for the other four complexes are placed in the SI. 

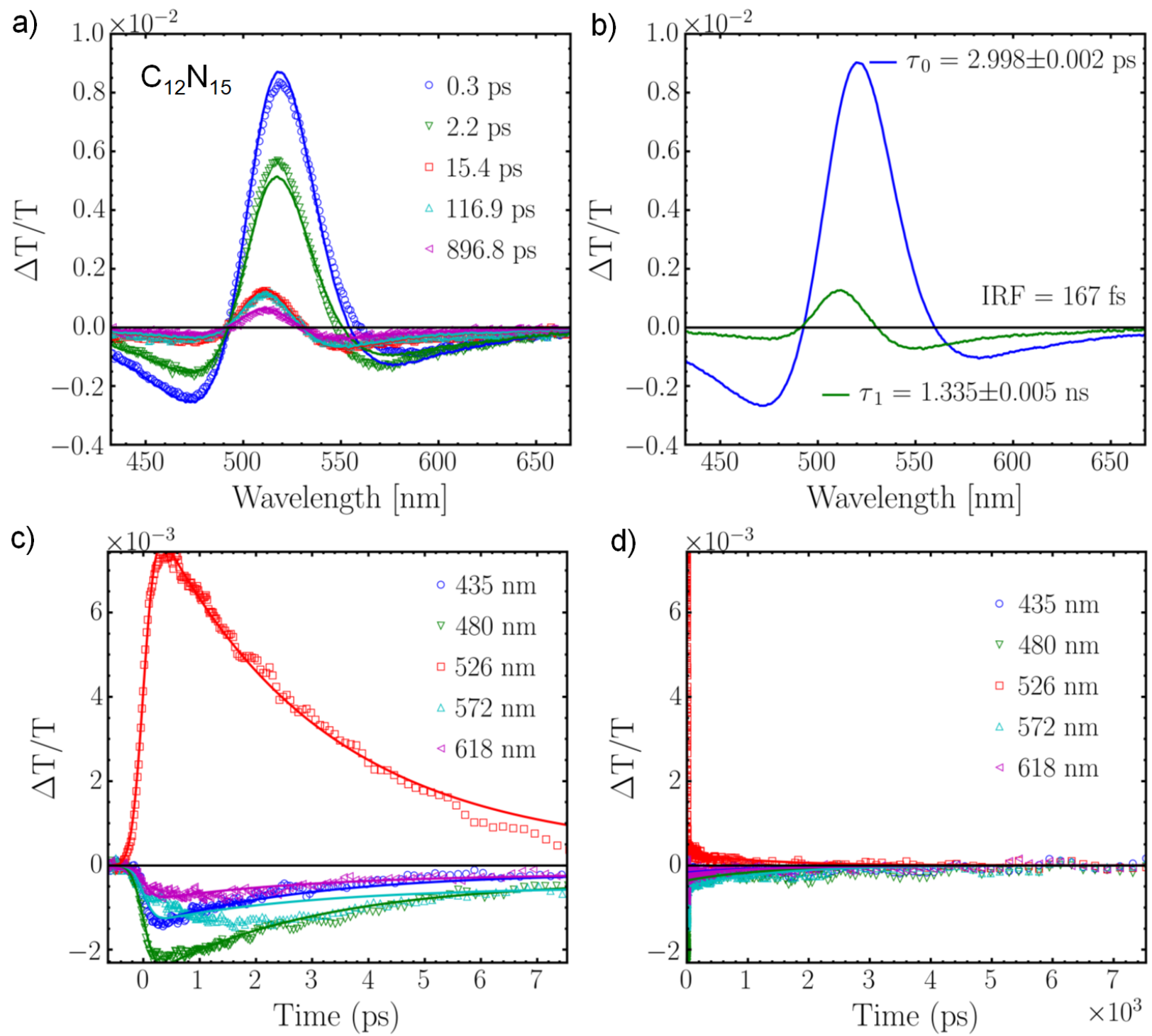

Figure S84: a) Time evolution of the fs-TAS of Au NPs generated upon the photodecomposition of $\mathbf{C}_{12} \mathbf{N}_{15}$ in $\mathrm{CH}_{2} \mathrm{Cl}_{2}\left(295 \mathrm{~K} ; \lambda_{\text {exc }}=266 \mathrm{~nm}\right.$; pulse power $\left.=0.2 \mathrm{~mJ} / \mathrm{cm}^{2}\right)$. Note that in this scale the positive and negative responses represent the bleached and transient signals, respectively. b) Corresponding decay associated spectra and the transient lifetimes (note that the lifetime indicated inside the frame are those directly issued from best fits. The uncertainties based on multiple measurements is $\pm 10 \%$. c) and d) Decay traces monitored at different wavelengths. The fs-TAS data for the other four complexes are placed in the SI. 


\section{Singlet Oxygen}

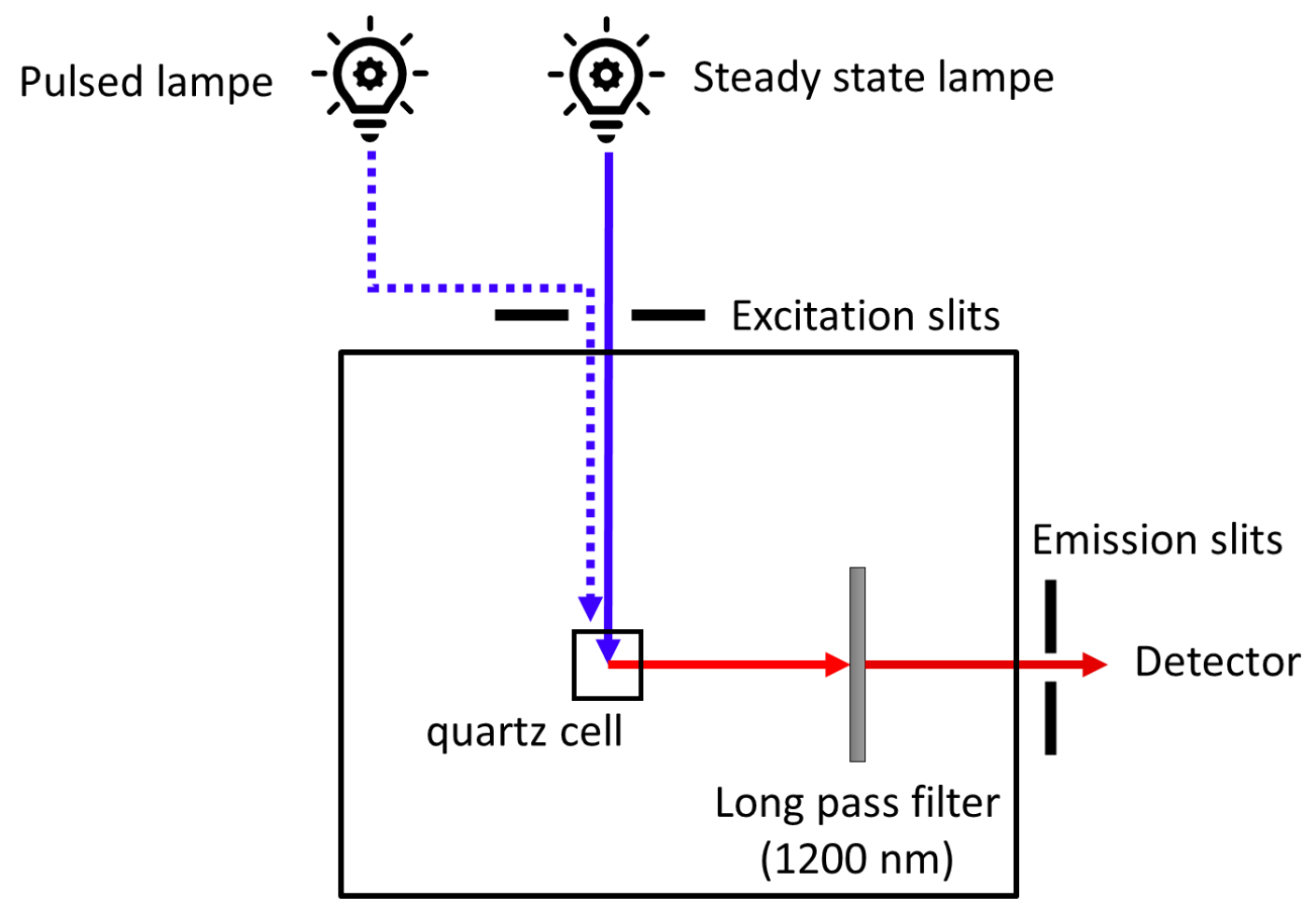

Figure S85: Experimental setup for near-infrared singlet oxygen steady state detection and lifetime measurements. 

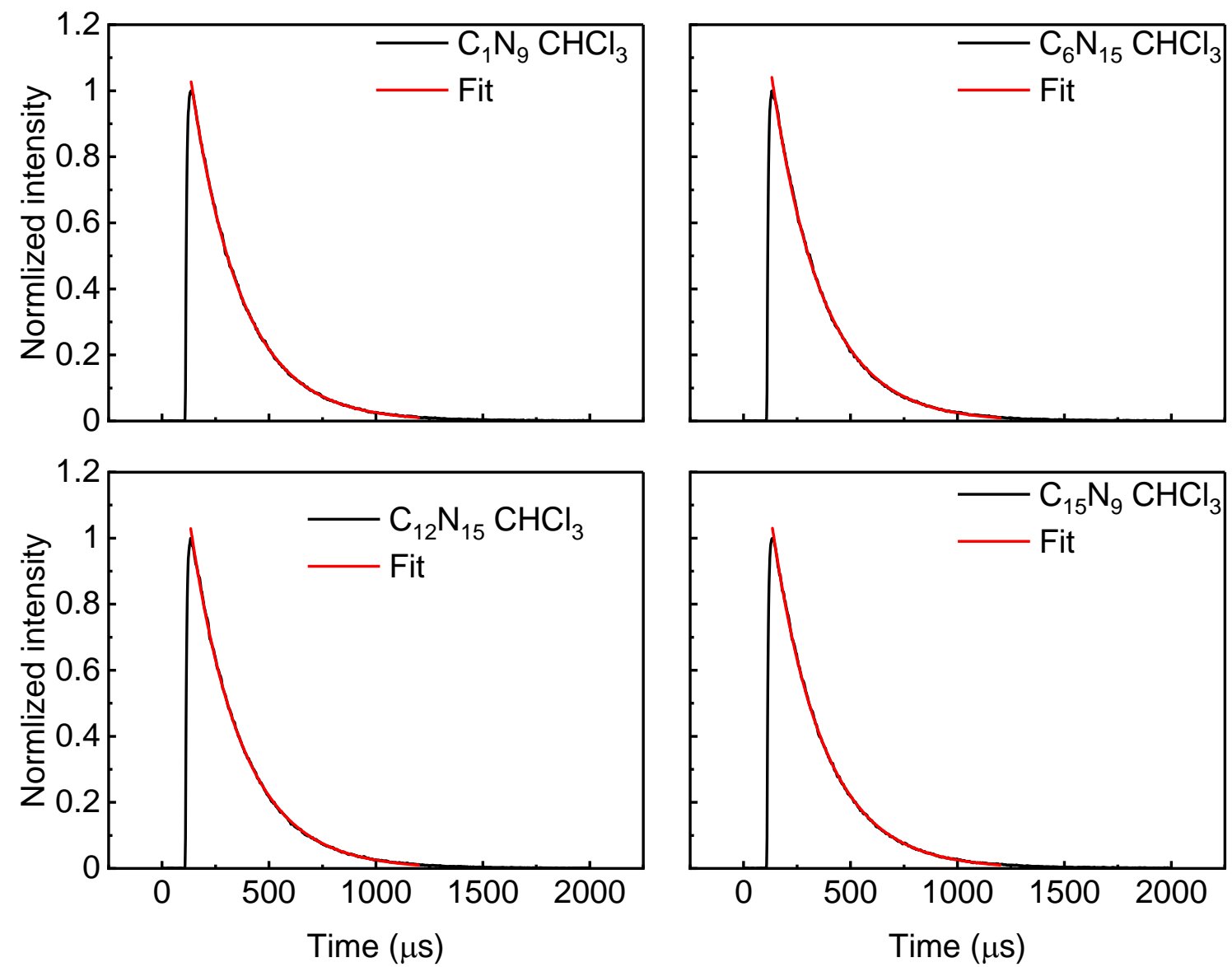

Figure S86: Emission decay of singlet oxygen photosensitized by gold complexes upon excitation at $300 \mathrm{~nm}$ in $\mathrm{CH}_{2} \mathrm{Cl}_{2}(\mathrm{DCM})$ at $298 \mathrm{~K}$. 

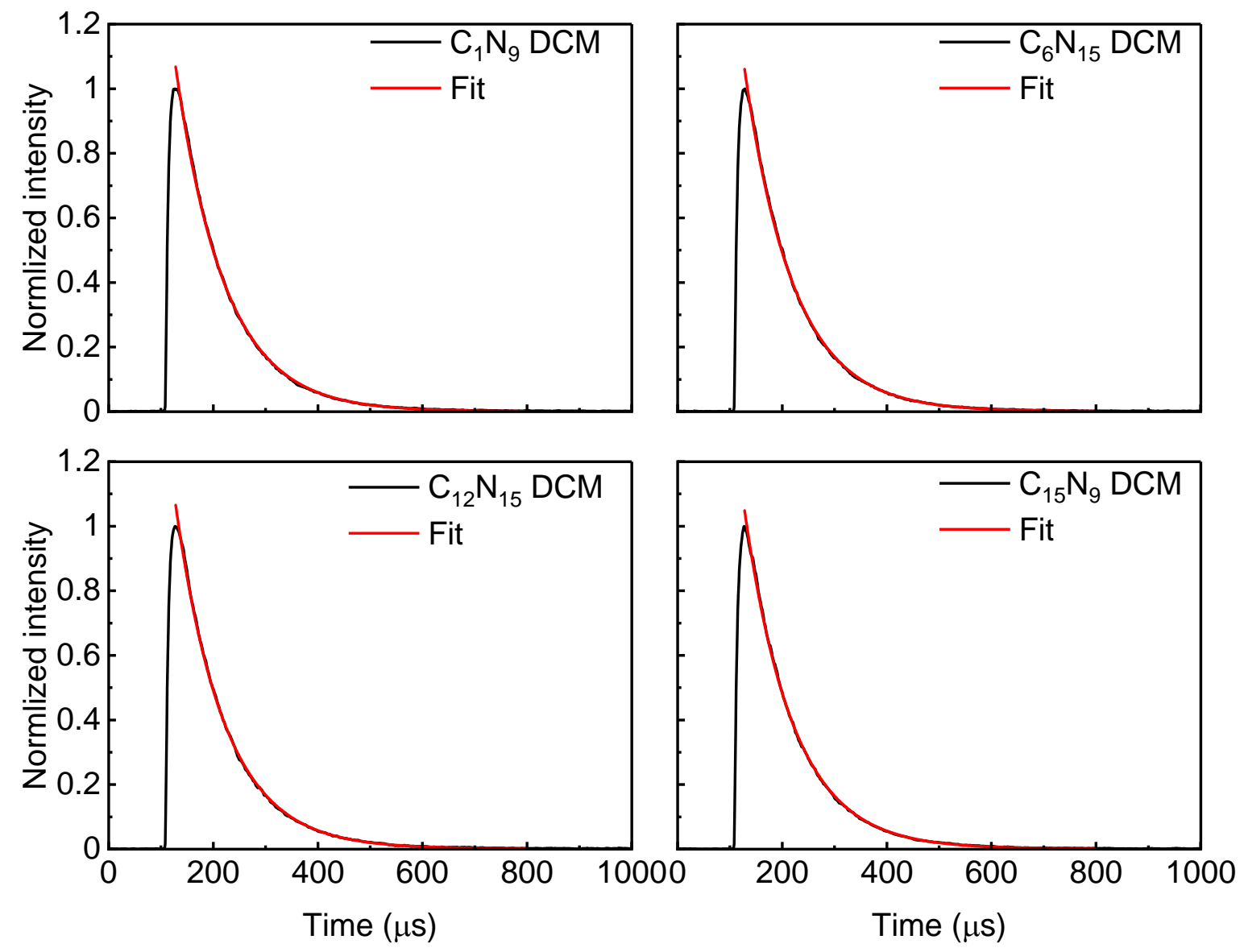

Figure S87: Emission decay of singlet oxygen photosensitized by gold complexes upon excitation at $300 \mathrm{~nm}$ in $\mathrm{CH}_{2} \mathrm{Cl}_{2}(\mathrm{DCM})$ at $298 \mathrm{~K}$. 


\section{Transmission electron microscopy}

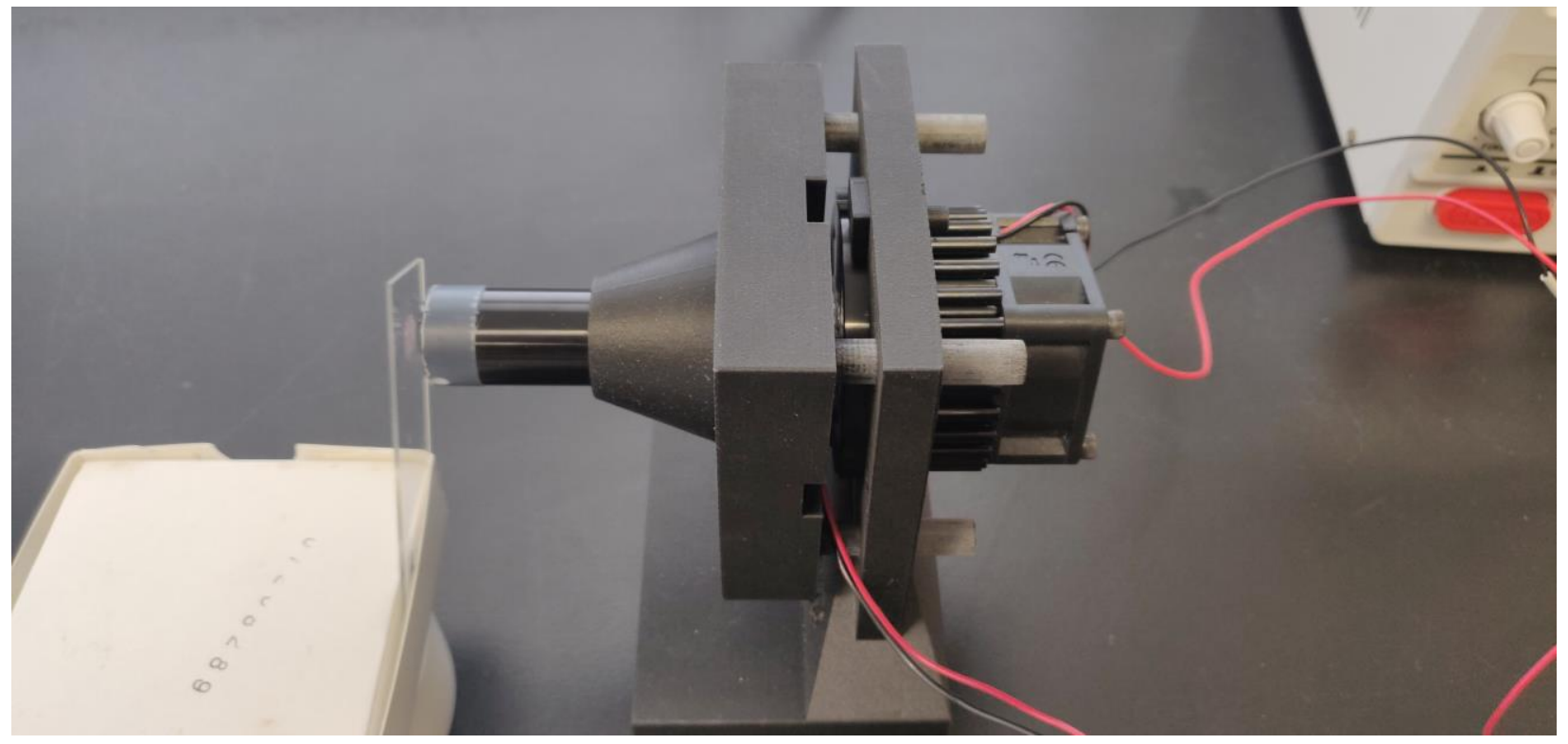

Figure S88: Setup for the irradiation of the gold complexes.

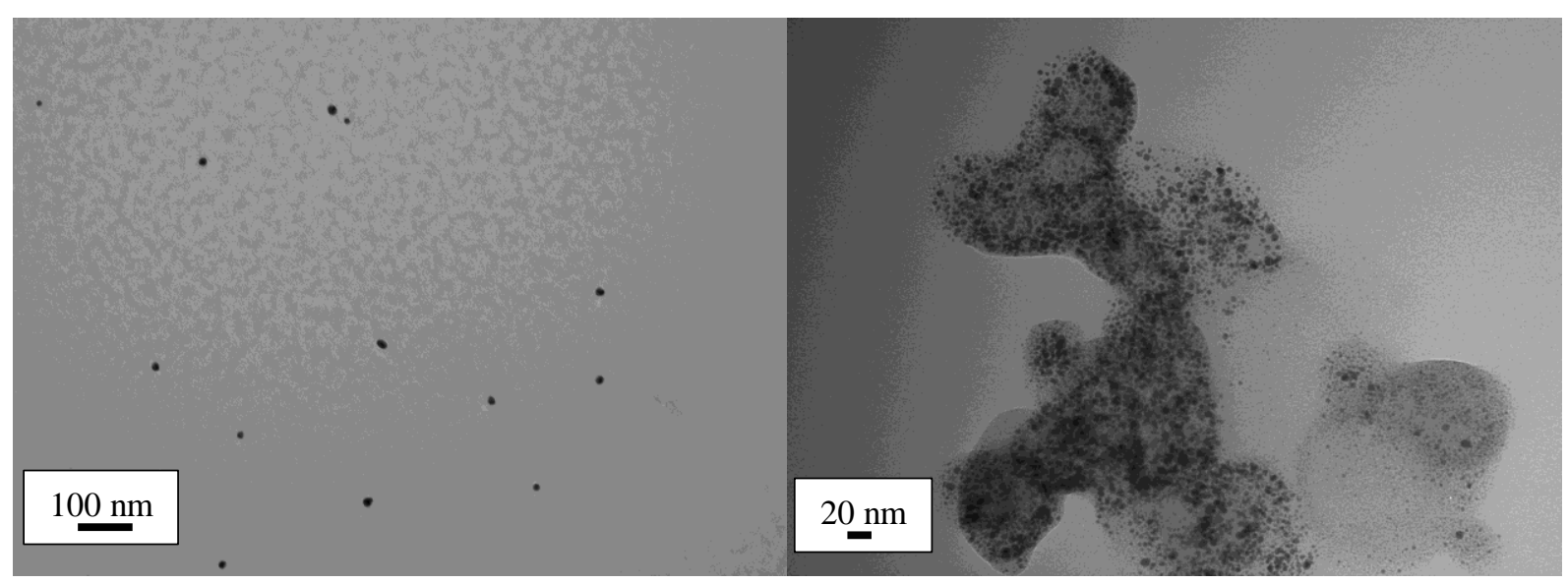

Figure S89: TEM images of $\mathbf{C}_{\mathbf{1}} \mathbf{N}_{\mathbf{9}}$. Left: thermal decomposition at $130^{\circ} \mathrm{C}$. Right: Photodecomposition at $405 \mathrm{~nm}$. 


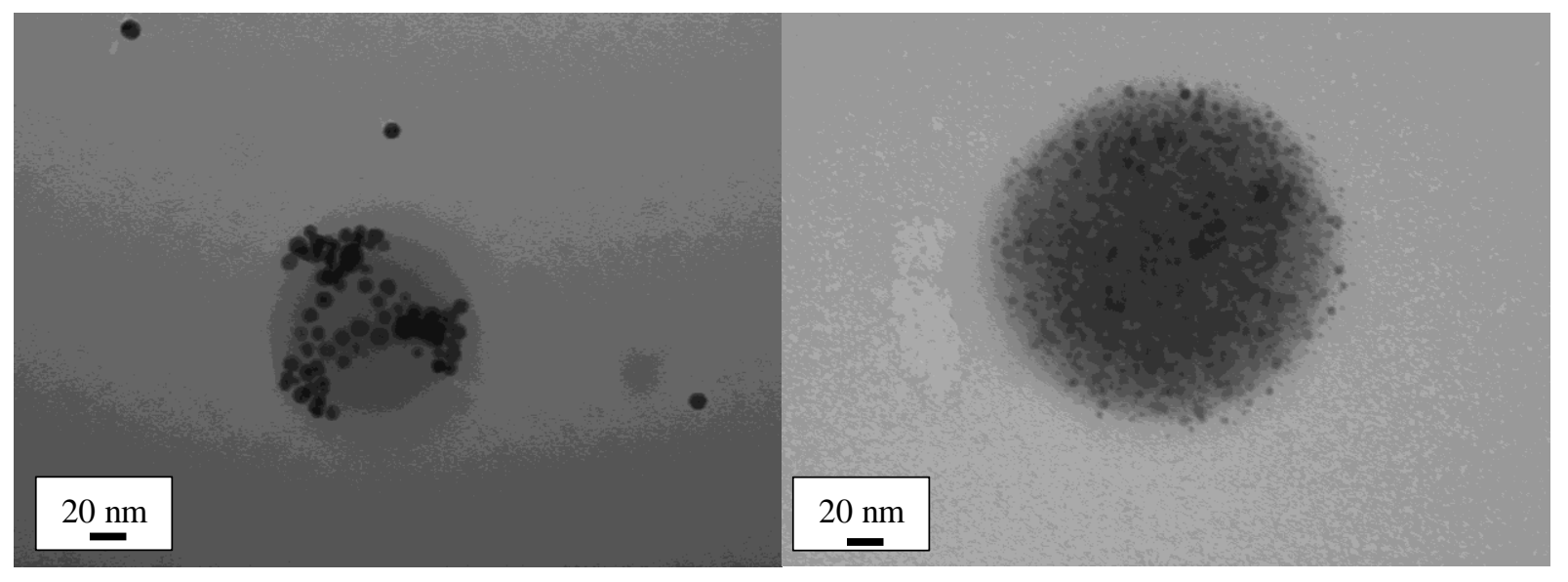

Figure S90: TEM images of $\mathbf{C}_{6} \mathbf{N}_{15}$. Left: thermal decomposition at $130^{\circ} \mathrm{C}$. Right: Photodecomposition at $365 \mathrm{~nm}$.

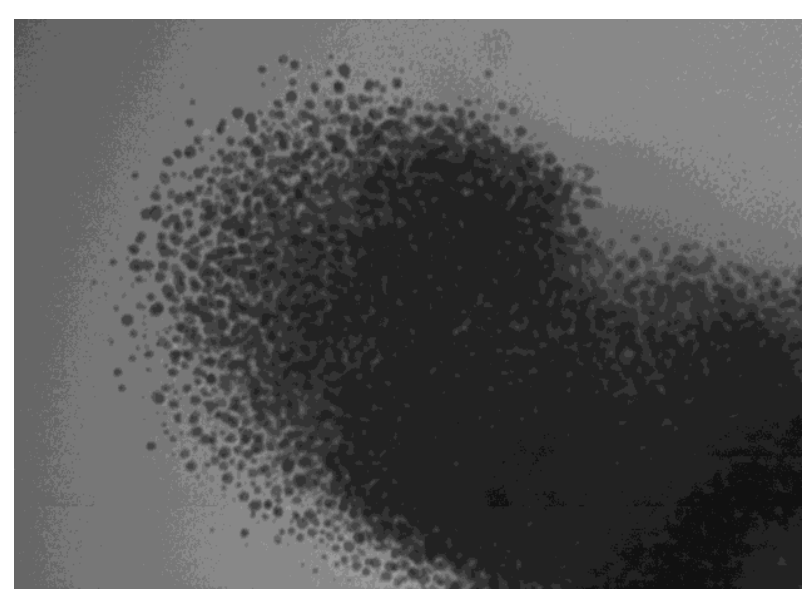

Figure S91: TEM images of $\mathbf{C}_{\mathbf{9}} \mathbf{N}_{\mathbf{1 5}}$, photodecomposition at $405 \mathrm{~nm}$.

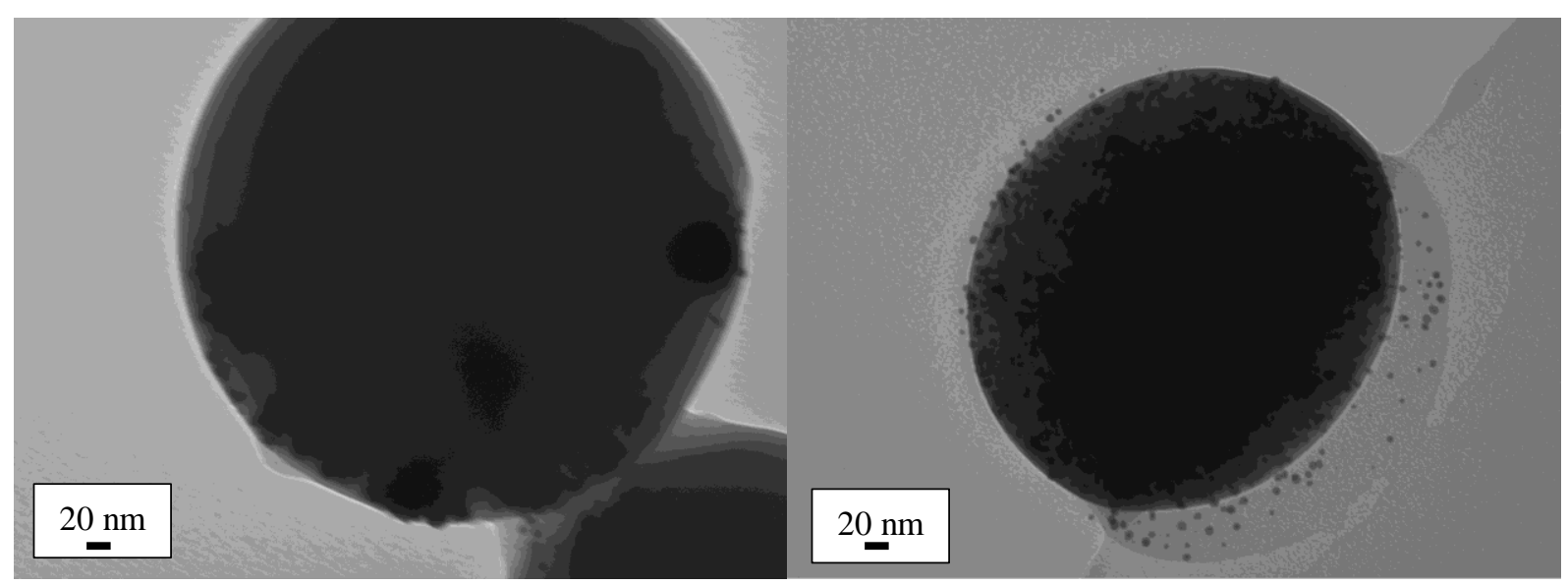

Figure S92: TEM images of $\mathbf{C}_{\mathbf{1 2}} \mathbf{N}_{\mathbf{1 5}}$. Left: thermal decomposition at $130^{\circ} \mathrm{C}$. Right: Photodecomposition at $365 \mathrm{~nm}$. 


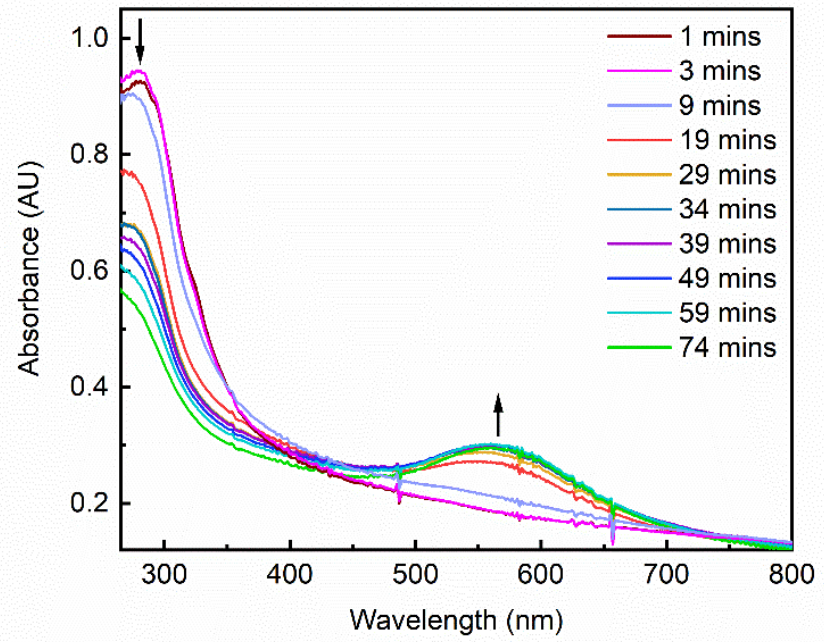

Figure S93: Evolution of the absorption spectra of $\mathbf{C}_{\mathbf{1}} \mathbf{N}_{\mathbf{9}}$ in the solid state upon photolysis $\left(\lambda_{\mathrm{exc}}=\right.$ $365 \mathrm{~nm}$ ). Note the apparence of the band at $560 \mathrm{~nm}$ witnessing the growth of the Au NPs. The setup for photolysis is shown in Figure S94.

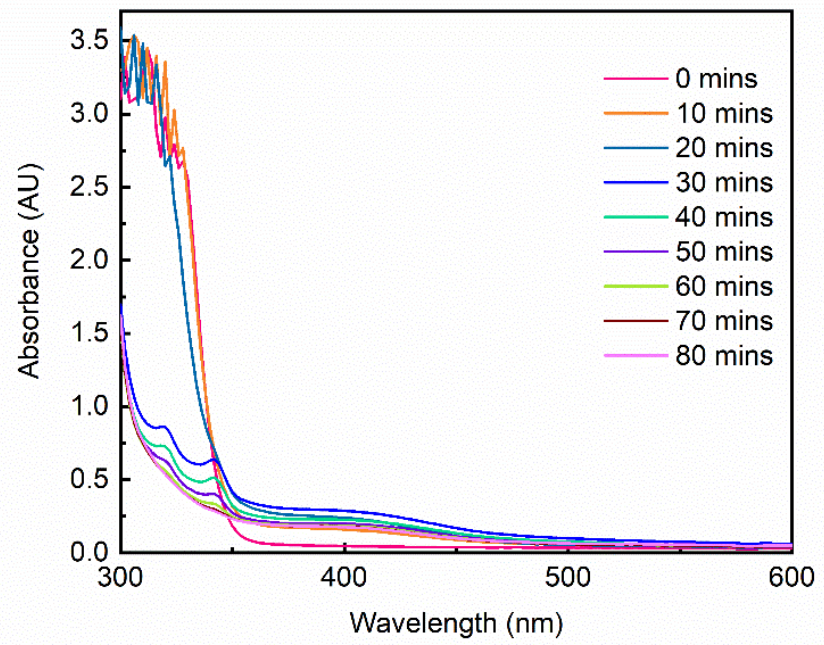

Figure S95: Evolution of the absorption spectra of $\mathbf{C}_{\mathbf{1}} \mathbf{N}_{9}$ in $\mathrm{CH}_{2} \mathrm{Cl}_{2}$ upon photolysis $\left(\lambda_{\mathrm{exc}}=365\right.$ $\mathrm{nm})$. Note the absence of the band at $560 \mathrm{~nm}$ associated with the Au NPs. The setup for photolysis is shown in Figure S96. 


\section{References}

(1) Frisch, M. J.; Trucks, G. W.; Schlegel, H. E.; Scuseria, G. E.; Robb, M. A.; Cheeseman, J. R.; Scalmani, G.; Barone, V.; Petersson, G. A.; O., F.; Foresman, J. B.; Fox, J. D. Gaussian 16. Gaussian, Inc., Wallingford CT, 2016, 3.

(2) Pritchard, B. P.; Altarawy, D.; Didier, B.; Gibson, T. D.; Windus, T. L. New Basis Set Exchange: An Open, Up-to-Date Resource for the Molecular Sciences Community. J. Chem. Inf. Model. 2019, 59 (11), 4814-4820. https://doi.org/10.1021/acs.jcim.9b00725.

(3) Feller, D. The Role of Databases in Support of Computational Chemistry Calculations. $J$. Comput. Chem. 1996, 17 (13), 1571-1586. https://doi.org/10.1002/(SICI)1096987X(199610)17:13<1571::AID-JCC9>3.0.CO;2-P.

(4) Schuchardt, K. L.; Didier, B. T.; Elsethagen, T.; Sun, L.; Gurumoorthi, V.; Chase, J.; Li, J.; Windus, T. L. Basis Set Exchange: A Community Database for Computational Sciences. J. Chem. Inf. Model. 2007, 47 (3), 1045-1052. https://doi.org/10.1021/ci600510j.

(5) Ditchfield, R.; Hehre, W. J.; Pople, J. A. Self-Consistent Molecular-Orbital Methods. IX. An Extended Gaussian-Type Basis for Molecular-Orbital Studies of Organic Molecules. J. Chem. Phys. 1971, 54 (2), 724-728. https://doi.org/10.1063/1.1674902.

(6) Hariharan, P. C.; Pople, J. A. The Influence of Polarization Functions on Molecular Orbital Hydrogenation Energies. Theor. Chim. Acta 1973, 28 (3), 213-222. https://doi.org/10.1007/BF00533485.

(7) Hehre, W. J.; Ditchfield, R.; Pople, J. A. Self-Consistent Molecular Orbital Methods. XII. Further Extensions of Gaussian-Type Basis Sets for Use in Molecular Orbital Studies of Organic Molecules. J. Chem. Phys. 1972, 56 (5), 2257-2261. https://doi.org/10.1063/1.1677527.

(8) Hay, P. J.; Wadt, W. R. Ab Initio Effective Core Potentials for Molecular Calculations. Potentials for K to Au Including the Outermost Core Orbitals. J. Chem. Phys. 1985, 82 (1), 299-310. https://doi.org/10.1063/1.448975.

(9) BIOVIA, Dassault Systèmes. BIOVIA, Dassault Systèmes, Material Studio 17, San Diego: Dassault Systèmes 2017. 
(10) Boultif, A.; Louër, D. Powder Pattern Indexing with the Dichotomy Method. J. Appl. Crystallogr. 2004, 37 (5), 724-731. https://doi.org/10.1107/S0021889804014876.

(11) Boultif, A.; Louër, D. Indexing of Powder Diffraction Patterns for Low-Symmetry Lattices by the Successive Dichotomy Method. J. Appl. Crystallogr. 1991, 24 (6), 987-993. https://doi.org/10.1107/S0021889891006441.

(12) Li, J.; Fu, H.; Hu, P.; Zhang, Z.; Li, X.; Cheng, Y. Catalysts for Suzuki Polycondensation: Ionic and "Quasi-Ionic" Amphipathic Palladium Complexes with Self-Phase-Transfer Features. Chem. - A Eur. J. 2012, 18 (44), 13941-13944. https://doi.org/10.1002/chem.201202162. 